Article

\title{
Synthesis and Antiplasmodial Activity of Bisindolylcyclobutenediones
}

\author{
Duc Hoàng Lande ${ }^{1}$, Abed Nasereddin ${ }^{2,3}$, Arne Alder ${ }^{4,5,6}$, Tim W. Gilberger ${ }^{4,5,6}$, Ron Dzikowski ${ }^{2} \oplus$, \\ Johann Grünefeld ${ }^{1}$ and Conrad Kunick ${ }^{1,7, *(1)}$
}

1 Institut für Medizinische und Pharmazeutische Chemie, Technische Universität Braunschweig, Beethoven straße 55, 38106 Braunschweig, Germany; h.lande@icloud.com (D.H.L.); j.gruenefeld@tu-bs.de (J.G.)

2 Department of Microbiology and Molecular Genetics, IMRIC, The Kuvin Center for the Study of Infectious and Tropical Diseases, The Hebrew University-Hadassah Medical School, Jerusalem 91120, Israel; abedn@ekmd.huji.ac.il (A.N.); rond@ekmd.huji.ac.il (R.D.)

3 Genomics Applications Laboratory, Core Research Facility, Faculty of Medicine, The Hebrew University-Hadassah Medical School, Jerusalem 91120, Israel

4 Centre for Structural Systems Biology, 22607 Hamburg, Germany; alder@bnitm.de (A.A.); gilberger@bnitm.de (T.W.G.)

5 Bernhard Nocht Institute for Tropical Medicine, 20359 Hamburg, Germany

6 Department of Biology, University of Hamburg, 20146 Hamburg, Germany

7 Zentrum für Pharmaverfahrenstechnik (PVZ), Technische Universität Braunschweig, Franz-Liszt-Straße 35A, 38106 Braunschweig, Germany

* Correspondence: c.kunick@tu-bs.de

check for updates

Citation: Lande, D.H.; Nasereddin, A.; Alder, A.; Gilberger, T.W.; Dzikowski, R.; Grünefeld, J.; Kunick, C. Synthesis and Antiplasmodial Activity of Bisindolylcyclobutenediones. Molecules 2021, 26, 4739. https:// doi.org/10.3390/molecules26164739

Academic Editors: David StC Black and Naresh Kumar

Received: 9 June 2021

Accepted: 15 July 2021

Published: 5 August 2021

Publisher's Note: MDPI stays neutral with regard to jurisdictional claims in published maps and institutional affiliations.

Copyright: (c) 2021 by the authors. Licensee MDPI, Basel, Switzerland. This article is an open access article distributed under the terms and conditions of the Creative Commons Attribution (CC BY) license (https:/ / creativecommons.org/licenses/by/ $4.0 /)$.

\begin{abstract}
Malaria is one of the most dangerous infectious diseases. Because the causative Plasmodium parasites have developed resistances against virtually all established antimalarial drugs, novel antiplasmodial agents are required. In order to target plasmodial kinases, novel $N$-unsubstituted bisindolylcyclobutenediones were designed as analogs to the kinase inhibitory bisindolylmaleimides. Molecular docking experiments produced favorable poses of the unsubstituted bisindolylcyclobutenedione in the ATP binding pocket of various plasmodial protein kinases. The synthesis of the title compounds was accomplished by sequential Friedel-Crafts acylation procedures. In vitro screening of the new compounds against transgenic NF54-luc P. falciparum parasites revealed a set of derivatives with submicromolar activity, of which some displayed a reasonable selectivity profile against a human cell line. Although the molecular docking studies suggested the plasmodial protein kinase PfGSK-3 as the putative biological target, the title compounds failed to inhibit the isolated enzyme in vitro. As selective submicromolar antiplasmodial agents, the $N$-unsubstituted bisindolylcyclobutenediones are promising starting structures in the search for antimalarial drugs, albeit for a rational development, the biological target addressed by these compounds has yet to be identified.
\end{abstract}

Keywords: bisindolylmaleimide; cyclobutenedione; drug design; drug screening; Friedel-Crafts reaction; glycogen synthase kinase-3; indole; malaria; molecular docking; plasmodium

\section{Introduction}

Occurring mainly in tropical and subtropical areas, malaria remains one of the most threatening infectious diseases on earth. Transmitted by the bite of an infected female Anopheles mosquito, malaria is caused by pathogenic protozoa of the genus Plasmodium, wherein the species $P$. falciparum is the most dangerous pathogen. It is responsible for malaria tropica, the most severe form of the disease, which can be fatal if left untreated. It is estimated that there were 229 million malaria cases in 2019, of which about 409,000 were fatal, most of them in sub-Saharan Africa [1]. Besides its impact on individual and public health, malaria causes enormous economic damage and is linked to the endemic poverty of the affected countries [2]. 
Plasmodia are intracellular protozoa whose complex life cycles are divided into two phases: asexual reproduction that occurs in vertebrates and sexual reproduction in the vector, the Anopheles mosquito [3]. As vector control and prevention measures, the World Health Organization promotes insecticide-treated bednets and the use of insecticides for regular indoor spraying. Implementation of these procedures has resulted in a significant decrease in infection number in the recent two decades [4]. Unfortunately, this progress has come to a standstill in recent years $[1,5,6]$. To treat severe malaria in countries with high resistance rates to conventional malaria drugs, the WHO recommends artemisinin-based combination therapies as the medication of choice. Increasing resistance to all classes of antimalarial agents, including artemisinin derivatives, poses a threat to endemic regions. A reason for the emerging resistance is the improper use of antimalarial drugs, which exerts selection pressure on the parasites [4,7-10].

For the treatment of infections with resistant parasites, new drugs are needed. To minimize the risk of cross-resistance, these new medications should be distinguished from established chemotherapeutics by mode of action and chemical structure. In this regard, it would be favorable to address alternative biological targets in the parasites. The plasmodial kinome offers such potential alternative targets [11-13]. In the genome of P. falciparum at least 65 kinases can be identified that belong to established eukaryotic protein kinase groups, many of which are similar to human protein kinases [12,14]. Nevertheless, significant phylogenetic divergence between the mammalian and the plasmodium kinome results in mechanistic and structural differences of the enzymes which may be exploited for drug design strategies. Basic reverse genetics experiments and phosphoproteomic analyses resulted in a list of plasmodial kinases that are essential either in erythrocytic schizogonia or in the sexual developmental stage of parasites [14]. Thus, plasmodial protein kinases have been suggested as drug targets [11-13]. However, while the inhibitor of the plasmodial phosphatidylinositol 4-kinase ( $P f \mathrm{P} 4 \mathrm{~K})$ MMV390048 is currently studied in clinical trials $[15,16]$, compounds acting on protein kinases of the parasites have not yet reached this status [6].

Bisindolylmaleimides (BIMs, 1) are an established protein kinase inhibitor class [17,18], represented by prominent examples such as GF 109203X [19], enzastaurin [20] and ruboxistaurin [21]. To identify protein kinase inhibitors based on new chemical matter, we designed the compound class of 3,4-bis(indol-3-yl)cyclobut-3-ene-1,2-diones 2 by replacing the imide ring of BIMs with a cyclobut-3-ene-1,2-dione element. The core structure of these molecules is derived from squaric acid (Figure 1). While a few examples of squaric acid diamides with antiplasmodial or other biological activities are known [22-25], up to now only a single 3,4-bis(indol-3-yl)cyclobut-3-ene-1,2-dione was prepared in a meager yield $(0.67 \%)[26]$, and biological activity of this congener was not reported.

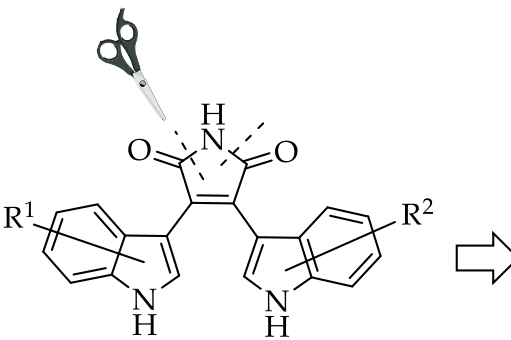

1

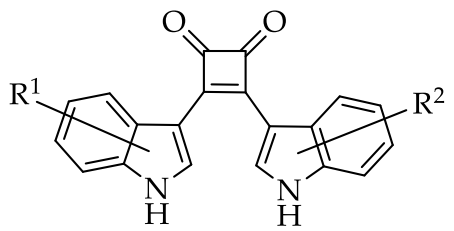

2

Figure 1. Design of 3,4-bis(indol-3-yl)cyclobut-3-ene-1,2-diones 2 by formally cutting out the imide nitrogen of bisindolylmaleimides (BIMs, 1 ). $R^{1}$ and $R^{2}$ indicate substituents attached to positions 1,2 , $4,5,6$, or 7 of the indole ring system.

Before synthesis methods for the production of bisindolylcyclobutenediones 2 were developed, docking studies were carried out to virtually fit the putative new inhibitors 
into the ATP binding pockets of exemplary plasmodial protein kinases. Since these in silico analyses generated promising results, the compounds 2 were synthesized and tested against erythrocytic stages of P. falciparum parasites. Indeed, some congeners proved to be active in submicromolar concentrations.

Based on the docking studies, the protein kinase PfGSK-3 [27-30] was assumed as a putative target structure for the antiplasmodial compounds within the parasites. However, in vitro enzyme inhibition assays refuted this assumption. The relevant biological target structure for bisindolylcyclobutenediones in plasmodia is therefore still unknown and has yet to be elucidated.

\section{Results}

\subsection{Molecular Docking}

The unsubstituted 3,4-bis(indol-3-yl)cyclobut-3-ene-1,2-dione 2a was docked into known structures of plasmodial protein kinases using the GOLD program [31], whereby no constraints were defined and the presence or absence of water molecules at suitable positions of the ATP binding pocket was permitted by the application of the "toggle" function. The plasmodial protein kinase structures were downloaded from the protein data bank [32], if available. The protein kinases PfGSK-3 (homology model [33], based on template 1J1B [34]), Pfmap-2 (PDB: 3NIE), PfPK5 (PDB: 1V0P [35]), PfCDPK2 (PDB: 4MVF) Pflammer (PDB: 3LLT) and PfPK7 (PDB: 2PML) were used as templates. The obtained docking results were assessed by visual inspection, and the most probable orientations are shown below. The structure of $2 \mathbf{a}$ was modified taking into account the suggested orientations to optimize the bioactivity. Furthermore, it was intended to generate clues regarding the relevant biological targets by comparing the structure-activity relationships in the compound class with the orientations in the six plasmodial protein kinases suggested by the docking analyses [36].

\subsubsection{PfGSK-3}

Since no experimentally determined spatial structure of $P f G S K-3$ exists at present, a homology model of the PfGSK-3 was selected for the investigations described here, which had been created using a crystal structure of human GSK-3 [33]. In the depicted pose, an indole ring of $2 \mathbf{a}$ occupies the adenine region and interacts with the hinge region via a hydrogen bond. The other indole ring is orthogonally arranged and forms a hydrogen bridge to the protein. Furthermore, a keto group of the ligand acts as an H-bond acceptor and interacts with the side chain of Lys166. The cyclobutenedione ring is positioned in the sugar region. In this docking pose, the ligand fills the binding pocket very well (Figure 2a).

\subsubsection{Pfmap-2}

In the docking experiment with 2a in Pfmap-2 (plasmodial mitogen-activated protein kinase 2; PDB: 3NIE), only one orientation of the molecule in the ATP binding pocket was identified, in which, however, no hydrogen bonds are formed to the hinge region (Figure 2b). An indole ring occupies parts of the ribose and adenine areas and forms a hydrogen bond to an aspartyl residue in the front region of the binding pocket. The second indole element is located in the front part of the binding pocket. One of the carbonyl groups forms a hydrogen bridge to catalytic lysine. Overall, this predicted pose appears unfavorable for a tight binding of the ligand.

\subsubsection{Pf PK5}

Molecular docking of 2a in PfPK5 (PDB: 1V0P, [35]) provided a very realistic pose in which the three ring systems are arranged almost in plane. Both indole-NH groups form hydrogen bonds with the hinge region. In addition, there are interactions of a water molecule with a carbonyl group of the cyclobutenedione element (Figure 2c). 


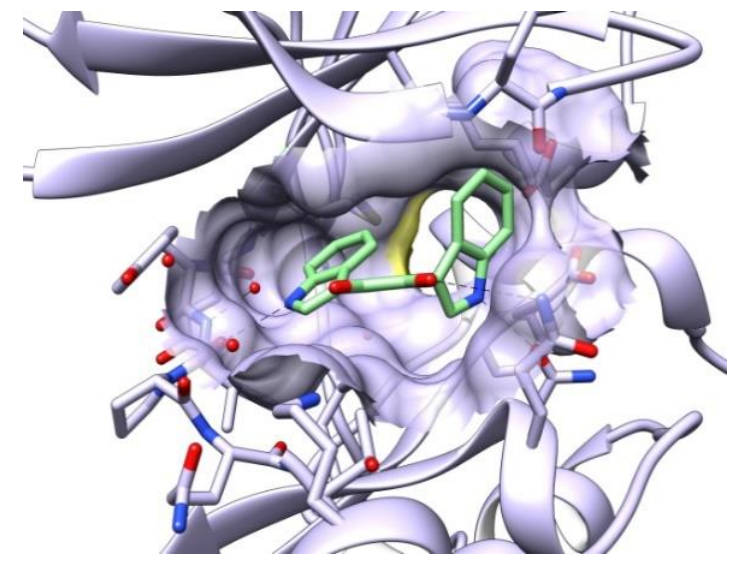

(a)

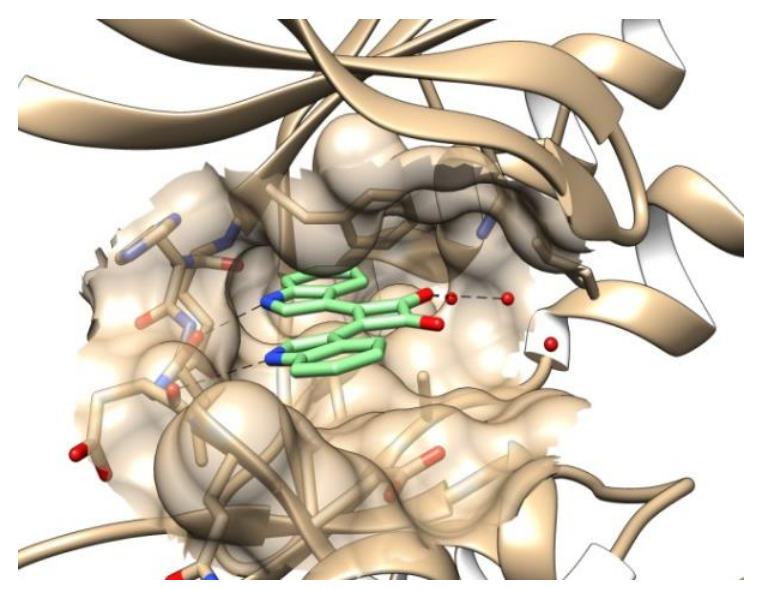

(c)

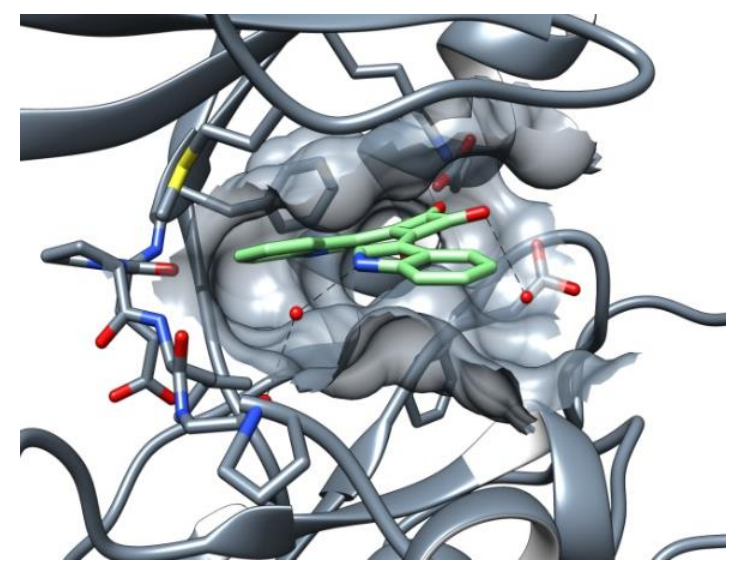

(e)

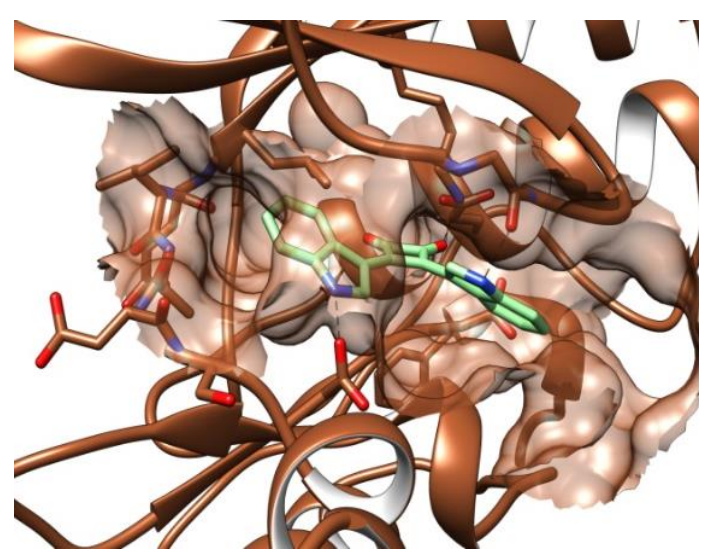

(b)

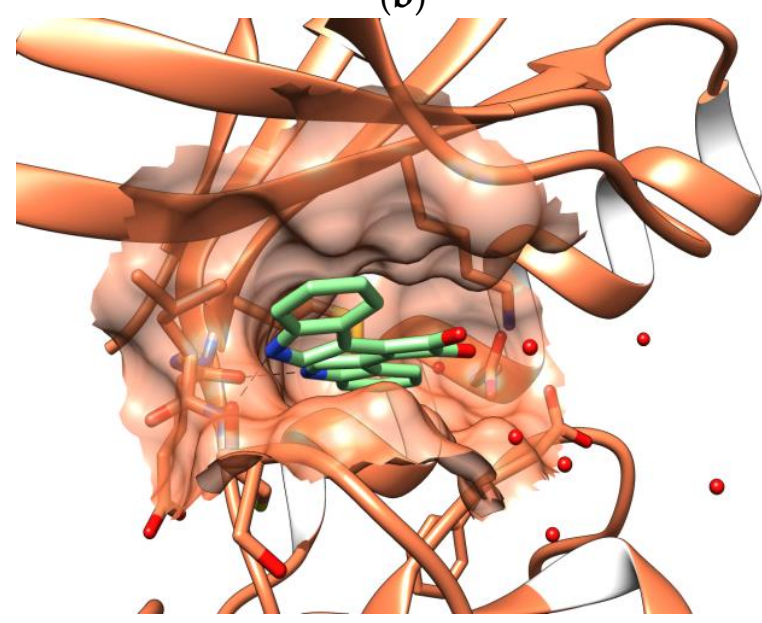

(d)

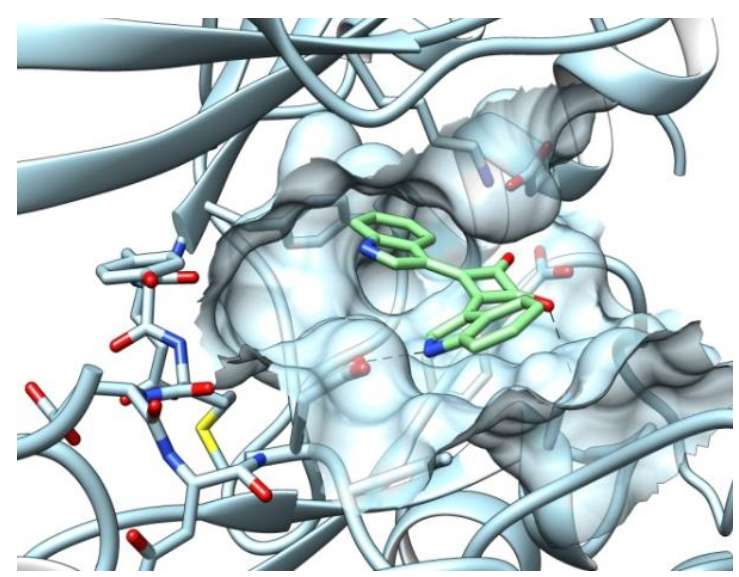

(f)

Figure 2. Poses of 2a in the ATP binding site of six plasmodial protein kinases resulting from molecular docking. (a) $P f G S K-3$ homology model based on template 1J1B. (b) Pfmap-2 (PDB: 3NIE). (c) Pf PK5 (PDB: 1V0P). (d) PfCDPK2 (PDB: 4MVF). (e) Pflammer (PDB: 3LLT). (f) PfPK7 (PDB: 2PML). Dashed lines indicate suggested hydrogen bonds.

\subsubsection{PfCDPK2}

The predicted pose of $\mathbf{2} \mathbf{a}$ in the plasmodial kinase PfCDPK2 (PDB: 4MVF) shown in Figure $2 d$ is very similar to the suggested orientation in PfPK5. Also in this case, the linked ring systems are arranged planar in the area of the adenine binding site. While the indole-NH groups point in the direction of the hinge region and form hydrogen bonds there, the carbonyl groups of the ligand in this pose are not involved in direct bonds to the protein. 


\subsubsection{Pflammer}

The docking of 2a in the plasmodial kinase Pflammer (PDB: 3LLT) resulted in an orientation of the cyclobutenedione ring towards the Lys-Glu salt bridge. One of the two carbonyl groups forms a hydrogen bridge to the conserved lysine in the rear area of the binding pocket. While direct bonds to the hinge region are lacking, one of the indole nitrogen atoms forms an interaction with this region mediated by a water molecule (Figure 2e).

\subsubsection{PfPK7}

The docking orientation of 2a in PfPK7 (2PML) shows that an indole ring is planar to the cyclobutenedione element and lies deep in the binding pocket. The other indole ring is inclined by about $45^{\circ}$ relative to the cyclobutenedione element and is placed in the sugar-binding region of the active center. $\mathbf{2} \mathbf{a}$ forms two hydrogen bonds in this pose, but these are not directed towards the hinge region. The ligand does occupy the adenine binding site (Figure 2f).

\subsection{Design Considerations}

The structure of $\mathbf{2 a}$ was modified, taking into account the docking experiments' orientations to optimize the bioactivity. These structure variations were also intended to generate clues regarding the relevant biological targets from the observed structure-activity relationships. In this context, symmetrical and nonsymmetrical analogs of $\mathbf{2 a}$ were designed by a formal introduction of substituents in both indole units. The known bisindolylmaleimide 8 [37] was included in the study for comparison.

\subsection{Chemistry}

The synthesis of the bisindolylcyclobutenediones 2a-2ar was based on 3,4-dichlorocyclobut-3-ene-1,2-dione (squaric acid dichloride, 4 ), which is readily obtained from squaric acid (3) and oxalyl chloride [38]. It has been reported that 3,4-bisarylcyclobutene-1,2-diones can be prepared by a reaction of 4 with two equivalents of an aromatic compound in the presence of aluminum chloride [39]. However, this method is only suitable for symmetrical compounds and resulted in very low yields of product 2a. Better results were gained by a sequential process. For this method, the dichloride 4 was first reacted with one indole equivalent [40]. Subsequent reaction with a second equivalent of the same or another indole resulted in better yields and enabled the production of asymmetric compounds with two differently substituted indole units. A further improvement was achieved by strengthening the nucleophilicity of the indoles 6 by conversion into magnesium derivatives 7 , a procedure that has already been described for the production of asymmetric bisindolylmaleimides [41]. The indole magnesium intermediates 7 were then transformed into the title compounds by reaction either with squaric acid dichloride 4 or monoarylated intermediate $\mathbf{5}$ (Scheme 1). The hydroxylated compound 2ap was produced by ether cleavage with boron tribromide from the methoxy-substituted analog 2ad (Scheme 2).

\subsection{Biological Evaluation}

All synthesized new bisindolylcyclobutenediones 2a-2ar and the related bisindolylmaleimide 8 [37] were screened for inhibition of erythrocytic stages of Plasmodium falciparum employing a bioluminescence-based viability assay on transgenic parasites that constitutively express luciferase ( $P f$ NF54-luc) [30]. Initially, the compounds were evaluated in single-dose test runs $(3 \mu \mathrm{M})$. If $>20 \%$ viability inhibition was observed, dose-response curves were generated and $\mathrm{IC}_{50}$ values were calculated (Table 1 ). Depending on the substitution pattern on the indole subunits, several congeners proved to be rather potent, exhibiting considerable inhibition in single-digit micromolar or in submicromolar concentrations. The bisindolylmaleimide 8 [37] inhibited the parasites in a single-digit micromolar concentration, similar to many of the bisindolylcyclobutenediones in the study. Because the bisindolylcyclobutenediones 2 display a higher degree of structural novelty, only this 
compound class was further pursued for its antiplasmodial activity. Some among the active compounds displayed substituents at the indole scaffolds in 1, 2, 5- or 7-position, respectively. These structural features were considered unfavorable for orientations as illustrated in Figure 2 with 2a and Pfmap-2, PfPK5, PfCDPK2, Pflammer, and PfPK7, respectively. However, a structure generated for $2 \mathbf{a}$ in $P f G S K-3$ in which the indole units are oriented perpendicular to each other (Figure 2a) was considered compatible with the indicated substitution pattern. Consequently, the potent antiplasmodial derivatives $\mathbf{2 k}$, 2ad, and 2ae were tested in a kinase Glo assay [42] for inhibition of recombinant PfGSK-3. However, these exemplary structures were inactive up to a concentration of $10 \mu \mathrm{M}$, so the biological target responsible for the antiplasmodial activity of the title compounds has not yet been identified. For the compounds with particularly potent antiplasmodial activity, cytotoxicity was also determined using the human cell line THP-1 to assess selectivity with respect to parasite cells (Table 2). In these studies, representative 2ai was found to be particularly beneficial with a selectivity index of 259 .

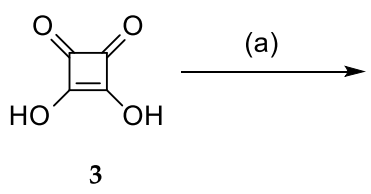

3

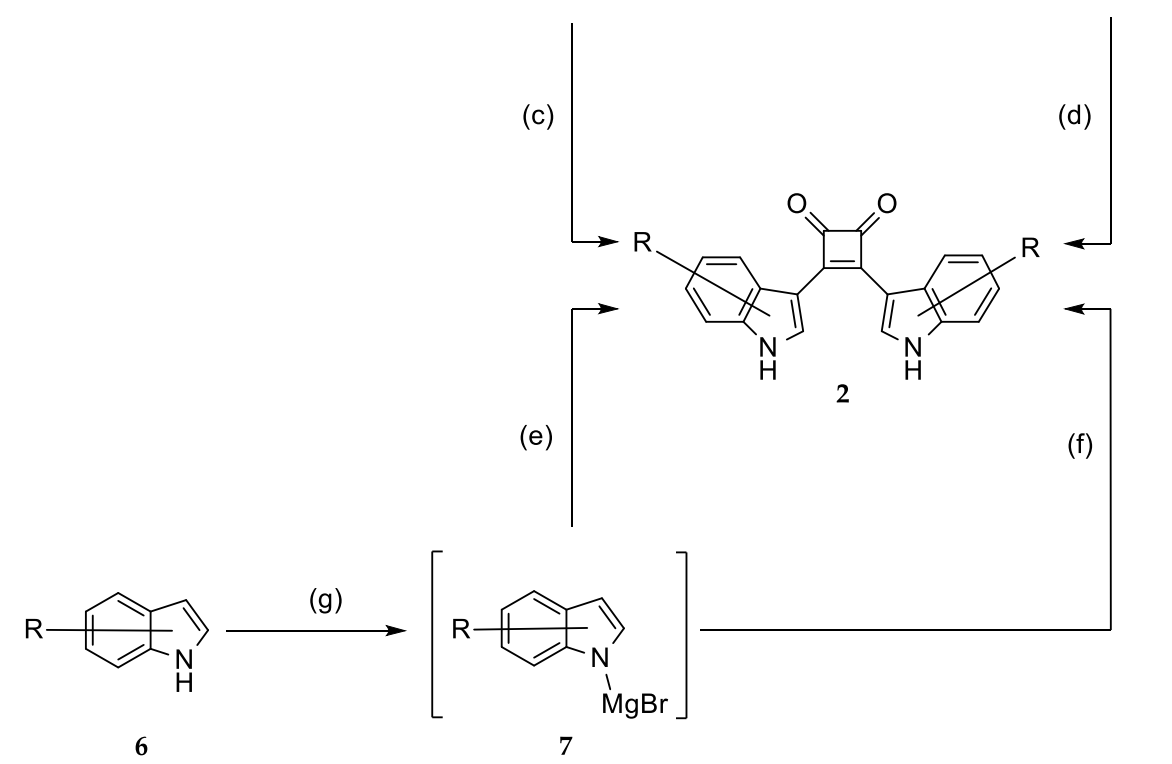

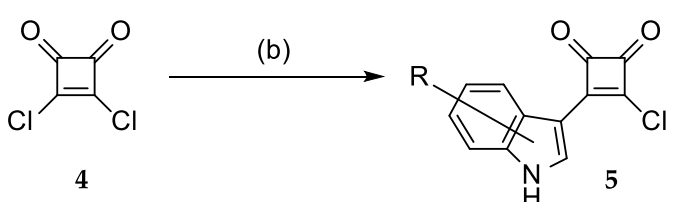

)

Scheme 1. Syntheses of bisindolylcyclobutenediones 2a-2ar. (a) $\mathrm{C}_{2} \mathrm{Cl}_{2} \mathrm{O}_{2}, \mathrm{CCl}_{4}, \mathrm{DMF}, 50{ }^{\circ} \mathrm{C}, 4 \mathrm{~h}$ (79\%); (b) indole (1 eq), $\mathrm{Et}_{2} \mathrm{O}, 0^{\circ} \mathrm{C} \rightarrow \mathrm{rt}$, ca. $24 \mathrm{~h}$; (c) 1. indole (2 eq), $\mathrm{CH}_{2} \mathrm{Cl}_{2}, \mathrm{AlCl}_{3}, 0^{\circ} \mathrm{C} \rightarrow \mathrm{rt}, 20-144$ h; $2 . \mathrm{HCl} / \mathrm{H}_{2} \mathrm{O}(<12 \%)$; (d) 1. indole (1 eq), $\mathrm{CH}_{2} \mathrm{Cl}_{2}, \mathrm{AlCl}_{3}, 0{ }^{\circ} \mathrm{C} \rightarrow \mathrm{rt}, 10-65 \mathrm{~h} ; 2 . \mathrm{HCl} / \mathrm{H}_{2} \mathrm{O}(5-70 \%)$; (e) 1. 4, toluene/ $\mathrm{Et}_{2} \mathrm{O} / \mathrm{THF}$ (5:1:1), $\mathrm{N}_{2}$, reflux, 4-6 h; $2 . \mathrm{H}_{2} \mathrm{O}$ (7-37\%); (f) 1. 5, toluene/ $\mathrm{Et}_{2} \mathrm{O} / \mathrm{THF}$ (5:1:1), $\mathrm{N}_{2}$, reflux, 4-6 h; 2 . $\mathrm{H}_{2} \mathrm{O}(7-66 \%)$; (g) EtMgBr, $\mathrm{N}_{2}, \mathrm{Et}_{2} \mathrm{O}$, toluene, $60{ }^{\circ} \mathrm{C}, 1 \mathrm{~h}$. For substituents $\mathrm{R}$ refer to Table 1 .<smiles>COc1ccc2[nH]cc(-c3c(-c4c[nH]c5ccc(Br)cc45)c(=O)c3=O)c2c1</smiles>

2ad (a)<smiles>O=c1c(-c2c[nH]c3ccc(O)cc23)c(-c2c[nH]c3ccc(Br)cc23)c1=O</smiles>

Scheme 2. Synthesis of bisindolylcyclobutenedione 2ap. Reagents and Conditions: (a) $1 . \mathrm{BBr}_{3}$ (8-16 eq), $\mathrm{CH}_{2} \mathrm{Cl}_{2}, \mathrm{RT}, 15 \mathrm{~h}, 2 . \mathrm{H}_{2} \mathrm{O}, \mathrm{RT}, 1 \mathrm{~h}$. 
Table 1. Structures and antiplasmodial activity of bisindolylcyclobutenediones $\mathbf{2 a}$-ar and bisindolylmaleimide $\mathbf{8}^{\mathrm{a}}$.<smiles>[R]c1ccc2[nH]cc(-c3c(-c4c[nH]c5ccccc45)c(=O)c3=O)c2c1</smiles>

2a-2ar<smiles>CN1C(=O)C(c2c[nH]c3ccccc23)=C(c2c[nH]c3ccccc23)C1=O</smiles>

8

\begin{tabular}{|c|c|c|c|c|}
\hline Entry & $\mathbf{R}^{1}$ & $\mathbf{R}^{2}$ & $\mathrm{IC}_{50}[\mu \mathrm{M}]^{\mathrm{b}}$ & Inhibition at $3 \mu \mathrm{M}[\%]^{\mathrm{c}}$ \\
\hline $2 a$ & $\mathrm{H}$ & $\mathrm{H}$ & 8.33 & $17.9 \pm 3.3$ \\
\hline $2 b$ & $\mathrm{H}$ & $5-\mathrm{Br}$ & 3.02 & $65.9 \pm 1.8$ \\
\hline $2 c$ & $\mathrm{H}$ & $5-\mathrm{Cl}$ & 4.23 & $44.7 \pm 0.5$ \\
\hline $2 d$ & $\mathrm{H}$ & $5-\mathrm{OCH}_{3}$ & n.d. & $18.3 \pm 5.0$ \\
\hline $2 e$ & $\mathrm{H}$ & $5-\mathrm{OCH}_{2} \mathrm{Ph}$ & n.d. & $-4.43 \pm 10.6$ \\
\hline $2 f$ & $\mathrm{H}$ & $5-\mathrm{CN}$ & 6.72 & $26.8 \pm 1.56$ \\
\hline $2 \mathrm{~g}$ & $\mathrm{H}$ & $2-\mathrm{CH}_{3}$ & $>30$ & $23.4 \pm 5.4$ \\
\hline $2 \mathrm{~h}$ & $\mathrm{H}$ & $2-\mathrm{Ph}$ & 6.38 & $65.0 \pm 2.8$ \\
\hline $2 \mathbf{i}$ & 1- $\mathrm{CH}_{3}$ & $1-\mathrm{CH}_{3}$ & n.d. & $3.53 \pm 1.7$ \\
\hline $2 k$ & $\mathrm{H}$ & 1-[3-(dimethyl-amino)propyl] & 0.376 & $98.1 \pm 1.8$ \\
\hline 21 & $2-\mathrm{CH}_{3}$ & $2-\mathrm{CH}_{3}$ & n.d. & $18.3 \pm 6.3$ \\
\hline $2 m$ & $2-\mathrm{Ph}$ & $2-\mathrm{Ph}$ & 2.47 & $41.1 \pm 0.6$ \\
\hline $2 n$ & $5-\mathrm{OCH}_{3}$ & $5-\mathrm{OCH}_{3}$ & n.d. & $19.7 \pm 3.6$ \\
\hline 20 & $5-\mathrm{Br}$ & $5-\mathrm{Br}$ & $>30$ & n.d. \\
\hline $2 p$ & $5-\mathrm{CN}$ & $5-\mathrm{CN}$ & n.d. & $-3.10 \pm 0.9$ \\
\hline $2 q$ & $\mathrm{H}$ & $1-\mathrm{CH}_{3}$ & 2.97 & $52.0 \pm 1.8$ \\
\hline $2 r$ & $\mathrm{H}$ & $5-\mathrm{I}$ & 0.915 & $31.3 \pm 2.7$ \\
\hline $2 s$ & 2-Ph & $5-\mathrm{Br}$ & n.d. & $16.0 \pm 0.7$ \\
\hline $2 t$ & $5-\mathrm{Br}$ & $1-\mathrm{CH}_{3}$ & n.d. & $1.38 \pm 3.3$ \\
\hline $2 u$ & $2-\mathrm{Ph}$ & $1-\mathrm{CH}_{3}$ & 1.72 & $67.7 \pm 0.7$ \\
\hline $2 v$ & $5-\mathrm{OCH}_{3}$ & $2-\mathrm{CH}_{3}$ & 10.0 & $34.2 \pm 8.0$ \\
\hline $2 w$ & $2-\mathrm{Ph}$ & $2-\mathrm{CH}_{3}$ & 9.26 & $41.1 \pm 1.7$ \\
\hline $2 x$ & $5-\mathrm{Br}$ & $2-\mathrm{CH}_{3}$ & $>30$ & $45.6 \pm 1.8$ \\
\hline $2 y$ & $1-\mathrm{CH}_{3}$ & $2-\mathrm{CH}_{3}$ & 2.67 & $59.6 \pm 0.2$ \\
\hline $2 z$ & $5-\mathrm{Br}, 1-\mathrm{CH}_{3}$ & $2-\mathrm{CH}_{3}$ & n.d. & $12.7 \pm 2.8$ \\
\hline $2 \mathrm{aa}$ & $2-\mathrm{Ph}$ & $5-\mathrm{OCH}_{3}$ & n.d. & $22.4 \pm 2.7$ \\
\hline $2 a b$ & $5-\mathrm{F}$ & $5-\mathrm{OCH}_{3}$ & n.d. & $19.2 \pm 3.1$ \\
\hline $2 \mathrm{ac}$ & $5-\mathrm{Cl}$ & $5-\mathrm{OCH}_{3}$ & 1.52 & $87.0 \pm 0.5$ \\
\hline $2 \mathrm{ad}$ & $5-\mathrm{Br}$ & $5-\mathrm{OCH}_{3}$ & 0.47 & $98.8 \pm 0.7$ \\
\hline $2 \mathrm{ae}$ & $5-\mathrm{I}$ & $5-\mathrm{OCH}_{3}$ & 0.64 & $99.1 \pm 0.3$ \\
\hline $2 \mathrm{af}$ & $1-\mathrm{CH}_{3}$ & $5-\mathrm{OCH}_{3}$ & n.d. & $13.6 \pm 3.9^{\mathrm{d}}$ \\
\hline $2 \mathrm{ag}$ & $5-\mathrm{Br}, 1-\mathrm{CH}_{3}$ & $5-\mathrm{OCH}_{3}$ & n.d. & $-0.06 \pm 2.43$ \\
\hline $2 \mathrm{ah}$ & $5-\mathrm{CN}$ & $5-\mathrm{OCH}_{3}$ & 6.92 & $26.8 \pm 1.1$ \\
\hline 2ai & $7-\mathrm{Cl}$ & $5-\mathrm{OCH}_{3}$ & 0.691 & $84.5 \pm 1.0$ \\
\hline $2 a j$ & $7-\mathrm{Br}$ & $5-\mathrm{OCH}_{3}$ & 0.296 & $99.5 \pm 0.4$ \\
\hline $2 \mathrm{ak}$ & $7-\mathrm{I}$ & $5-\mathrm{OCH}_{3}$ & 0.116 & $98.8 \pm 1.2$ \\
\hline $2 \mathrm{al}$ & 7- $\mathrm{C}_{2} \mathrm{H}_{5}$ & $5-\mathrm{OCH}_{3}$ & 0.511 & $87.0 \pm 0.5$ \\
\hline 2 am & $6-\mathrm{Br}$ & $5-\mathrm{OCH}_{3}$ & n.d. & $9.55 \pm 5.8$ \\
\hline 2 an & $4-\mathrm{Br}$ & $5-\mathrm{OCH}_{3}$ & n.d. & $25.7 \pm 2.7$ \\
\hline 2 ao & $5-\mathrm{Br}$ & $1-\mathrm{CH}_{3}, 5-\mathrm{OCH}_{3}$ & 0.504 & $95.4 \pm 1.1$ \\
\hline $2 a p$ & $5-\mathrm{Br}$ & $5-\mathrm{OH}$ & n.d. & $2.52 \pm 1.4$ \\
\hline $2 a q$ & $5-\mathrm{I}$ & 5-I & n.d. & $1.79 \pm 1.8$ \\
\hline $2 a r$ & $5-\mathrm{OBz}$ & $5-\mathrm{OCH}_{3}$ & n.d. & $21.7 \pm 2.5$ \\
\hline 8 & - & - & 4.0 & $34.6 \pm 0.8$ \\
\hline $\mathrm{BSD}^{\mathrm{e}}$ & - & - & 0.288 & $97.6 \pm 0.5$ \\
\hline
\end{tabular}

${ }^{\mathrm{a}}$ n.d. $=$ not determined. ${ }^{\mathrm{b}}$ Concentration $[\mu \mathrm{M}]$ for $50 \%$ inhibition of $P$. falciparum (NF54-luc strain) erythrocytic stages. ${ }^{\mathrm{c}}$ Inhibition of P. falciparum (NF54-luc strain) erythrocytic stages at $3 \mu \mathrm{M} .{ }^{\mathrm{d}}$ determined at $30 \mu \mathrm{M}$. ${ }^{\mathrm{e}}$ Blasticidin (BSD) was used as the positive control. 
Table 2. Selectivity of the most active bisindolylcyclobutenediones on P. falciparum parasites versus the human THP-1 cell line.

\begin{tabular}{|c|c|c|c|c|c|}
\hline Entry & $\mathbf{R}^{1}$ & $\mathbf{R}^{2}$ & $\mathrm{IC}_{50, P f}[\mu \mathrm{M}]^{\mathrm{a}}$ & $\mathrm{IC}_{50, \text { THP-1 }}[\mu \mathrm{M}]^{\mathrm{b}}$ & $\mathrm{SI}^{\mathrm{c}}$ \\
\hline $2 b$ & $\mathrm{H}$ & $5-\mathrm{Br}$ & 3.02 & 23.0 & 7.6 \\
\hline $2 \mathrm{~h}$ & $\mathrm{H}$ & 2-Ph & 6.38 & 6.37 & 1.0 \\
\hline $2 \mathbf{k}$ & $\mathrm{H}$ & 1-[3-(dimethyl-amino)propyl] & 0.38 & 12.8 & 34 \\
\hline $2 q$ & $\mathrm{H}$ & $1-\mathrm{CH}_{3}$ & 2.97 & 14.0 & 4.7 \\
\hline $2 r$ & $\mathrm{H}$ & $5-\mathrm{I}$ & 0.92 & 7.25 & 7.9 \\
\hline $2 u$ & 2-Ph & $1-\mathrm{CH}_{3}$ & 1.72 & 2.10 & 1.2 \\
\hline $2 y$ & $1-\mathrm{CH}_{3}$ & $2-\mathrm{CH}_{3}$ & 2.67 & 8.40 & 3.1 \\
\hline $2 \mathrm{ad}$ & $5-\mathrm{Br}$ & $5-\mathrm{OCH}_{3}$ & 0.47 & 14.1 & 30 \\
\hline 2ae & $5-\mathrm{I}$ & $5-\mathrm{OCH}_{3}$ & 0.64 & 14.5 & 23 \\
\hline 2ai & 7-Cl & $5-\mathrm{OCH}_{3}$ & 0.69 & 179 & 259 \\
\hline 2aj & $7-\mathrm{Br}$ & $5-\mathrm{OCH}_{3}$ & 0.30 & 1.42 & 4.7 \\
\hline 2ak & 7-I & $5-\mathrm{OCH}_{3}$ & 0.12 & 0.84 & 7.0 \\
\hline 2al & $7-\mathrm{C}_{2} \mathrm{H}_{5}$ & $5-\mathrm{OCH}_{3}$ & 0.51 & 0.70 & 1.4 \\
\hline 2ao & $5-\mathrm{Br}$ & $1-\mathrm{CH}_{3}, 5-\mathrm{OCH}_{3}$ & 0.50 & 3.13 & 6.3 \\
\hline
\end{tabular}

${ }^{\mathrm{a}}$ Inhibition $\left(\mathrm{IC}_{50}\right)$ of Plasmodium falciparum (NF54-luc strain) erythrocytic stages. ${ }^{\mathrm{b}}$ Inhibition $\left(\mathrm{IC}_{50}\right.$ ) of human THP-1 cell line. ${ }^{\mathrm{c}}$ Selectivity Index (SI) $=\mathrm{IC}_{50}$, THP-1 $/ \mathrm{IC}_{50,}$ Pf.

\section{Discussion}

In view of the increasingly critical resistance situation in drug therapy for malaria, the development of additional active agents is urgently required. These agents should be structurally distinct from established antiplasmodial drugs and directed against previously unaddressed biological targets. Representing a well-studied enzyme class, the plasmodial protein kinases comprise entities which are essential for parasite development and replication. Given the high number of protein kinase inhibitors approved as anticancer drugs, protein kinases are generally accepted as "druggable". Hitherto, the compound class of 3,4-bis(indol-3-yl)cyclobut-3-ene-1,2-diones 2 has been neglected in the search for biologically active compounds. This is surprising since the compounds show structural similarity to bisindolylmaleimides $\mathbf{1}$, which are established protein kinase inhibitors. Therefore, we investigated whether the unsubstituted prototype $\mathbf{2 a}$ could be fitted into the ATP-binding pockets of plasmodial protein kinases by a docking routine. In these experiments, structures of plasmodial kinases from the Protein Data Bank were used as templates. A commonly observed binding motif generated by docking showed in some cases (PfGSK-3, PfPk5, PfCDPK2) hydrogen bonding between the hinge region of the kinase and the potential ligands, with at least one of the indole nitrogen atoms acting as a hydrogen bond donor (Figure 2). A literature survey revealed that bisindolylcyclobutenediones without substituents on one or both nitrogen atoms were previously unknown. A series of corresponding compounds was therefore synthesized. Sequential Friedel-Crafts reactions of squaric acid dichloride (4) with two differently substituted indole systems provided access to unsymmetrically substituted title compounds. Since the biological target in plasmodia was not a foregone conclusion, the new compounds were tested in phenotypic screening. Phenotypic screenings have the advantage over target-oriented methods in that the antiparasitic effect can be achieved by attacking different, even initially unknown, target structures. In addition, positive results from phenotypic screenings ensure that the active ingredients can overcome the cell membrane of the parasites and remain there intracellularly long enough to exert their effect [43-49].

Testing of the unsubstituted prototype $\mathbf{2 a}$ in a viability assay on genetically modified parasites constitutively expressing luciferase resulted in inhibition of the parasites 
in the single-digit micromolar concentration range. Although bisindolylmaleimide 8 [37] inhibited the parasites at comparable concentrations, we decided rather to further investigate the structurally novel 3,4-bis(indol-3-yl)cyclobut-3-ene-1,2-diones 2. Substitution at the 5-position on one of the indole rings of $2 \mathbf{a}$ with halogen or cyano substituents led to slightly improved results $(\mathbf{2 b}, \mathbf{2 c}, \mathbf{2} \mathbf{f})$. The introduction of a 5-iodo substituent even shifted the antiplasmodial activity into the submicromolar range. In contrast, a symmetric 5,5disubstitution with halogen, cyano, or methoxy substituents resulted in lower inhibitory activities (2n, 2o, 2p, 2aq).

While methyl substitution at both indole nitrogen atoms (compound 2i) significantly decreased the antiplasmodial activity, single $N$-methylation gave improved results in some cases $(\mathbf{2 q}, \mathbf{2} \mathbf{u}, \mathbf{2} \mathbf{y})$. The otherwise unsubstituted representative $\mathbf{2 k}$ with a basic side chain on one of the two indole nitrogen atoms also showed a solid antiplasmodial efficacy. In contrast, diminished activity was observed when $N$-methylation at one of the indole nitrogen atoms was combined with a substitution at the 5-position of the other indole ring (2t, 2af, 2ag). While most representatives with 2-substituted indole rings were hardly active $(2 \mathrm{~g}, 2 \mathbf{2}, \mathbf{2 s}, \mathbf{2 z}, \mathbf{2 a a})$, some congeners with 2-phenylindole substitution still showed activity $(\mathbf{2 h}, \mathbf{2 m}, \mathbf{2 u})$. A benzyloxy substituent on one of the two indole rings prevented potent antiplasmodial activity of the corresponding derivatives $2 \mathbf{e}, \mathbf{2 a r}$.

The influence of a methoxy substituent in the 5-position at one of the two indole elements connected with the substitution at the other indole ring was striking but inconsistent. While the bromo substitution at the second indole ring in 4- and 6-position reduced the antiparasitic effect (2am, 2an), the 5- or 7-bromo isomers exhibited strong antiplasmodial activity in the submicromolar concentration range (2ad, 2aj). Similarly, the 5-methoxy-substituted derivatives with chloro (2ac, 2ai) or iodo substitution (2ae, 2ak) in 5- or 7-position on the other indole ring also showed strong antiparasitic activity. The 7-substituent could also be replaced by an ethyl residue (2al).

The question arose whether a hypothesis about a protein kinase as a biological target in plasmodia could be derived from the observed structure-activity relationships. Substitution in the 2-position on one or both indole rings prevents a planar arrangement of these structural elements and would be incompatible with the predicted orientations of the compounds in PfPK5, PfCDPK2, and Pflammer (Figure 2). The structure-activity relationships derived from these observations present an inconsistent picture when viewed as a whole, making it doubtful whether plasmodial kinases are indeed the biological targets of this new class of drugs. However, it is clear that monosubstitution at one of the two nitrogen atoms is possible, whereas substitution at both indole nitrogen atoms reduces the activity. This argues against both indole nitrogen atoms interacting simultaneously with the hinge region of a plasmodial kinase. The combined substitution pattern on both indole rings also indicates that in the biologically active conformation, the two indole rings are most likely not aligned planar to each other.

Of the enzyme-ligand complexes shown in Figure 2, the structure of PfGSK-3 is most consistent with the above observations. Using some 5-bromosubstituted analogs (2b, 2t, 2ag, 2ao) as examples, this possibility was further investigated by docking experiments. The 5-monobrominated compound $\mathbf{2 b}\left(\mathrm{IC}_{50}\right.$ P. falciparum $\left.=3 \mu \mathrm{M}\right)$ can be unconstrainedly docked into the homology model of PfGSK-3, with the bromine atom filling a hydrophobic pocket in the backspace of the ATP-binding site. An additional 5-methoxy group on the second indole ring advantageously occupies a small binding pocket in the upper region of the ATP-binding site, which could explain the enhanced inhibitory activity of this compound (2ad, $\mathrm{IC}_{50}$ P.f $\left.=0.47 \mu \mathrm{M}\right)$ (Figure S1). In this orientation, $N$-methylation on the methoxy-substituted indole ring would also be compatible (2ao, $\mathrm{IC}_{50}$ P.f $\left.=0.54 \mu \mathrm{M}\right)$. In contrast, $\mathrm{N}$-methylation on the bromine-substituted indole ring would prevent its interaction with the hinge region, which could account for the inactivity of this compound (2ag, IC 50 P.f $>10 \mu \mathrm{M}$ ).

In light of these considerations, it was hypothesized that $P f G S K-3$ could represent the biologically relevant target structure in plasmodia. However, this assumption was 
refuted by testing three particularly potent compounds on isolated recombinant $P f G S K-3$ enzyme. At a concentration of $10 \mu \mathrm{M}$, the particularly potent antiplasmodial agents $\mathbf{2 k}$, 2ad and 2ae did not inhibit PfGSK-3. Therefore, the target structure responsible for the antiplasmodial activity of the substance class must be identified in further studies. In this regard, other mechanisms of action and other targets (e.g. hemoglobin degradation, hemozoin formation, $\beta$-hematin inhibition) should be considered which already have been identified for indole-derived antimalarial agents (recently reviewed by Li et al. [50]).

When used as drugs, antimicrobial agents should, as far as possible, only damage the pathogen cells without affecting the viability of the host cells. Therefore, to obtain an overview of selectivity in this class of compounds, a selection of particularly potent antiplasmodially active compounds were evaluated using the human cell line THP-1 (Table 2). While most compounds showed only weak selectivity, the three compounds 2ad, 2ae, and 2ai turned out to be highly selective with selectivity indices ranging from two to three digits.

The bisindolylcyclobutenediones are compounds with multiple aromatic ring systems and a high fraction of $\mathrm{sp}^{2}$-hybridized carbon atoms, which also typically exhibit low solubility in aqueous media due to the solid crystal lattice structure. For compounds intended to be used as drugs, this often results in poor absorption after oral administration and thus low bioavailability. Further studies of this class of compounds must therefore be directed not only at elucidating the molecular mechanism of action of the antiplasmodial activity. Rather, derivatives must be prepared that have a higher fraction of $\mathrm{sp}^{3}$-hybridized carbon atoms and exhibit optimized solubility.

Nevertheless, the pronounced antiparasitic activity, novelty value of the structural class, and selectivity versus human cells warrant further exploration of these antiplasmodial agents.

\section{Materials and Methods}

\subsection{General Information}

Starting materials, reagents, and solvents were purchased from Acros Organics (Geel, Belgium), Sigma Aldrich (Steinheim, Germany), and Alfa Aesar (Karlsruhe, Germany). The known bisindolylmaleimide 8 was synthesized according to a published procedure [37]. ${ }^{1} \mathrm{H}-\mathrm{NMR}$ spectra were recorded on a Bruker Avance DRX-400 (400 MHz), a Bruker Avance III-400 (400 MHz), or a Bruker Avance II-600 (600 MHz), respectively, using DMSO- $d_{6}$ as solvent. The elemental analyses were recorded on a CE Instruments FlashEA 1112 Elemental Analyzer (Thermo Quest, San Jose, CA, USA). The reactions were monitored by TLC on Polygram SIL G/UV254 plates (Macherey-Nagel, Düren, Germany). Isocratic HPLC experiments were performed on a Merck Hitachi LaChrom Elite system (pump: L-2130, DAD detector: L-2450; autosampler: L-2200; column: Merck LiChroCART 125-4. LiChrospher $100 \mathrm{RP}-18$ ( $5 \AA$ A); elution rate $1.000 \mathrm{~mL} / \mathrm{min}$; dectection wavelength: $254 \mathrm{~nm}$ and $280 \mathrm{~nm}$, overall run time: $15 \mathrm{~min}$ unless otherwise described); $\mathrm{t}_{\mathrm{ms}}=$ total retention time, $\mathrm{t}_{\mathrm{m}}=$ dead time; eluents: mixtures of acetonitrile and double-distilled water (Hitachi High Technologies Corporation, Tokyo, Japan). Gradient HPLC was performed on a Merck Hitachi LaChrom Elute system (pump: L2130, UV detector: L-2400; autosampler: L-2200; column: Merck LiChroCART 125-4, LiChrospher 100 RP-18 (5 ̊̊); elution rate $1.000 \mathrm{~mL} / \mathrm{min}$; dectection wavelength: $254 \mathrm{~nm}$ unless otherwise described; overall run time: $25 \mathrm{~min}$ unless otherwise described, the eluents were mixed on-line). Gradient elution conditions: $0 \rightarrow 2$ min: acetonitrile $/ \mathrm{H}_{2} \mathrm{O} 10: 90,2 \rightarrow 12 \mathrm{~min}$ : acetonitrile $/ \mathrm{H}_{2} \mathrm{O}$ 10:90 $\rightarrow$ acetonitrile $/ \mathrm{H}_{2} \mathrm{O} 90: 10,12 \rightarrow 20 \mathrm{~min}$ : acetonitrile $/ \mathrm{H}_{2} \mathrm{O}$ 90:10 [36]. The mass spectra were recorded on a Thermofinnigan MAT95XL (Thermo Finnigan MAT, Bremen, Germany). 


\subsection{Compound Synthesis and Characterization}

4.2.1. General Procedure A for the Syntheses of 3-Chloro-4-(1H-indol-3-yl)cyclobut-3 -ene-1,2-dione Derivatives $\mathbf{5 a}-\mathbf{f}$

The syntheses were performed following an adapted protocol initially developed by Schmidt et al. [40]. To squaric acid dichloride (4) $(1.51 \mathrm{~g}, 10.0 \mathrm{mmol})$ [38] dissolved in dry diethyl ether $(25 \mathrm{~mL})$ and cooled to $0{ }^{\circ} \mathrm{C}$, a solution of the appropriate indole $(12.0 \mathrm{mmol})$ in the same solvent $(25 \mathrm{~mL})$ is added dropwise. The mixture is allowed to warm to room temperature and stirred for twenty-four hours. The resulting precipitate is filtered, washed with diethyl ether, and crystallized from chloroform $/ N, N$-dimethylformamide. The product is dried at $110^{\circ} \mathrm{C}$ in vacuo.

4.2.2. General Procedure B for the Syntheses of 3,4-Bis(indol-3-yl)cyclobut-3-ene-1,2-diones $21,2 \mathrm{~m}, 2 \mathrm{p}$

With reference to Green et al. [39] and Matsuoka et al. [26], the 3,4-bis(indol-3yl)cyclobut-3-ene-1,2-diones $\mathbf{2 1}, \mathbf{2 m}, \mathbf{2 p}$ are synthesized by the following procedure: To a suspension of 3,4-dichlorocyclobut-3-ene-1,2-dione $(4,0.300 \mathrm{~g}, 2.00 \mathrm{mmol})$ and anhydrous aluminum chloride $(800 \mathrm{mg}, 6.00 \mathrm{mmol})$ in dry dichloromethane, the appropriate indole $(4.00 \mathrm{mmol})$ is added. The mixture is stirred for $10-65 \mathrm{~h}$ at room temperature with moisture protection. Subsequently, the reaction suspension is stirred in a mixture of water $(50 \mathrm{~mL})$ and five drops of $37 \%$ aqueous hydrochloric acid. The resulting precipitate is separated and washed with water. After drying, the residue is dissolved in acetone $(10 \mathrm{~mL})$ and eluted through a column of acidic aluminum oxide with acetone. The yellow or tawny fraction is collected and evaporated under reduced pressure. The solid residue is crystallized from an appropriate solvent or purified by silica gel column chromatography. The resulting product is dried at $80-90^{\circ} \mathrm{C}$ in vacuo.

4.2.3. General Procedure $C$ for the Syntheses of 3,4-Bis(indol-3-yl)cyclobut-3-ene-1,2-diones $2 b-i, 2 n, 2 q-t, 2 v-y, 2 a a-a c, 2 a e-a i$

With reference to Green et al. [39] and Matsuoka et al. [26], the 3,4-bis(indol-3yl)cyclobut-3-ene-1,2-diones $\mathbf{2 b - i}, \mathbf{2 n}, \mathbf{2 q -}-\mathbf{t}, \mathbf{2 v - \mathbf { y }}, \mathbf{2 a a}-\mathbf{a c}, \mathbf{2 a e}-\mathbf{a i}$ are synthesized by the following procedure: To the stirred suspension of an appropriate 3-chloro-4-(1H-indol3 -yl)cyclobut-3-ene-1,2-dione derivative $(1.00 \mathrm{mmol})$ and anhydrous aluminum chloride $(400 \mathrm{mg}, 3.00 \mathrm{mmol})$ in dry dichloromethane $(20 \mathrm{~mL})$, precooled to $0{ }^{\circ} \mathrm{C}$, a solution of an appropriate indole $(1.50 \mathrm{mmol})$ in the same solvent $(10 \mathrm{~mL})$ is added dropwise. The reaction mixture is allowed to warm to room temperature. After stirring for twenty-four to forty-eight hours at room temperature with moisture protection, the suspension is added to a mixture of water $(50 \mathrm{~mL})$ and 5 drops of $37 \%$ aqueous hydrochloric acid. The resulting precipitate is filtered and washed with water. After drying, the solid is eluted through a column of acidic aluminum oxide using acetone. The yellow or tawny eluent is collected and evaporated under reduced pressure. Subsequently, the solid residue is crystallized from the given solvent or purified by silica gel column chromatography using ethyl acetate/petroleum ether. The resulting product is dried at $80-90^{\circ} \mathrm{C}$ in vacuo.

4.2.4. General Procedure D for the Syntheses of 3,4-Bis(indol-3-yl)cyclobut-3-ene-1,2diones 2o, 2u, 2z, 2aj-ao

With reference to Green et al. [39] the 3,4-bis(indol-3-yl)cyclobut-3-ene-1,2-diones 2o, $2 \mathbf{u}, \mathbf{2 z}, \mathbf{2 a j}-\mathbf{a o}$ are synthesized by the following procedure. To the stirred suspension of an appropriate 3 -chloro-4-(1H-indol-3-yl)cyclobut-3-ene-1,2-dione $(1.00 \mathrm{mmol})$ derivative and anhydrous aluminum chloride $(400 \mathrm{mg}, 3.00 \mathrm{mmol})$ in dry dichloromethane $(20 \mathrm{~mL})$, precooled to $0{ }^{\circ} \mathrm{C}$, a solution of an appropriate indole $(1.50 \mathrm{mmol})$ in the same solvent $(10 \mathrm{~mL})$ is added dropwise. The reaction mixture is allowed to warm to room temperature. After stirring for twenty-four hours at room temperature with moisture protection, the suspension is added to a mixture of water $(50 \mathrm{~mL})$ and 5 drops of $37 \%$ aqueous hydrochloric acid. The resulting precipitate is filtered and washed with water. After drying, the residue is dissolved in ethyl acetate $(30 \mathrm{~mL})$ and washed with water $(2 \times 50 \mathrm{~mL})$ and brine $(50 \mathrm{~mL})$. 
The aqueous layer is extracted with ethyl acetate $(3 \times 20 \mathrm{~mL})$. After drying the combined organic layers with anhydrous sodium sulfate, the solvent is removed under reduced pressure. Subsequently, the resulting residue is crystallized from a suitable solvent and dried at $80-90^{\circ} \mathrm{C}$ in vacuo.

4.2.5. General Procedure E for the Syntheses of 3,4-Bis(indol-3-yl)cyclobut-3-ene-1,2dione 2 aq

With reference to Faul et al. [41] the 3,4-bis(indol-3-yl)cyclobut-3-ene-1,2-dione derivative 2aq is synthesized by the following procedure. To a stirred solution of the appropriate indole $(5 \mathrm{mmol})$ in anhydrous toluene $(8.35 \mathrm{~mL})$ is added ethyl magnesium bromide $(3.0 \mathrm{M}$ in diethyl ether, $1.67 \mathrm{~mL}$ ) under nitrogen. After heating to $60^{\circ} \mathrm{C}$ for one hour, a solution of squaric acid dichloride (4) in dry tetrahydrofuran $(1.64 \mathrm{~mL})$ is added slowly. Subsequently, the reaction mixture is refluxed for four $\mathrm{h}$ under nitrogen, cooled to room temperature, and diluted with ethyl acetate $(25 \mathrm{~mL})$. The organic layer is washed successively with $1 \mathrm{M}$ aqueous hydrochloric acid $(15 \mathrm{~mL})$, water $(2 \times 15 \mathrm{~mL})$, and brine $(15 \mathrm{~mL})$ and dried with anhydrous sodium sulfate. After evaporation under reduced pressure, the product is crystallized from the given solvent and then dried at $80-90^{\circ} \mathrm{C}$ in vacuo.

4.2.6. General Procedure F for the Syntheses of 3,4-Bis(indol-3-yl)cyclobut-3-ene-1,2-diones 2a, 2ad, 2ar

With reference to Faul et al. [41] the 3,4-bis(indol-3-yl)cyclobut-3-ene-1,2-dione derivatives $2 \mathrm{a}, \mathbf{2 a d}$, 2ar are synthesized by the following procedure. To a stirred solution of an appropriate indole $(3 \mathrm{mmol})$ in anhydrous toluene $(8.35 \mathrm{~mL})$ is added ethyl magnesium bromide (3.0 M in diethyl ether, $1.67 \mathrm{~mL}$ ) under nitrogen. After heating to $60{ }^{\circ} \mathrm{C}$ for one hour, a suspension of an appropriate 3-chloro-4-indol-3-ylcyclobut-3-ene-1,2-dione derivative in a mixture of dry toluene/diethyl ether/tetrahydrofuran $(8.35 \mathrm{~mL} / 1 \mathrm{~mL} / 2.67 \mathrm{~mL})$ is added slowly. Subsequently, the reaction mixture is refluxed for four $\mathrm{h}$ under nitrogen, cooled to room temperature, and diluted with ethyl acetate $(25 \mathrm{~mL})$. The organic layer is washed successively with $1 \mathrm{M}$ aqueous hydrochloric acid $(15 \mathrm{~mL})$, water $(2 \times 15 \mathrm{~mL})$, brine $(15 \mathrm{~mL})$, and dried with anhydrous sodium sulfate. After evaporation under reduced pressure, the product is crystallized from the given solvent and then dried at $80-90{ }^{\circ} \mathrm{C}$ in vacuo.

\subsubsection{Synthesis Procedures and Characterization Data for Individual Compounds \\ 3-Chloro-4-(1H-indol-3-yl)cyclobut-3-ene-1,2-dione (5a)}

Synthesis according to General Procedure A from squaric acid dichloride $(4,3.09 \mathrm{~g}$, $0.02 \mathrm{~mol})$ and $1 \mathrm{H}$-indole $(2.39 \mathrm{~g}, 0.02 \mathrm{~mol})$. The yield of the ocher solid was $3.10 \mathrm{~g}(67 \%)$. IR (KBr): $3193 \mathrm{~cm}^{-1}(\mathrm{NH}), 1773 \mathrm{~cm}^{-1}, 1755 \mathrm{~cm}^{-1}$ (C=O), $1616 \mathrm{~cm}^{-1}$ (C=C, arom.); ${ }^{1} \mathrm{H}-\mathrm{NMR}$ $\left(600 \mathrm{MHz}, \mathrm{DMSO}-d_{6}\right): \delta(\mathrm{ppm})=7.20(\mathrm{ddd}, J=8.1,7.0,1.2 \mathrm{~Hz}, 1 \mathrm{H}, \mathrm{ArH}), 7.22(\mathrm{ddd}, J=8.1$, 7.1, $1.3 \mathrm{~Hz}, 1 \mathrm{H}, \mathrm{ArH}), 7.51$ (dt, $J=8.1,1.0 \mathrm{~Hz}, 1 \mathrm{H}, \mathrm{ArH}), 8.20(\mathrm{~d}, J=3.0 \mathrm{~Hz}, 1 \mathrm{H}, \mathrm{ArH}), 8.30$ $(\mathrm{ddt}, J=7.9,1.4,0.8 \mathrm{~Hz}, 1 \mathrm{H}, \mathrm{ArH}), 12.27(\mathrm{~s}, 1 \mathrm{H}, \mathrm{NH}) ;{ }^{13} \mathrm{C}-\mathrm{NMR}\left(151 \mathrm{MHz}, \mathrm{DMSO}-d_{6}\right): \delta$ $(\mathrm{ppm})=112.3,121.2,121.6,122.9,128.7(\mathrm{CH}), 105.8,124.7,136.4,171.2,192.8(2 \mathrm{C}), 193.3(\mathrm{C})$; $\mathrm{C}_{12} \mathrm{H}_{6} \mathrm{ClNO}_{2}$ [231.64]; Anal. calcd. for $\mathrm{C}_{12} \mathrm{H}_{6} \mathrm{ClNO}_{2}$ : C 62.22, $\mathrm{H}$ 2.61, N 6.05; found C 61.95, H 2.52, N 5.82; MS (EI): $m / z(\%)=231[\mathrm{M}]^{+} \cdot(40), 203\left[\mathrm{M}^{+}-28\right](6), 175\left[\mathrm{M}^{+}-56\right](100)$.

\section{3-Chloro-4-(1-methyl-1H-indol-3-yl)cyclobut-3-ene-1,2-dione (5b)}

Synthesis according to General Procedure A from squaric acid dichloride $(4,453 \mathrm{mg}$, $3.00 \mathrm{mmol})$ and 1-methyl-1H-indole $(0.44 \mathrm{~mL}, 3.52 \mathrm{mmol})$. The yield of the yellow solid was $0.21 \mathrm{~g}(27 \%)$. IR (KBr): $1812 \mathrm{~cm}^{-1}, 1777 \mathrm{~cm}^{-1}, 1738 \mathrm{~cm}^{-1}(\mathrm{C}=\mathrm{O}, \mathrm{C}=\mathrm{C}), 1619 \mathrm{~cm}^{-1}$, $1556 \mathrm{~cm}^{-1}, 1509 \mathrm{~cm}^{-1}$ (C=C, arom.); ${ }^{1} \mathrm{H}-\mathrm{NMR}\left(400 \mathrm{MHz}, \mathrm{DMSO}-d_{6}\right): \delta(\mathrm{ppm})=3.93(\mathrm{~s}$, $\left.3 \mathrm{H}, \mathrm{CH}_{3}\right), 7.26(\mathrm{ddd}, J=8.0,7.1,1.1 \mathrm{~Hz}, 1 \mathrm{H}, \mathrm{ArH}), 7.32(\mathrm{ddd}, J=8.2,7.1,1.3 \mathrm{~Hz}, 1 \mathrm{H}, \mathrm{ArH})$, $7.57(\mathrm{dt}, J=8.2,0.9 \mathrm{~Hz}, 1 \mathrm{H}, \mathrm{ArH}), 8.26(\mathrm{~s}, 1 \mathrm{H}, \mathrm{ArH}), 8.29-8.32(\mathrm{~m}, 1 \mathrm{H}, \mathrm{ArH}) ;{ }^{13} \mathrm{C}-\mathrm{NMR}$ $\left(101 \mathrm{MHz}, \mathrm{DMSO}-d_{6}\right): \delta(\mathrm{ppm})=33.2\left(\mathrm{CH}_{3}\right), 110.8,121.5,121.9,123.0,132.4(\mathrm{CH}), 104.9$, $125.2,137.1,170.7,192.8(2 \mathrm{C}), 193.2(\mathrm{C}) ; \mathrm{C}_{13} \mathrm{H}_{8} \mathrm{ClNO}_{2}$ [245.66]; Anal. calcd. for $\mathrm{C}_{13} \mathrm{H}_{8} \mathrm{ClNO}_{2}$ : 
C 63.56, H 3.28, N 5.70; found C 63.44, H 3.23, N 5.59; MS (EI): $m / z(\%)=245[\mathrm{M}]^{+\cdot}(32), 217$ $\left[\mathrm{M}^{+}-28\right](2), 189\left[\mathrm{M}^{+}-56\right](100)$.

3-Chloro-4-(5-methoxy-1H-indol-3-yl)cyclobut-3-ene-1,2-dione (5c)

Synthesis according to General Procedure A from squaric acid dichloride $(4,1.53 \mathrm{~g}$, $10.1 \mathrm{mmol})$ and 5 -methoxy- $1 H$-indole $(1.51 \mathrm{~g}, 10.3 \mathrm{mmol})$. The yield of the green powder was $2.22 \mathrm{~g}(74 \%)$. IR (KBr): $3184 \mathrm{~cm}^{-1}(\mathrm{NH}), 1800 \mathrm{~cm}^{-1}, 1776 \mathrm{~cm}^{-1}, 1741 \mathrm{~cm}^{-1}(\mathrm{C}=\mathrm{O}$, $\mathrm{C}=\mathrm{C}), 1631 \mathrm{~cm}^{-1}, 1543 \mathrm{~cm}^{-1}$ (C=C, arom.); ${ }^{1} \mathrm{H}-\mathrm{NMR}\left(400 \mathrm{MHz}, \mathrm{DMSO}-d_{6}\right): \delta(\mathrm{ppm})=3.78$ $\left(\mathrm{s}, 3 \mathrm{H}, \mathrm{CH}_{3}\right), 6.88(\mathrm{dd}, J=8.8,2.5 \mathrm{~Hz}, 1 \mathrm{H}, \mathrm{ArH}), 7.40(\mathrm{dd}, J=8.8,0.6 \mathrm{~Hz}, 1 \mathrm{H}, \mathrm{ArH}), 7.84(\mathrm{~d}$, $J=2.5 \mathrm{~Hz}, 1 \mathrm{H}, \mathrm{ArH}), 8.13(\mathrm{~d}, J=3.1 \mathrm{~Hz}, 1 \mathrm{H}, \mathrm{ArH}), 11.41(\mathrm{~s}, 1 \mathrm{H}, \mathrm{NH}) ;{ }^{13} \mathrm{C}-\mathrm{NMR}(101 \mathrm{MHz}$, DMSO- $\left.d_{6}\right): \delta(\mathrm{ppm})=60.6\left(\mathrm{CH}_{3}\right), 109.2,117.9,118.4,134.5(\mathrm{CH}), 111.0,111.1,130.9,136.7$, 160.1, 176.6, 197.9, 198.0 (C); $\mathrm{C}_{13} \mathrm{H}_{8} \mathrm{ClNO}_{3}$ [261.52]; Anal. calcd. for $\mathrm{C}_{13} \mathrm{H}_{8} \mathrm{ClNO}_{3}: \mathrm{C}$ 59.65, H 3.06, N 5.35; found C 59.38, H 3.09, N 5.32; MS (EI): $m / z(\%)=261[\mathrm{M}]^{+} .(45), 233$ $\left[\mathrm{M}^{+}-28\right](2), 205\left[\mathrm{M}^{+}-56\right](100)$.

3-Chloro-4-(2-phenyl-1H-indol-3-yl)cyclobut-3-ene-1,2-dione (5d)

Synthesis according to General Procedure A from squaric acid dichloride $(4,1.51 \mathrm{~g}$, $10.0 \mathrm{mmol}$ ) and 2-phenyl- $1 \mathrm{H}$-indole $(2.08 \mathrm{~g}, 10.8 \mathrm{mmol})$. The crude product was purified by column chromatography on silica gel using ethyl acetate/petroleum ether $(1 / 1)$. The yield of the orange powder was $2.00 \mathrm{~g}(65 \%)$. IR $(\mathrm{KBr}): 3219 \mathrm{~cm}^{-1}(\mathrm{NH}), 1769 \mathrm{~cm}^{-1}, 1743 \mathrm{~cm}^{-1}$ $(\mathrm{C}=\mathrm{O}) ;{ }^{1} \mathrm{H}-\mathrm{NMR}\left(400 \mathrm{MHz}, \mathrm{DMSO}-d_{6}\right): \delta(\mathrm{ppm})=7.16(\mathrm{ddd}, J=8.1,7.1,1.1 \mathrm{~Hz}, 1 \mathrm{H}, \mathrm{ArH})$, 7.23 (ddd, $J=8.1,7.1,1.3 \mathrm{~Hz}, 1 \mathrm{H}, \mathrm{ArH}), 7.40-7.50(\mathrm{~m}, 4 \mathrm{H}, \mathrm{ArH}), 7.54-7.62(\mathrm{~m}, 2 \mathrm{H}, \mathrm{ArH})$, $8.06(\mathrm{dd}, J=7.7,1.0 \mathrm{~Hz}, 1 \mathrm{H}, \mathrm{ArH}), 12.30(\mathrm{~s}, 1 \mathrm{H}, \mathrm{NH}) ;{ }^{13} \mathrm{C}-\mathrm{NMR}\left(101 \mathrm{MHz}, \mathrm{DMSO}-d_{6}\right): \delta$ $(\mathrm{ppm})=111.7,120.6,121.7,122.8,128.1,128.6,129.0(\mathrm{CH}), 102.1,126.9,128.3,131.9,136.5$, 140.0, 173.6, 193.3, 196.2 (C); $\mathrm{C}_{18} \mathrm{H}_{10} \mathrm{ClNO}_{2}$ [307.73]; Anal. calcd. for $\mathrm{C}_{18} \mathrm{H}_{10} \mathrm{ClNO}_{2}$ : C 70.26, H 3.28, N 4.55; found C 70.08, H 3.26, N 4.46; MS (EI): $m / z(\%)=307[\mathrm{M}]^{+}$(45), 279 $\left[\mathrm{M}^{+}-28\right](14), 251\left[\mathrm{M}^{+}-56\right](67), 216\left[\mathrm{M}^{+}-91\right](100)$.

3-(5-Bromo-1H-indol-3-yl)-4-chlorocyclobut-3-ene-1,2-dione (5e)

Synthesis according to General Procedure A from squaric acid dichloride (4, 1.97 $\mathrm{g}, 0.01 \mathrm{~mol})$ and 5-bromo- $1 \mathrm{H}$-indole $(1.50 \mathrm{~g}, 0.01 \mathrm{~mol})$. The yield of the ocher powder was $432 \mathrm{mg}(14 \%)$. IR (KBr): $3460 \mathrm{~cm}^{-1}(\mathrm{NH}), 1817 \mathrm{~cm}^{-1}, 1773 \mathrm{~cm}^{-1}, 1740 \mathrm{~cm}^{-1}(\mathrm{C}=\mathrm{O}$, $\mathrm{C}=\mathrm{C}), 1614 \mathrm{~cm}^{-1}, 1550 \mathrm{~cm}^{-1}$ (C=C, arom.); ${ }^{1} \mathrm{H}-\mathrm{NMR}\left(400 \mathrm{MHz}, \mathrm{DMSO}-d_{6}\right): \delta(\mathrm{ppm})=7.37$ $(\mathrm{dd}, J=8.7,2.0 \mathrm{~Hz}, 1 \mathrm{H}, \mathrm{ArH}), 7.49(\mathrm{dd}, J=8.6,0.5 \mathrm{~Hz}, 1 \mathrm{H}, \mathrm{ArH}), 8.21(\mathrm{~d}, J=3.0 \mathrm{~Hz}, 1 \mathrm{H}$, ArH), $8.49(\mathrm{~d}, J=2.0 \mathrm{~Hz}, 1 \mathrm{H}, \mathrm{ArH}), 12.42(\mathrm{~s}, 1 \mathrm{H}, \mathrm{NH}) ;{ }^{13} \mathrm{C}-\mathrm{NMR}\left(101 \mathrm{MHz}, \mathrm{DMSO}-d_{6}\right): \delta$ $(\mathrm{ppm})=114.4,124.0,125.4,129.4(\mathrm{CH}), 105.7,113.6,126.6,135.2,170.8,193.2(2 \mathrm{C}), 194.6(\mathrm{C})$; $\mathrm{C}_{12} \mathrm{H}_{5} \mathrm{BrClNO}_{2}$ [310.53]; MS (EI): $m / z(\%)=309$ [M] ${ }^{+} \cdot(28), 253$ [M $\left.\mathrm{M}^{+}-56\right]$ (100); Anal. calcd. for $\mathrm{C}_{12} \mathrm{H}_{5} \mathrm{BrClNO}_{2}$ : C 46.41, $\mathrm{H}$ 1.62, N 4.51; found C 46.57, H 1.56, N 4.52.

3-Chloro-4-(2-methyl-1H-indol-3-yl)cyclobut-3-ene-1,2-dione (5f)

Synthesis according to General Procedure A from squaric acid dichloride $(4,1.21 \mathrm{~g}$, $9.17 \mathrm{mmol})$ and 2-methyl- $1 \mathrm{H}$-indole $(1.49 \mathrm{~g}, 9.84 \mathrm{mmol})$. The yield of the green powder was $2.25 \mathrm{~g}(83 \%)$. IR (KBr): $3447 \mathrm{~cm}^{-1}(\mathrm{NH}), 1765 \mathrm{~cm}^{-1}, 1736 \mathrm{~cm}^{-1}(\mathrm{C}=\mathrm{O}) ;{ }^{1} \mathrm{H}-\mathrm{NMR}$ $\left(400 \mathrm{MHz}, \mathrm{DMSO}-d_{6}\right): \delta(\mathrm{ppm})=2.80\left(\mathrm{~s}, 3 \mathrm{H}, \mathrm{CH}_{3}\right), 7.12(\mathrm{dtd}, J=16.0,7.2,1.4 \mathrm{~Hz}, 2 \mathrm{H}, \mathrm{ArH})$, $7.35(\mathrm{dd}, J=7.2,1.6 \mathrm{~Hz}, 1 \mathrm{H}, \mathrm{ArH}), 8.21(\mathrm{dd}, J=7.4,1.5 \mathrm{~Hz}, 1 \mathrm{H}, \mathrm{ArH}), 12.12(\mathrm{~s}, 1 \mathrm{H}, \mathrm{NH})$; ${ }^{13} \mathrm{C}-\mathrm{NMR}\left(100.7 \mathrm{MHz}\right.$, DMSO- $\left.d_{6}\right): \delta(\mathrm{ppm})=14.1\left(\mathrm{CH}_{3}\right), 111.1,120.7,121.6,122.0(\mathrm{CH})$, 103.8, 126.6, 136.2, 141.8, 173.4, 192.5, 193.7, 195.2 (C); $\mathrm{C}_{13} \mathrm{H}_{8} \mathrm{O}_{2} \mathrm{ClN}$ [245.66]; MS (EI): $\mathrm{m} / \mathrm{z}$ $(\%)=245[\mathrm{M}]^{+} .(36), 217\left[\mathrm{M}^{+}-28\right](5), 189\left[\mathrm{M}^{+}-56\right](100)$; HRMS (EI) $(\mathrm{m} / z)$ : Calcd. for $[\mathrm{M}]^{+}=245.02381$; found $[\mathrm{M}]^{+}=245.02362$.

\section{3,4-Bis(1H-indol-3-yl)cyclobut-3-ene-1,2-dione (2a)}

Synthesis according to General Procedure F from 3-chloro-4-(1H-indol-3-yl)cyclobut-3ene-1,2-dione ( $5 \mathbf{a}, 0.262 \mathrm{~g}, 1.13 \mathrm{mmol})$ and $1 H$-indole $(0.360 \mathrm{mg}, 3.08 \mathrm{mmol})$. Crystallization from ethanol/toluene yielded a yellow powder (59 mg, 66\%). 
IR (KBr): $3388 \mathrm{~cm}^{-1}(\mathrm{NH}), 1766 \mathrm{~cm}^{-1}, 1704 \mathrm{~cm}^{-1}(\mathrm{C}=\mathrm{O}), 1616 \mathrm{~cm}^{-1}, 1589 \mathrm{~cm}^{-1}$, $1513 \mathrm{~cm}^{-1}$ (C=C, arom.), ${ }^{1} \mathrm{H}-\mathrm{NMR}\left(400 \mathrm{MHz}, \mathrm{DMSO}-d_{6}\right): \delta(\mathrm{ppm})=7.17$ (ddd, $J=8.1$, $7.1,1.1 \mathrm{~Hz}, 2 \mathrm{H}), 7.28(\mathrm{ddd}, J=8.2,7.1,1.2 \mathrm{~Hz}, 2 \mathrm{H}), 7.58(\mathrm{dt}, J=8.2,0.9 \mathrm{~Hz}, 2 \mathrm{H}), 7.93$ $(\mathrm{dt}, J=8.0,0.9 \mathrm{~Hz}, 2 \mathrm{H}), 8.26(\mathrm{~d}, J=3.0 \mathrm{~Hz}, 2 \mathrm{H}), 12.44(\mathrm{~s}, 2 \mathrm{H}, \mathrm{NH}),{ }^{13} \mathrm{C}-\mathrm{NMR}(101 \mathrm{MHz}$, DMSO- $\left.d_{6}\right): \delta(\mathrm{ppm})=112.6,121.3,122.6,123.0,131.1(\mathrm{CH}), 106.3,125.0,136.8,177.0,194.8$ (C); $\mathrm{C}_{20} \mathrm{H}_{12} \mathrm{~N}_{2} \mathrm{O}_{2}$ (312.33); Anal. calcd. for $\mathrm{C}_{20} \mathrm{H}_{12} \mathrm{~N}_{2} \mathrm{O}_{2}$ : C 76.91, $\mathrm{H}$ 3.87, $\mathrm{N}$ 8.97; found $\mathrm{C}$ 76.41, H 3.70, N 8.87; MS (EI): $m / z(\%)=312[\mathrm{M}]^{+}(35), 256\left[\mathrm{M}^{+}-56\right]$ (100); isocratic HPLC: $97.1 \%$ at $254 \mathrm{~nm}, 97.6 \%$ at $280 \mathrm{~nm}, \mathrm{t}_{\mathrm{ms}}=3.63 \mathrm{~min}, \mathrm{t}_{\mathrm{m}}(\mathrm{DMSO})=1.15 \mathrm{~min}\left(\mathrm{ACN} / \mathrm{H}_{2} \mathrm{O} 50: 50\right)$; gradient HPLC: $95.1 \%$ at $254 \mathrm{~nm}, \mathrm{t}_{\mathrm{ms}}=11.0 \mathrm{~min}, \mathrm{t}_{\mathrm{m}}(\mathrm{DMSO})=1.25 \mathrm{~min} ; \lambda_{\max }(\mathrm{nm}): 271$, 331,410 .

3-(5-Bromo-1H-indol-3-yl)-4-(1H-indol-3-yl)cyclobut-3-ene-1,2-dione (2b)

Synthesis according to General Procedure C (reaction time: $48 \mathrm{~h}$ ) from 3-chloro-4(1H-indol-3-yl)cyclobut-3-ene-1,2-dione (5a, $256 \mathrm{mg}, 1.11 \mathrm{mmol})$ and 5-bromo- $1 H$-indole (392 mg, $2.00 \mathrm{mmol}$ ). The yield of the tawny powder was $166 \mathrm{mg}(38 \%)$. IR (KBr): $3425 \mathrm{~cm}^{-1}$ (NH), $3127 \mathrm{~cm}^{-1}$ (CH, arom.), $2919 \mathrm{~cm}^{-1}\left(\mathrm{CH}\right.$, aliph.), $1748 \mathrm{~cm}^{-1}, 1714 \mathrm{~cm}^{-1}(\mathrm{C}=\mathrm{O}) ;{ }^{1} \mathrm{H}-$ NMR $\left(400 \mathrm{MHz}\right.$, DMSO- $\left.d_{6}\right): \delta(\mathrm{ppm})=7.19(\mathrm{ddd}, J=8.1,7.1,1.1 \mathrm{~Hz}, 1 \mathrm{H}, \mathrm{ArH}), 7.30(\mathrm{ddd}$, $J=8.2,7.1,1.2 \mathrm{~Hz}, 1 \mathrm{H}, \mathrm{ArH}), 7.41(\mathrm{dd}, J=8.6,2.0 \mathrm{~Hz}, 1 \mathrm{H}, \mathrm{ArH}), 7.51-7.63(\mathrm{~m}, 2 \mathrm{H}, \mathrm{ArH}), 7.90$ $(\mathrm{ddt}, J=8.0,1.2,0.6 \mathrm{~Hz}, 1 \mathrm{H}, \mathrm{ArH}), 8.22(\mathrm{~d}, J=2.0 \mathrm{~Hz}, 1 \mathrm{H}, \mathrm{ArH}), 8.26(\mathrm{~d}, J=3.0 \mathrm{~Hz}, 1 \mathrm{H}, \mathrm{ArH})$, $8.35(\mathrm{~d}, J=3.1 \mathrm{~Hz}, 1 \mathrm{H}, \mathrm{ArH}), 12.50(\mathrm{~d}, J=3.2 \mathrm{~Hz}, 1 \mathrm{H}, \mathrm{NH}), 12.57(\mathrm{~d}, J=3.3 \mathrm{~Hz}, 1 \mathrm{H}, \mathrm{NH})$; ${ }^{13} \mathrm{C}-\mathrm{NMR}\left(151 \mathrm{MHz}, \mathrm{DMSO}-d_{6}\right): \delta(\mathrm{ppm})=112.7,114.6,121.4,122.6,123.1,124.8,125.6$, $131.2,132.0(\mathrm{CH}), 106.0,106.2,113.8,124.9,127.0,135.5,136.9,176.3,177.3,194.6,194.7(\mathrm{C})$; $\mathrm{C}_{20} \mathrm{H}_{11} \mathrm{BrN}_{2} \mathrm{O}_{2}$ [391.22]; Anal. calcd. for $\mathrm{C}_{20} \mathrm{H}_{11} \mathrm{BrN}_{2} \mathrm{O}_{2}$ : C 61.40, H 2.83, N 7.16; found $\mathrm{C}$ 61.38, H 2.74, N 6.85; MS (EI): $m / z(\%)=390[\mathrm{M}]^{+}(29), 334\left[\mathrm{M}^{+}-56\right]$ (100); isocratic HPLC: $99.4 \%$ at $254 \mathrm{~nm}$ and $99.6 \%$ at $280 \mathrm{~nm}, \mathrm{t}_{\mathrm{ms}}=5.84 \mathrm{~min}, \mathrm{t}_{\mathrm{m}}=1.11 \mathrm{~min}\left(\mathrm{ACN} / \mathrm{H}_{2} \mathrm{O} 50: 50\right)$; $\lambda_{\max }(\mathrm{nm}): 273,329$, 346; gradient HPLC: $98.0 \%$ at $254 \mathrm{~nm}, \mathrm{t}_{\mathrm{ms}}=11.9 \mathrm{~min}, \mathrm{t}_{\mathrm{m}}=1.25 \mathrm{~min}$.

3-(5-Chloro-1H-indol-3-yl)-4-(1H-indol-3-yl)cyclobut-3-ene-1,2-dione (2c)

Synthesis according to General Procedure C (reaction time: $20 \mathrm{~h}$ ) from 3-chloro-4(1H-indol-3-yl)cyclobut-3-ene-1,2-dione (5a, $241 \mathrm{mg}, 1.04 \mathrm{mmol})$ and 5-chloro- $1 \mathrm{H}$-indole $(227 \mathrm{mg}, 1.50 \mathrm{mmol})$. Boiling in ethanol/toluene yielded a yellowish powder (133 mg, $38 \%$ ). IR (KBr): $3395 \mathrm{~cm}^{-1}(\mathrm{NH}), 1749 \mathrm{~cm}^{-1}, 1714 \mathrm{~cm}^{-1}$ (C=O), $1618 \mathrm{~cm}^{-1}, 1539 \mathrm{~cm}^{-1}$ $\left(\mathrm{C}=\mathrm{C}\right.$, arom.); ${ }^{1} \mathrm{H}-\mathrm{NMR}\left(600 \mathrm{MHz}, \mathrm{DMSO}-d_{6}\right): \delta(\mathrm{ppm})=7.20(\mathrm{ddd}, J=8.1,7.0,1.1 \mathrm{~Hz}, 1 \mathrm{H}$, ArH), 7.27-7.33 (m, 2H, ArH), 7.57-7.63 (m, 2H, ArH), $7.91(\mathrm{ddt}, J=8.1,1.4,0.7 \mathrm{~Hz}, 1 \mathrm{H}$, ArH), $8.08(\mathrm{dt}, J=2.1,0.6 \mathrm{~Hz}, 1 \mathrm{H}, \mathrm{ArH}), 8.28(\mathrm{~d}, J=3.1 \mathrm{~Hz}, 1 \mathrm{H}, \mathrm{ArH}), 8.35(\mathrm{~d}, J=3.1 \mathrm{~Hz}$, $1 \mathrm{H}, \mathrm{ArH}), 12.50(\mathrm{~d}, J=3.1 \mathrm{~Hz}, 1 \mathrm{H}, \mathrm{NH}), 12.58(\mathrm{~d}, J=3.0 \mathrm{~Hz}, 1 \mathrm{H}, \mathrm{NH}) ;{ }^{13} \mathrm{C}-\mathrm{NMR}(151 \mathrm{MHz}$, DMSO- $\left.d_{6}\right): \delta(\mathrm{ppm})=112.7,114.2,121.4,121.9,122.6,123.1,123.2,131.3,132.2(\mathrm{CH}), 106.2$. 106.2, 124.9, 125.8, 126.4, 135.3, 136.9, 176.4, 177.4, 194.7, 194.8 (C); $\mathrm{C}_{20} \mathrm{H}_{11} \mathrm{ClN}_{2} \mathrm{O}_{2}$ [347.77]; Anal. calcd. for $\mathrm{C}_{20} \mathrm{H}_{11} \mathrm{ClN}_{2} \mathrm{O}_{2}$ : C 69.27, H 3.20, N 8.08; found C 68.87, H 3.10, N 7.93; MS (EI): $m / z(\%)=346[\mathrm{M}]^{+\cdot}(23), 290\left[\mathrm{M}^{+}-56\right](100)$; isocratic HPLC: $95.9 \%$ at $254 \mathrm{~nm}$ and $96.8 \%$ at $280 \mathrm{~nm}, \mathrm{t}_{\mathrm{ms}}=5.17 \mathrm{~min}, \mathrm{t}_{\mathrm{m}}=1.11 \mathrm{~min}\left(\mathrm{ACN} / \mathrm{H}_{2} \mathrm{O} 50: 50\right) ; \lambda_{\max }(\mathrm{nm}): 273,328$ and 347; gradient HPLC: $98.3 \%$ at $254 \mathrm{~nm}, \mathrm{t}_{\mathrm{ms}}=11.8 \mathrm{~min}, \mathrm{t}_{\mathrm{m}}=1.25 \mathrm{~min}$.

3-(1H-Indol-3-yl)-4-(5-methoxy-1H-indol-3-yl)cyclobut-3-ene-1,2-dione (2d)

Synthesis according to General Procedure C (reaction time: $20 \mathrm{~h}$ ) from 3-chloro-4(1H-indol-3-yl)cyclobut-3-ene-1,2-dione (5a, $241 \mathrm{mg}, 1.04 \mathrm{mmol})$ and 5-methoxy- $1 \mathrm{H}$-indole (322 mg, $2.19 \mathrm{mmol})$. The yield of the yellow powder was $40 \mathrm{mg}(11 \%)$. IR (KBr): $3298 \mathrm{~cm}^{-1}$ (NH), $3144 \mathrm{~cm}^{-1}$ (CH, arom.), $2964 \mathrm{~cm}^{-1}\left(\mathrm{CH}\right.$, aliph.), $1748 \mathrm{~cm}^{-1}, 1704 \mathrm{~cm}^{-1}(\mathrm{C}=\mathrm{O}) ;{ }^{1} \mathrm{H}-$ NMR $\left(600 \mathrm{MHz}, \mathrm{DMSO}-d_{6}\right): \delta(\mathrm{ppm})=3.53\left(\mathrm{~s}, 3 \mathrm{H}, \mathrm{CH}_{3}\right), 6.89(\mathrm{dd}, J=8.8,2.5 \mathrm{~Hz}, 1 \mathrm{H}, \mathrm{ArH})$, 7.15 (ddd, $J=8.0,7.0,1.0 \mathrm{~Hz}, 1 \mathrm{H}, \mathrm{ArH}), 7.27(\mathrm{ddd}, J=8.2,7.1,1.1 \mathrm{~Hz}, 1 \mathrm{H}, \mathrm{ArH}), 7.31-7.34$ $(\mathrm{m}, 1 \mathrm{H}, \mathrm{ArH}), 7.47(\mathrm{dd}, J=8.8,0.5 \mathrm{~Hz}, 1 \mathrm{H}, \mathrm{ArH}), 7.58(\mathrm{dt}, J=8.1,0.9 \mathrm{~Hz}, 1 \mathrm{H}, \mathrm{ArH}), 7.91(\mathrm{dt}$, $J=8.0,0.9 \mathrm{~Hz}, 1 \mathrm{H}, \mathrm{ArH}), 8.21(\mathrm{~s}, 1 \mathrm{H}, \mathrm{ArH}), 8.25(\mathrm{~s}, 1 \mathrm{H}, \mathrm{ArH}), 12.38(\mathrm{~s}, 2 \mathrm{H}, \mathrm{NH}) ;{ }^{13} \mathrm{C}-\mathrm{NMR}$ $\left(151 \mathrm{MHz}, \mathrm{DMSO}-d_{6}\right): \delta(\mathrm{ppm})=54.8\left(\mathrm{CH}_{3}\right), 104.7,112.5,112.8,113.3,121.1,122.5,122.9$, 131.0, $131.4(\mathrm{CH}), 106.2,106.3,125.1,125.5,131.6,136.6,154.5,176.3,176.9,194.4,195.0$ (C); 
$\mathrm{C}_{21} \mathrm{H}_{14} \mathrm{~N}_{2} \mathrm{O}_{3}$ [342.35]; MS (EI): $m / z(\%)=342$ [M] ${ }^{+}$(35), 286 [ $\mathrm{M}^{+}-56$ ] (100); HRMS (EI) $(m / z)$ : Calcd. for $[\mathrm{M}]^{+}=342.09989$; found $[\mathrm{M}]^{+}=342.10005$; isocratic HPLC: $98.6 \%$ at $254 \mathrm{~nm}$ and $98.9 \%$ at $280 \mathrm{~nm}, \mathrm{t}_{\mathrm{ms}}=3.49 \mathrm{~min}, \mathrm{t}_{\mathrm{m}}=1.11 \mathrm{~min}\left(\mathrm{ACN} / \mathrm{H}_{2} \mathrm{O} 50: 50\right) ; \lambda_{\max }(\mathrm{nm}): 229,273,336$; gradient HPLC: $97.6 \%$ at $254 \mathrm{~nm}, \mathrm{t}_{\mathrm{ms}}=10.8 \mathrm{~min}, \mathrm{t}_{\mathrm{m}}=1.25 \mathrm{~min}$.

3-[5-(Benzyloxy)-1H-indol-3-yl]-4-(1H-indol-3-yl)cyclobut-3-ene-1,2-dione (2e)

Synthesis according to General Procedure $C$ (reaction time: $10 \mathrm{~h}$ ) from 3-chloro-4(1H-indol-3-yl)cyclobut-3-ene-1,2-dione (5a, $262 \mathrm{mg}, 1.13 \mathrm{mmol})$ and 5-benzyloxy- $1 \mathrm{H}$ indole $(335 \mathrm{mg}, 1.50 \mathrm{mmol})$. The oily product obtained after column chromatography on $\mathrm{Al}_{2} \mathrm{O}_{3}$ was taken up in ethyl acetate $(3 \mathrm{~mL})$. Upon addition of petroleum ether a tan precipitate appeared, which was subsequently crystallized from petroleum ether/ethyl acetate/ethanol. The yield of the tan powder was $20 \mathrm{mg}(5 \%)$. IR (KBr): $3405 \mathrm{~cm}^{-1}(\mathrm{NH})$, $1750 \mathrm{~cm}^{-1}, 1712 \mathrm{~cm}^{-1}(\mathrm{C}=\mathrm{O}), 1628 \mathrm{~cm}^{-1}, 1540 \mathrm{~cm}^{-1}, 1512 \mathrm{~cm}^{-1}$ (C=C, arom.); ${ }^{1} \mathrm{H}-\mathrm{NMR}$ $\left(600 \mathrm{MHz}, \mathrm{DMSO}-d_{6}\right): \delta(\mathrm{ppm})=4.73\left(\mathrm{~s}, 2 \mathrm{H}, \mathrm{CH}_{2}\right), 6.95(\mathrm{dd}, J=8.8,2.5 \mathrm{~Hz}, 1 \mathrm{H}, \mathrm{ArH})$, 7.15 (ddd, $J=8.1,7.1,1.0 \mathrm{~Hz}, 1 \mathrm{H}, \mathrm{ArH}), 7.23-7.37(\mathrm{~m}, 6 \mathrm{H}, \mathrm{ArH}), 7.47$ (d, $J=8.8 \mathrm{~Hz}$, $2 \mathrm{H}, \mathrm{ArH}), 7.60(\mathrm{dt}, J=8.2,0.9 \mathrm{~Hz}, 1 \mathrm{H}, \mathrm{ArH}), 7.87(\mathrm{dt}, J=8.0,1.0 \mathrm{~Hz}, 1 \mathrm{H}, \mathrm{ArH}), 8.23(\mathrm{~d}$, $J=3.0 \mathrm{~Hz}, 1 \mathrm{H}, \mathrm{ArH}), 8.27(\mathrm{~d}, J=3.2 \mathrm{~Hz}, 1 \mathrm{H}, \mathrm{ArH}), 12.36(\mathrm{~d}, J=3.2 \mathrm{~Hz}, 1 \mathrm{H}, \mathrm{NH}), 12.44$ $(\mathrm{d}, J=3.1 \mathrm{~Hz}, 1 \mathrm{H}, \mathrm{NH}) ;{ }^{13} \mathrm{C}-\mathrm{NMR}\left(151 \mathrm{MHz}, \mathrm{DMSO}-d_{6}\right): \delta(\mathrm{ppm})=69.3\left(\mathrm{CH}_{2}\right), 106.2$, 112.6, 113.4, 113.5, 121.2, 122.5, 123.1, 127.5, 128.3, 131.1, 131.7 (CH), 106.3, 106.4, 125.3, $125.5,127.3,127.7,128.3,131.8,136.8,137.1,153.7,176.3,177.0,194.5,195.1(\mathrm{C}) ; \mathrm{C}_{27} \mathrm{H}_{18} \mathrm{~N}_{2} \mathrm{O}_{3}$ [418.45]; MS (EI): $m / z(\%)=418$ [M] ${ }^{+}$(59), 362 [M+ - 56] (100); HRMS (EI) $(m / z)$ : Calcd. for $[\mathrm{M}]^{+}=418.13119$, found $[\mathrm{M}]^{+}=418.13169$; isocratic HPLC: $95.2 \%$ at $254 \mathrm{~nm}$ and $95.5 \%$ at $280 \mathrm{~nm}, \mathrm{t}_{\mathrm{ms}}=7.26 \mathrm{~min}, \mathrm{t}_{\mathrm{m}}=1.11 \mathrm{~min}\left(\mathrm{ACN} / \mathrm{H}_{2} \mathrm{O} 50: 50\right) ; \lambda_{\max }(\mathrm{nm}): 273$; gradient HPLC: $95.0 \%$ at $254 \mathrm{~nm}, \mathrm{t}_{\mathrm{ms}}=12.4 \mathrm{~min}, \mathrm{t}_{\mathrm{m}}=1.25 \mathrm{~min}$.

3-[2-(1H-Indol-3-yl)-3,4-dioxocyclobut-1-ene-1-yl]-1H-indol-5-carbonitrile (2f)

Synthesis according to General Procedure $\mathrm{C}$ (reaction time: $20 \mathrm{~h}$ ) from 3-chloro-4-(1Hindol-3-yl)cyclobut-3-ene-1,2-dione (5a, $265 \mathrm{mg}, 1.14 \mathrm{mmol})$ and $1 \mathrm{H}$-indole-5-carbonitrile (213 mg, $1.50 \mathrm{mmol}$ ). The residue obtained after column chromatography on $\mathrm{Al}_{2} \mathrm{O}_{3}$ was crystallized from ethanol/toluene. The yield of the yellow powder was $200 \mathrm{mg}(52 \%)$. IR (KBr): $3300 \mathrm{~cm}^{-1}(\mathrm{NH}), 2229 \mathrm{~cm}^{-1}(\mathrm{C} \equiv \mathrm{N}), 1750 \mathrm{~cm}^{-1}, 1723 \mathrm{~cm}^{-1}(\mathrm{C}=\mathrm{O}), 1619 \mathrm{~cm}^{-1}$, $1554 \mathrm{~cm}^{-1}, 1528 \mathrm{~cm}^{-1}$ (C=C, arom.); ${ }^{1} \mathrm{H}-\mathrm{NMR}\left(600 \mathrm{MHz}, \mathrm{DMSO}-d_{6}\right): \delta(\mathrm{ppm})=7.19(\mathrm{ddd}$, $J=8.1,7.1,1.1 \mathrm{~Hz}, 1 \mathrm{H}, \mathrm{ArH}), 7.30(\mathrm{ddd}, J=8.2,7.0,1.1 \mathrm{~Hz}, 1 \mathrm{H}, \mathrm{ArH}), 7.60(\mathrm{dt}, J=8.1$, $0.9 \mathrm{~Hz}, 1 \mathrm{H}, \mathrm{ArH}), 7.65(\mathrm{dd}, J=8.5,1.6 \mathrm{~Hz}, 1 \mathrm{H}, \mathrm{ArH}), 7.75(\mathrm{dd}, J=8.5,0.7 \mathrm{~Hz}, 1 \mathrm{H}, \mathrm{ArH})$, $7.88(\mathrm{ddt}, J=8.0,1.3,0.7 \mathrm{~Hz}, 1 \mathrm{H}, \mathrm{ArH}), 8.39(\mathrm{~d}, J=3.0 \mathrm{~Hz}, 1 \mathrm{H}, \mathrm{ArH}), 8.42(\mathrm{~d}, J=3.1 \mathrm{~Hz}, 1 \mathrm{H}$, ArH), $8.47(\mathrm{dt}, J=1.5,0.7 \mathrm{~Hz}, 1 \mathrm{H}, \mathrm{ArH}), 12.54-12.58(\mathrm{~m}, 1 \mathrm{H}, \mathrm{NH}), 12.82-12.86(\mathrm{~m}, 1 \mathrm{H}, \mathrm{NH})$; ${ }^{13} \mathrm{C}-\mathrm{NMR}\left(151 \mathrm{MHz}, \mathrm{DMSO}-d_{6}\right): \delta(\mathrm{ppm})=112.8,114.1,121.6,122.6,123.3,125.1,127.8$, 131.7, $132.8(\mathrm{CH}), 103.3,106.2,106.9,120.2,124.9,125.2,137.0,138.6,175.6,178.1,194.5,195.0$ (C); $\mathrm{C}_{21} \mathrm{H}_{11} \mathrm{~N}_{3} \mathrm{O}_{2}$ [337.34]; MS (EI): $m / z(\%)=337$ [M] ${ }^{+}$(12), 281 [M $\left.\mathrm{M}^{+}-56\right]$ (100); HRMS (EI) $(m / z)$ : Calcd. for $[\mathrm{M}]^{+} \cdot=337.08458$, found [M] ${ }^{+}=337.08486$; isocratic HPLC: $97.0 \%$ at $254 \mathrm{~nm}$ and $97.2 \%$ at $280 \mathrm{~nm}, \mathrm{t}_{\mathrm{ms}}=6.42 \mathrm{~min}, \mathrm{t}_{\mathrm{m}}=1.11 \mathrm{~min}\left(\mathrm{ACN} / \mathrm{H}_{2} \mathrm{O} 40: 60\right) ; \lambda_{\max }(\mathrm{nm})$ : 224, 327 and 346; gradient HPLC: $98.5 \%$ at $254 \mathrm{~nm}, \mathrm{t}_{\mathrm{ms}}=10.7 \mathrm{~min}, \mathrm{t}_{\mathrm{m}}=1.25 \mathrm{~min}$.

3-(1H-Indol-3-yl)-4-(2-methyl-1H-indol-3-yl)cyclobut-3-ene-1,2-dione (2g)

Synthesis according to General Procedure C (reaction time: $19 \mathrm{~h}$ ) from 3-chloro-4(2-methyl-1H-indol-3-yl)cyclobut-3-ene-1,2-dione (5e, $233 \mathrm{mg}, 0.95 \mathrm{mmol}$ ) and $1 \mathrm{H}$-indole (233 mg, $1.99 \mathrm{mmol})$. The yield of the yellow powder was $52 \mathrm{mg}(17 \%)$. IR (KBr): $3367 \mathrm{~cm}^{-1}$, $3256 \mathrm{~cm}^{-1}(\mathrm{NH}), 1759 \mathrm{~cm}^{-1}, 1706 \mathrm{~cm}^{-1}(\mathrm{C}=\mathrm{O}), 1618 \mathrm{~cm}^{-1}, 1555 \mathrm{~cm}^{-1}, 1522 \mathrm{~cm}^{-1}(\mathrm{C}=\mathrm{C}$, arom.); ${ }^{1} \mathrm{H}-\mathrm{NMR}\left(600 \mathrm{MHz}, \mathrm{DMSO}-d_{6}\right): \delta(\mathrm{ppm})=2.55(\mathrm{~s}, 3 \mathrm{H}), 6.98(\mathrm{ddd}, J=7.9,7.1,1.0 \mathrm{~Hz}$, $1 \mathrm{H}), 7.08(\mathrm{ddd}, J=8.0,7.1,1.0 \mathrm{~Hz}, 1 \mathrm{H}), 7.14-7.18(\mathrm{~m}, 2 \mathrm{H}), 7.23(\mathrm{ddd}, J=8.2,7.1,1.1 \mathrm{~Hz}, 1 \mathrm{H})$, 7.44-7.47 (m, 1H), $7.53(\mathrm{dt}, J=8.1,0.9 \mathrm{~Hz}, 1 \mathrm{H}), 7.84(\mathrm{~d}, J=8.1 \mathrm{~Hz}, 1 \mathrm{H}), 7.91(\mathrm{~s}, 1 \mathrm{H}), 12.17(\mathrm{~s}$, $1 \mathrm{H}), 12.38(\mathrm{~s}, 1 \mathrm{H}) ;{ }^{13} \mathrm{C}-\mathrm{NMR}\left(151 \mathrm{MHz}, \mathrm{DMSO}-d_{6}\right): \delta(\mathrm{ppm})=13.9\left(\mathrm{CH}_{3}\right), 111.6,112.5,120.3$, 121.1, 121.4, 121.9, 122.1, 123.0, $132.1(\mathrm{CH}), 103.9,106.6,125.3,125.4,136.4,136.5,141.2,178.4$, 178.7, 194.7, 195.8 (C); $\mathrm{C}_{21} \mathrm{H}_{14} \mathrm{~N}_{2} \mathrm{O}_{2}$ [326.36]; Anal. calcd. for $\mathrm{C}_{21} \mathrm{H}_{14} \mathrm{~N}_{2} \mathrm{O}_{2}$ : C 77.29, $\mathrm{H}$ 4.32, 
N 8.58; found C 77.00, H 4.20, N 8.49; MS (EI): $m / z(\%)=326[\mathrm{M}]^{+}$(30), $270\left[\mathrm{M}^{+}-56\right](100)$; isocratic HPLC: $96.7 \%$ at $254 \mathrm{~nm}, 96.5 \%$ at $280 \mathrm{~nm}, \mathrm{t}_{\mathrm{ms}}=3.85 \mathrm{~min}, \mathrm{t}_{\mathrm{m}}=1.11 \mathrm{~min}\left(\mathrm{ACN} / \mathrm{H}_{2} \mathrm{O}\right.$ 50:50); $\lambda_{\max }(\mathrm{nm})$ : 273; gradient HPLC: $95.1 \%$ at $254 \mathrm{~nm}, \mathrm{t}_{\mathrm{ms}}=11.1 \mathrm{~min}, \mathrm{t}_{\mathrm{m}}=1.25 \mathrm{~min}$.

3-(1H-Indol-3-yl)-4-(2-phenyl-1H-indol-3-yl)cyclobut-3-ene-1,2-dione (2h)

Synthesis according to General Procedure C (reaction time: $21 \mathrm{~h}$ ) from 3-chloro-4(1H-indol-3-yl)cyclobut-3-ene-1,2-dione (5a, $238 \mathrm{mg}, 1.03 \mathrm{mmol}$ ) and 2-phenyl-1H-indole $(430 \mathrm{mg}, 3.25 \mathrm{mmol})$. The yield of the yellow powder was $280 \mathrm{mg}(70 \%)$. IR (KBr): $3248 \mathrm{~cm}^{-1}$ (NH), $3066 \mathrm{~cm}^{-1}$ (CH, arom.), $1752 \mathrm{~cm}^{-1}, 1712 \mathrm{~cm}^{-1}(\mathrm{C}=\mathrm{O}) ;{ }^{1} \mathrm{H}-\mathrm{NMR}$ (400 MHz, DMSO$\left.d_{6}\right): \delta(\mathrm{ppm})=6.99-7.11(\mathrm{~m}, 2 \mathrm{H}, \mathrm{ArH}), 7.12-7.35(\mathrm{~m}, 5 \mathrm{H}, \mathrm{ArH}), 7.38-7.48(\mathrm{~m}, 2 \mathrm{H}, \mathrm{ArH})$, 7.48-7.60 (m, 3H, ArH), 7.75-7.81 (m, 1H, ArH), $7.85(\mathrm{~d}, J=7.9 \mathrm{~Hz}, 1 \mathrm{H}, \mathrm{ArH}), 12.24(\mathrm{~d}$, $J=3.0 \mathrm{~Hz}, 1 \mathrm{H}, \mathrm{NH}), 12.44(\mathrm{~s}, 1 \mathrm{H}, \mathrm{NH}) ;{ }^{13} \mathrm{C}-\mathrm{NMR}\left(101 \mathrm{MHz}, \mathrm{DMSO}-d_{6}\right): \delta(\mathrm{ppm})=112.1$, $112.4,120.7,121.3,121.5,122.2,122.9,122.9,128.2,128.3,128.6,132.1(\mathrm{CH}), 102.7,106.9$, $125.1,126.4,131.5,136.5,136.8,139.8,178.9,180.2,194.2,196.8(\mathrm{C}) ; \mathrm{C}_{26} \mathrm{H}_{16} \mathrm{~N}_{2} \mathrm{O}_{2}$ [388.43]; Anal. calcd. for $\mathrm{C}_{26} \mathrm{H}_{16} \mathrm{~N}_{2} \mathrm{O}_{2}$ : C 80.40, $\mathrm{H} 4.15, \mathrm{~N} 7.21$; found C 79.99, $\mathrm{H} \mathrm{4.11,} \mathrm{N} \mathrm{6.89;} \mathrm{MS}$ (EI): $m / z(\%)=388[\mathrm{M}]^{+}(17), 360\left[\mathrm{M}^{+}-28\right](8), 332\left[\mathrm{M}^{+}-56\right](100)$; isocratic HPLC: $98.5 \%$ at $254 \mathrm{~nm}$ and $98.6 \%$ at $280 \mathrm{~nm}, \mathrm{t}_{\mathrm{ms}}=5.69 \mathrm{~min}, \mathrm{t}_{\mathrm{m}}=1.11 \mathrm{~min}\left(\mathrm{ACN} / \mathrm{H}_{2} \mathrm{O} 50: 50\right) ; \lambda_{\max }(\mathrm{nm})$ : 280, 297, 331; gradient HPLC: $98.0 \%$ at $254 \mathrm{~nm}, \mathrm{t}_{\mathrm{ms}}=11.7 \mathrm{~min}, \mathrm{t}_{\mathrm{m}}=1.25 \mathrm{~min}$.

3,4-Bis(1-methyl-1H-indol-3-yl)cyclobut-3-ene-1,2-dione (2i)

Synthesis according to General Procedure C (reaction time: $24 \mathrm{~h}$ ) from 3-chloro-4(1-methyl-1H-indol-3-yl)cyclobut-3-ene-1,2-dione (5b, $248 \mathrm{mg}, 1.01 \mathrm{mmol}$ ) and 1-methyl$1 H$-indol $(0.190 \mathrm{~mL}, 1.52 \mathrm{mmol})$. Due to the poor solubility, the green brown precipitate was boiled successively in ethanol/toluene and then in acetone for purification avoiding column chromatography. The yield of the yellow-green powder was $300 \mathrm{mg}$ (56\%). IR (KBr): $1766 \mathrm{~cm}^{-1}, 1731 \mathrm{~cm}^{-1}(\mathrm{C}=\mathrm{O}), 1615 \mathrm{~cm}^{-1}, 1576 \mathrm{~cm}^{-1}, 1561 \mathrm{~cm}^{-1}, 1517 \mathrm{~cm}^{-1}(\mathrm{C}=\mathrm{C}$, arom.); ${ }^{1} \mathrm{H}-\mathrm{NMR}(600 \mathrm{MHz}$, chloroform- $d): \delta(\mathrm{ppm})=3.93\left(\mathrm{~s}, 6 \mathrm{H}, \mathrm{CH}_{3}\right), 7.15(\mathrm{ddd}, J=8.1$, 7.1, 1.0 Hz, 2H, ArH), 7.35 (dd, J = 8.2, 7.1 Hz, 2H, ArH), 7.42-7.47 (m, 2H, ArH), 7.79 $(\mathrm{dd}, J=8.0,0.9 \mathrm{~Hz}, 2 \mathrm{H}, \mathrm{ArH}), 8.01$ (s, 2H, ArH); ${ }^{13} \mathrm{C}-\mathrm{NMR}(151 \mathrm{MHz}$, Chloroform- $d): \delta$ $(\mathrm{ppm})=33.7\left(\mathrm{CH}_{3}\right), 110.1,121.7,123.5,123.6,125.7(\mathrm{CH}), 106.6,134.1,137.7,176.4,195.4$ (C); $\mathrm{C}_{22} \mathrm{H}_{16} \mathrm{~N}_{2} \mathrm{O}_{2}$ [340.38]; MS (EI): $m / z(\%)=340$ [M] ${ }^{+\cdot}$ (32), 284 [M $\mathrm{M}^{+}$- 56] (100); HRMS (EI) $(\mathrm{m} / z)$ : Calcd. for $[\mathrm{M}]^{+}=340.12063$, found $[\mathrm{M}]^{+} \cdot=340.12124$; isocratic HPLC: $95.1 \%$ at $254 \mathrm{~nm}$ and $97.4 \%$ at $280 \mathrm{~nm}, \mathrm{t}_{\mathrm{ms}}=4.53 \mathrm{~min}, \mathrm{t}_{\mathrm{m}}=1.11 \mathrm{~min}\left(\mathrm{ACN} / \mathrm{H}_{2} \mathrm{O} 60: 40\right) ; \lambda_{\max }(\mathrm{nm})$ : 224, 273 and 333; gradient HPLC: $95.1 \%$ at $254 \mathrm{~nm}, \mathrm{t}_{\mathrm{ms}}=12.8 \mathrm{~min}, \mathrm{t}_{\mathrm{m}}=1.25 \mathrm{~min}$.

3-\{1-[3-(Dimethylamino)propyl]-1H-indol-3-yl\}-4-(1H-indol-3-yl)cyclobut-3-ene-1,2dione (2k)

To a suspension of 3-chloro-4-(1H-indol-3-yl)cyclobut-3-ene-1,2-dione (5a, $235 \mathrm{mg}$, $1.01 \mathrm{mmol})$ in anhydrous dichloromethane $(10 \mathrm{~mL})$ at $0{ }^{\circ} \mathrm{C}$, anhydrous $\mathrm{AlCl}_{3}(400 \mathrm{mg}$, $3.00 \mathrm{mmol})$ was added. A solution of 3-(1H-indol-1-yl)- $N, N$-dimethylpropane-1-amine $(0.248 \mathrm{~mL}, 1.20 \mathrm{mmol})$ in dichloromethane $(10 \mathrm{~mL})$ was slowly added dropwise with stirring,. While stirring was continued for $24 \mathrm{~h}$, the temperature was allowed to rise from $0{ }^{\circ} \mathrm{C}$ to $\mathrm{RT}$. The reaction mixture was then poured into water $(50 \mathrm{~mL})$ with stirring and filtered. The filtrate was added to ethyl acetate $(100 \mathrm{~mL})$. The mixture was washed with sat. $\mathrm{Na}_{2} \mathrm{CO}_{3}$ solution $(2 \times 50 \mathrm{~mL})$, water $(2 \times 50 \mathrm{~mL})$ and saturated $\mathrm{NaCl}$ solution $(2 \times 50 \mathrm{~mL})$. After drying the organic phase over anhydrous $\mathrm{Na}_{2} \mathrm{SO}_{4}$, it was concentrated under reduced pressure. The resulting oily residue was eluted through silica gel with ethanol/ethyl acetate/triethylamine (50/50/1), wherein the yellow phase was collected and concentrated. The residue was then crystallized from acetone and dried in vacuo at $80-90{ }^{\circ} \mathrm{C}$. The yield of yellow powder was $35 \mathrm{mg}(9 \%)$. IR (KBr): $3426 \mathrm{~cm}^{-1}(\mathrm{NH})$, $1750 \mathrm{~cm}^{-1}(\mathrm{C}=\mathrm{O}), 1615 \mathrm{~cm}^{-1}, 1553 \mathrm{~cm}^{-1}, 1521 \mathrm{~cm}^{-1}\left(\mathrm{C}=\mathrm{C}\right.$, arom.); ${ }^{1} \mathrm{H}-\mathrm{NMR}(600 \mathrm{MHz}$, DMSO- $d$ ): $\delta(\mathrm{ppm})=2.01$ (quin, $\left.J=7.1 \mathrm{~Hz}, 2 \mathrm{H}, \mathrm{CH}_{2}-\mathrm{CH}_{2}-\mathrm{CH}_{2}-\mathrm{N}\left(\mathrm{CH}_{3}\right)_{2}\right), 2.23\left(\mathrm{~s}, 6 \mathrm{H}, \mathrm{CH}_{3}\right)$, 2.35 (s, br, 2H, $\left.\mathrm{CH}_{2}-\mathrm{CH}_{2}-\mathrm{CH}_{2}-\mathrm{N}\left(\mathrm{CH}_{3}\right)_{2}\right), 4.39\left(\mathrm{t}, \mathrm{J}=\overline{7.0 \mathrm{~Hz}}, 2 \mathrm{H}, \mathrm{CH}_{2}-\mathrm{CH}_{2}-\mathrm{CH}_{2}-\mathrm{N}\left(\mathrm{CH}_{3}\right)_{2}\right)$, $7.18(\mathrm{ddd}, J=\overline{8.0}, 7.0,1.0 \mathrm{~Hz}, 1 \mathrm{H}, \mathrm{ArH}), 7.22(\mathrm{ddd}, J=8.1,7.0,0.9 \mathrm{~Hz}, \overline{1 \mathrm{H}}, \mathrm{ArH}), 7.32$ 
(dddd, $J=34.1,8.1,7.1,1.2 \mathrm{~Hz}, 2 \mathrm{H}, \mathrm{ArH}), 7.59$ (dt, $J=8.3,1.0 \mathrm{~Hz}, 1 \mathrm{H}, \mathrm{ArH}), 7.71(\mathrm{dt}$, $J=8.3,0.9 \mathrm{~Hz}, 1 \mathrm{H}, \mathrm{ArH}), 7.92(\mathrm{dt}, J=8.0,1.0 \mathrm{~Hz}, 1 \mathrm{H}, \mathrm{ArH}), 7.98(\mathrm{dt}, J=8.1,1.0 \mathrm{~Hz}, 1 \mathrm{H}$, $\mathrm{ArH}), 8.29$ (d, $J=5.3 \mathrm{~Hz}, 2 \mathrm{H}, \mathrm{ArH}), 12.48(\mathrm{~s}, 1 \mathrm{H}, \mathrm{NH}) ;{ }^{13} \mathrm{C}-\mathrm{NMR}\left(151 \mathrm{MHz}, \mathrm{DMSO}-d_{6}\right)$ : $\delta(\mathrm{ppm})=26.3\left(\mathrm{CH}_{2}-\mathrm{CH}_{2}-\mathrm{CH}_{2}-\mathrm{N}\left(\mathrm{CH}_{3}\right)_{2}\right), 44.2\left(\mathrm{CH}_{2}-\mathrm{CH}_{2}-\mathrm{CH}_{2}-\mathrm{N}\left(\mathrm{CH}_{3}\right)_{2}\right), 44.6\left(2 \mathrm{C}, \mathrm{CH}_{3}\right)$, $55.5\left(\mathrm{CH}_{2}-\mathrm{CH}_{2}-\mathrm{CH}_{2}-\mathrm{N}\left(\mathrm{CH}_{3}\right)_{2}\right), 111.1,112.7,121.3,121.6,122.7,123.0,123.1,123.2,131.2$, $133.8(\mathrm{CH}), 105.6,106.3,125.0,125.6,136.7,136.9,176.4,177.0,194.7,194.8(\mathrm{C}) ; \mathrm{C}_{25} \mathrm{H}_{23} \mathrm{~N}_{3} \mathrm{O}_{2}$ [397.48]; MS (EI): $m / z(\%)=397$ [M] $]^{+} .(79), 269$ [M M $^{+\cdot}$ 128] (100); HRMS (EI) ( $\left.\mathrm{m} / \mathrm{z}\right)$ : Calcd. for $[\mathrm{M}]^{+} \cdot=397.17848$, found $[\mathrm{M}]^{+} \cdot=397.17823$; isocratic HPLC: $95.1 \%$ at $254 \mathrm{~nm}$ and $97.4 \%$ at $280 \mathrm{~nm}, \mathrm{t}_{\mathrm{ms}}=3.13 \mathrm{~min}, \mathrm{t}_{\mathrm{m}}=1.11 \mathrm{~min}$ (ACN/triethyl ammonium sulfate buffer $\mathrm{pH} 2.7$ : 33:67); $\lambda_{\max }(\mathrm{nm}): 272,335$ and 345.

\section{3,4-Bis(2-methyl-1H-indol-3-yl)cyclobut-3-ene-1,2-dione (21)}

Synthesis according to General Procedure B (reaction time: $30 \mathrm{~h}$ ) from squaric acid dichloride (4, $302 \mathrm{mg}, 2.00 \mathrm{mmol}$ ) and 2-methyl-1H-indole (525 mg, $4.01 \mathrm{mmol})$. Crystallization from ethyl acetate yieled a yellow powder $(59 \mathrm{mg}, 56 \%)$. IR (KBr): $3385 \mathrm{~cm}^{-1}(\mathrm{NH})$, $1760 \mathrm{~cm}^{-1}, 1720 \mathrm{~cm}^{-1}$ (C=O), $1619 \mathrm{~cm}^{-1}, 1557 \mathrm{~cm}^{-1}, 1518 \mathrm{~cm}^{-1}$ (C=C, arom.); ${ }^{1} \mathrm{H}-\mathrm{NMR}$ $\left(400 \mathrm{MHz}, \mathrm{DMSO}-d_{6}\right): \delta(\mathrm{ppm})=2.40\left(\mathrm{~s}, 6 \mathrm{H}, \mathrm{CH}_{3}\right), 6.90(\mathrm{ddd}, J=8.0,7.1,1.0 \mathrm{~Hz}, 2 \mathrm{H}$, ArH), 7.10 (ddd, $J=8.1,7.1,1.1 \mathrm{~Hz}, 2 \mathrm{H}, \mathrm{ArH}), 7.20-7.25$ (m, 2H, ArH), 7.39 (dt, J = 8.1, $0.9 \mathrm{~Hz}, 2 \mathrm{H}, \mathrm{ArH}), 12.12(\mathrm{~s}, 2 \mathrm{H}, \mathrm{NH}) ;{ }^{13} \mathrm{C}-\mathrm{NMR}\left(101 \mathrm{MHz}, \mathrm{DMSO}-d_{6}\right): \delta(\mathrm{ppm})=13.8$ $\left(\mathrm{CH}_{3}\right), 104.8,111.3,120.4,120.5,121.9(\mathrm{CH}), 126.4,135.9,141.9,180.1,195.6(\mathrm{C}) ; \mathrm{C}_{22} \mathrm{H}_{16} \mathrm{~N}_{2} \mathrm{O}_{2}$ [340.38]; MS (EI) $(m / z): 340$ [M] ${ }^{+}$(32), 284 [M+ - 56] (100); HRMS (EI) ( $\left.m / z\right)$ : Calcd. for $[\mathrm{M}]^{+}=340.12063$, found $[\mathrm{M}]^{+}=340.12098$; isocratic HPLC: $99.9 \%$ at $254 \mathrm{~nm}, 99.9 \%$ at $280 \mathrm{~nm}, \mathrm{t}_{\mathrm{ms}}=3.02 \mathrm{~min}, \mathrm{t}_{\mathrm{m}}=1.25 \mathrm{~min}\left(\mathrm{ACN} / \mathrm{H}_{2} \mathrm{O} 50: 50\right) ; \lambda_{\max }(\mathrm{nm}): 275 ;$ gradient HPLC: $97.0 \%$ at $254 \mathrm{~nm}, \mathrm{t}_{\mathrm{ms}}=11.2 \mathrm{~min}, \mathrm{t}_{\mathrm{m}}=1.25 \mathrm{~min}$.

\section{3,4-Bis(2-phenyl-1H-indol-3-yl)cyclobut-3-ene-1,2-dione (2m)}

Synthesis according to General Procedure B (reaction time: $19 \mathrm{~h}$ ) from squaric acid dichloride (4, $196 \mathrm{mg}, 1.30 \mathrm{mmol})$ and 2-phenyl- $1 H$-indole $(567 \mathrm{mg}, 2.93 \mathrm{mmol})$. Crystallization from ethyl acetate yieled an orange powder $(72 \mathrm{mg}, 12 \%)$. IR $(\mathrm{KBr}): 3350 \mathrm{~cm}^{-1}(\mathrm{NH})$, $1727 \mathrm{~cm}^{-1}, 1711 \mathrm{~cm}^{-1}$ (C=O), $1548 \mathrm{~cm}^{-1}, 1520 \mathrm{~cm}^{-1}$ (C=C, arom.); ${ }^{1} \mathrm{H}-\mathrm{NMR}$ (400 MHz, DMSO- $\left.d_{6}\right): \delta(\mathrm{ppm})=7.01(\mathrm{ddd}, J=8.1,7.1,1.0 \mathrm{~Hz}, 2 \mathrm{H}), 7.05-7.22(\mathrm{~m}, 8 \mathrm{H}), 7.26-7.32(\mathrm{~m}$, $4 \mathrm{H}), 7.36(\mathrm{dt}, J=8.1,0.9 \mathrm{~Hz}, 2 \mathrm{H}), 7.43(\mathrm{~d}, J=8.0 \mathrm{~Hz}, 2 \mathrm{H}), 12.12(\mathrm{~s}, 2 \mathrm{H}, \mathrm{NH}) ;{ }^{13} \mathrm{C}-\mathrm{NMR}$ $\left.(100.7 \mathrm{MHz} \text {, DMSO-d })_{6}\right) \delta(\mathrm{ppm})=111.7,120.8,121.1,122.7,127.3,128.2,128.5(\mathrm{CH}), 104.2$, $126.5,131.0,136.5,141.2,181.6,196.0(\mathrm{C}) ; \mathrm{C}_{32} \mathrm{H}_{20} \mathrm{~N}_{2} \mathrm{O}_{2}$ [464.52]; MS (EI) (m/z): 464 [M] ${ }^{+}$ (33), $436\left[\mathrm{M}^{+}-28\right](12), 420\left[\mathrm{M}^{+}-44\right]$ (32), 408 [M+ -56$]$ (100); HRMS (EI) (m/z): Calcd. for $[\mathrm{M}]^{+}=464.15193$, found $[\mathrm{M}]^{+}=464.15250$; isocratic HPLC: $97.4 \%$ at $254 \mathrm{~nm}, 99.3 \%$ at $280 \mathrm{~nm}, \mathrm{t}_{\mathrm{ms}}=3.90 \mathrm{~min}, \mathrm{t}_{\mathrm{m}}=1.03 \mathrm{~min}\left(\mathrm{ACN} / \mathrm{H}_{2} \mathrm{O}\right.$ 60:40); $\lambda_{\max }(\mathrm{nm}): 344,297$ and 238; gradient HPLC: $95.1 \%$ at $254 \mathrm{~nm}, \mathrm{t}_{\mathrm{ms}}=12.4 \mathrm{~min}, \mathrm{t}_{\mathrm{m}}=1.25 \mathrm{~min}$.

\section{3,4-Bis(5-methoxy-1H-indol-3-yl)cyclobut-3-ene-1,2-dione (2n)}

Synthesis according to General Procedure C from 3-chloro-4-(5-methoxy- $1 H$-indol3-yl)cyclobut-3-ene-1,2-dione (5c, $267 \mathrm{mg}, 1.02 \mathrm{mmol}$ ) and 5-methoxy-1H-indole (315 mg, $2.14 \mathrm{mmol}$ ); yellow powder (Yield: $12 \%)$. IR (KBr): $3274 \mathrm{~cm}^{-1}(\mathrm{NH}), 1748 \mathrm{~cm}^{-1}, 1715 \mathrm{~cm}^{-1}$ $(\mathrm{C}=\mathrm{O}), 1625 \mathrm{~cm}^{-1}, 1586 \mathrm{~cm}^{-1}, 1533 \mathrm{~cm}^{-1}$ (C=C, arom.); ${ }^{1} \mathrm{H}-\mathrm{NMR}$ (400 MHz, DMSO- $\left.d_{6}\right): \delta$ $(\mathrm{ppm})=3.51\left(\mathrm{~s}, 6 \mathrm{H}, \mathrm{CH}_{3}\right), 6.88(\mathrm{ddd}, J=8.8,2.5,0.3 \mathrm{~Hz}, 2 \mathrm{H}, \mathrm{ArH}), 7.31-7.35(\mathrm{~m}, 2 \mathrm{H}, \mathrm{ArH})$, $7.46(\mathrm{dd}, J=8.8,0.5 \mathrm{~Hz}, 2 \mathrm{H}, \mathrm{ArH}), 8.20$ (d, $J=0.4 \mathrm{~Hz}, 2 \mathrm{H}, \mathrm{ArH}), 12.32(\mathrm{~s}, 2 \mathrm{H}, \mathrm{NH}) ;{ }^{13} \mathrm{C}-\mathrm{NMR}$ $\left(151 \mathrm{MHz}, \mathrm{DMSO}-d_{6}\right): \delta(\mathrm{ppm})=54.7\left(\mathrm{CH}_{3}\right), 104.6,112.8,113.2,131.4(\mathrm{CH}), 106.3,125.7$, 131.5, 154.4, 176.3, $194.6(\mathrm{C}) ; \mathrm{C}_{22} \mathrm{H}_{16} \mathrm{~N}_{2} \mathrm{O}_{4}$ [372.38]; Anal. calcd. for $\mathrm{C}_{22} \mathrm{H}_{16} \mathrm{~N}_{2} \mathrm{O}_{4}$ : C 70.96, H 4.33, N 7.52; found C 70.69, H 4.17, N 7.31; MS (EI): $m / z(\%)=372[\mathrm{M}]^{+}(35), 316\left[\mathrm{M}^{+}-\right.$ 56] (100); isocratic HPLC: $96.5 \%$ at $254 \mathrm{~nm}, 98.0 \%$ at $280 \mathrm{~nm}, \mathrm{t}_{\mathrm{ms}}=3.28 \mathrm{~min}, \mathrm{t}_{\mathrm{m}}=1.11 \mathrm{~min}$ $\left(\mathrm{ACN} / \mathrm{H}_{2} \mathrm{O} 50: 50\right) ; \lambda_{\max }(\mathrm{nm}): 277$; gradient HPLC: $97.6 \%$ at $254 \mathrm{~nm}, \mathrm{t}_{\mathrm{ms}}=10.9 \mathrm{~min}$, $\mathrm{t}_{\mathrm{m}}=1.25 \mathrm{~min}$. 
3,4-Bis(5-bromo-1H-indol-3-yl)cyclobut-3-ene-1,2-dione (2o)

Synthesis according to General Procedure D from 5-bromo- $1 H$-indole (589 mg, $3.00 \mathrm{mmol}$ ) and squaric acid dichloride $(4,151 \mathrm{mg}, 1.00 \mathrm{mmol})$. Crystallization from toluene/acetone yieled a tan powder $(37 \mathrm{mg}, 8 \%)$. IR (KBr): $3390 \mathrm{~cm}^{-1}(\mathrm{NH}), 1749 \mathrm{~cm}^{-1}, 1701 \mathrm{~cm}^{-1}(\mathrm{C}=\mathrm{O})$; ${ }^{1} \mathrm{H}-\mathrm{NMR}\left(600 \mathrm{MHz}, \mathrm{DMSO}-d_{6}\right): \delta(\mathrm{ppm})=7.42(\mathrm{dd}, J=8.6,2.0 \mathrm{~Hz}, 2 \mathrm{H}, \mathrm{ArH}), 7.56(\mathrm{dd}$, $J=8.6,0.6 \mathrm{~Hz}, 2 \mathrm{H}, \mathrm{ArH}), 8.20(\mathrm{dd}, J=2.0,0.5 \mathrm{~Hz}, 2 \mathrm{H}, \mathrm{ArH}), 8.36(\mathrm{~s}, 2 \mathrm{H}, \mathrm{ArH}), 12.64(\mathrm{~s}, 2 \mathrm{H}$, $\mathrm{NH}),{ }^{13} \mathrm{C}-\mathrm{NMR}\left(151 \mathrm{MHz}, \mathrm{DMSO}-d_{6}\right): \delta(\mathrm{ppm})=114.7,124.9,125.7,132.2(\mathrm{CH}), 105.9,113.9$, 126.9, 135.6, 176.7, 194.6 (C); $\mathrm{C}_{20} \mathrm{H}_{10} \mathrm{Br}_{2} \mathrm{~N}_{2} \mathrm{O}_{2}$ [470.12]; Anal. calcd. for $\mathrm{C}_{20} \mathrm{H}_{10} \mathrm{Br}_{2} \mathrm{~N}_{2} \mathrm{O}_{2}$ : C 50.88, H 2.56, N 5.93; found C 50.53, H 2.14, N 5.62; MS (EI): $m / z(\%)=468[\mathrm{M}]^{+}(12)$, $412\left[\mathrm{M}^{+}-56\right]$ (100); isocratic HPLC: $97.6 \%$ at $254 \mathrm{~nm}$ and $98.4 \%$ at $280 \mathrm{~nm}, \mathrm{t}_{\mathrm{ms}}=9.81 \mathrm{~min}$, $\mathrm{t}_{\mathrm{m}}=1.11 \mathrm{~min}\left(\mathrm{ACN} / \mathrm{H}_{2} \mathrm{O} 50: 50\right) ; \lambda_{\max }(\mathrm{nm}): 327,278,228$; gradient HPLC: $98.1 \%$ at $254 \mathrm{~nm}$, $\mathrm{t}_{\mathrm{ms}}=12.8 \mathrm{~min}, \mathrm{t}_{\mathrm{m}}=1.25 \mathrm{~min}$.

\section{3,3'-(3,4-Dioxocyclobut-1-ene-1,2-diyl)bis(1H-indole-5-carbonitrile) (2p)}

Synthesis according to General Procedure B (reaction time: $24 \mathrm{~h}$ ) from squaric acid dichloride $(4,295 \mathrm{mg}, 1.95 \mathrm{mmol})$ and $1 H$-indole-5-carbonitrile $(570 \mathrm{mg}, 4.01 \mathrm{mmol})$. Crystallization from chloroform/DMF yielded a yellow powder (59 mg, 12\%). IR (KBr): $3232 \mathrm{~cm}^{-1}(\mathrm{NH}), 2230 \mathrm{~cm}^{-1}(\mathrm{C} \equiv \mathrm{N}), 1764 \mathrm{~cm}^{-1}, 1727 \mathrm{~cm}^{-1}(\mathrm{C}=\mathrm{O}), 1619 \mathrm{~cm}^{-1}, 1556 \mathrm{~cm}^{-1}$, $1513 \mathrm{~cm}^{-1}$ (C=C, arom.); ${ }^{1} \mathrm{H}-\mathrm{NMR}\left(600 \mathrm{MHz}, \mathrm{DMSO}-d_{6}\right): \delta(\mathrm{ppm})=7.68(\mathrm{dd}, J=8.5,1.7 \mathrm{~Hz}$, $2 \mathrm{H}, \mathrm{ArH}) .7 .78(\mathrm{dd}, J=8.5,0.8 \mathrm{~Hz}, 2 \mathrm{H}, \mathrm{ArH}), 8.46(\mathrm{dt}, J=1.6,0.7 \mathrm{~Hz}, 2 \mathrm{H}, \mathrm{ArH}), 8.56(\mathrm{~d}$, $J=3.1 \mathrm{~Hz}, 2 \mathrm{H}, \mathrm{ArH}), 12.95(\mathrm{~d}, J=3.6 \mathrm{~Hz}, 2 \mathrm{H}, \mathrm{NH}) ;{ }^{13} \mathrm{C}-\mathrm{NMR}\left(151 \mathrm{MHz}, \mathrm{DMSO}-d_{6}\right): \delta$ $(\mathrm{ppm})=114.6,126.4,128.3,133.7(\mathrm{CH}), 104.0,107.1,120.5,125.5,139.2,177.4,195.1(\mathrm{C})$; $\mathrm{C}_{22} \mathrm{H}_{10} \mathrm{~N}_{4} \mathrm{O}_{2}$ [362.35]; MS (EI): $m / z(\%)=362[\mathrm{M}]^{+} .(6), 206$ [M $\mathrm{M}^{+}$- 56] (100); HRMS (EI) $(m / z)$ : Calcd. for $[\mathrm{M}]^{+}=362.07983$, found $[\mathrm{M}]^{+}=362.07983$; isocratic HPLC: $95.3 \%$ at $254 \mathrm{~nm}$ and $95.9 \%$ at $280 \mathrm{~nm}, \mathrm{t}_{\mathrm{ms}}=5.11 \mathrm{~min}, \mathrm{t}_{\mathrm{m}}=1.11 \mathrm{~min}\left(\mathrm{ACN} / \mathrm{H}_{2} \mathrm{O} 50: 50\right) ; \lambda_{\max }(\mathrm{nm}): 239,322$ and 400; gradient HPLC: $96.9 \%$ at $254 \mathrm{~nm}, \mathrm{t}_{\mathrm{ms}}=10.5 \mathrm{~min}, \mathrm{t}_{\mathrm{m}}=1.25 \mathrm{~min}$.

\section{3-(1H-Indol-3-yl)-4-(1-methyl-1H-indol-3-yl)cyclobut-3-ene-1,2-dione (2q)}

Synthesis according to General Procedure $\mathrm{C}$ from 3-chloro-4-(1H-indol-3-yl)cyclobut3-ene-1,2-dione (5a, $295 \mathrm{mg}, 1.95 \mathrm{mmol})$ and 1-methyl-1H-indole $(0.274 \mathrm{~mL}, 2.19 \mathrm{mmol})$ yielded a yellow powder (88 mg, 26\%). IR (KBr): $3422 \mathrm{~cm}^{-1}(\mathrm{NH}), 3171 \mathrm{~cm}^{-1}, 1749 \mathrm{~cm}^{-1}$, $1713 \mathrm{~cm}^{-1}$ (C=O), $1616 \mathrm{~cm}^{-1}, 1551 \mathrm{~cm}^{-1}, 1524 \mathrm{~cm}^{-1}$ (C=C, arom.); ${ }^{1} \mathrm{H}-\mathrm{NMR}(400 \mathrm{MHz}$, DMSO- $\left.d_{6}\right): \delta(\mathrm{ppm})=3.98\left(\mathrm{~s}, 3 \mathrm{H}, \mathrm{CH}_{3}\right), 7.13-7.40(\mathrm{~m}, 4 \mathrm{H}, \mathrm{ArH}), 7.62(\mathrm{ddt}, J=29.0,8.2$, $0.9 \mathrm{~Hz}, 2 \mathrm{H}, \mathrm{ArH}), 7.89-8.03$ (m, 2H, ArH), 8.24-8.30 (m, 1H, ArH), 8.35 (s, 1H, ArH), 12.44 $(\mathrm{s}, 1 \mathrm{H}, \mathrm{NH}) ;{ }^{13} \mathrm{C}-\mathrm{NMR}\left(101 \mathrm{MHz}, \mathrm{DMSO}-d_{6}\right): \delta(\mathrm{ppm})=33.4\left(\mathrm{CH}_{3}\right), 111.0,112.5,121.3$, 121.5, 122.6, 122.8, 123.1, 131.0, $134.5(\mathrm{CH}), 105.3,106.4,125.2,125.4,136.7,137.4,176.3$, 176.9, 194.6, 194.7 (C); $\mathrm{C}_{21} \mathrm{H}_{14} \mathrm{~N}_{2} \mathrm{O}_{2}$ [326.36]; Anal. calcd. for $\mathrm{C}_{21} \mathrm{H}_{14} \mathrm{~N}_{2} \mathrm{O}_{2}$ : C 77.29, H 4.32, $\mathrm{N}$ 8.58; found C 76.80, H 4.17, N 8.21; MS (EI): $m / z(\%)=231[\mathrm{M}]^{+}(35), 203\left[\mathrm{M}^{+}-28\right](4)$, 175 [ $\left.\mathrm{M}^{+}-56\right]$ (100); isocratic HPLC: $99.3 \%$ at $254 \mathrm{~nm}, 99.4 \%$ at $280 \mathrm{~nm}, \mathrm{t}_{\mathrm{ms}}=5.69 \mathrm{~min}$, $\mathrm{t}_{\mathrm{m}}=1.11 \mathrm{~min}\left(\mathrm{ACN} / \mathrm{H}_{2} \mathrm{O} 50: 50\right) ; \lambda_{\max }(\mathrm{nm}): 222,272,333$; gradient HPLC: $98.1 \%$ at $254 \mathrm{~nm}$, $\mathrm{t}_{\mathrm{ms}}=11.8 \mathrm{~min}, \mathrm{t}_{\mathrm{m}}=1.25 \mathrm{~min}$.

\section{3-(1H-Indol-3-yl)-4-(5-iodo-1H-indol-3-yl)cyclobut-3-ene-1,2-dione (2r)}

Synthesis according to General Procedure C (reaction time: $20 \mathrm{~h}$ ) from 3-chloro-4-(1Hindol-3-yl)cyclobut-3-ene-1,2-dione (5a, $234 \mathrm{mg}, 1.01 \mathrm{mmol}$ ) and 5-iodo- $1 \mathrm{H}$-indole ( $360 \mathrm{mg}$, $1.48 \mathrm{mmol})$. Crystallization from ethyl acetate yielded a yellow powder $(160 \mathrm{mg}, 36 \%)$. IR (KBr): $3305 \mathrm{~cm}^{-1}(\mathrm{NH}), 1751 \mathrm{~cm}^{-1}, 1699 \mathrm{~cm}^{-1}(\mathrm{C}=\mathrm{O}), 1613 \mathrm{~cm}^{-1}, 1537 \mathrm{~cm}^{-1}, 1508 \mathrm{~cm}^{-1}$ $\left(\mathrm{C}=\mathrm{C}\right.$, arom.); ${ }^{1} \mathrm{H}-\mathrm{NMR}\left(600 \mathrm{MHz}, \mathrm{DMSO}-d_{6}\right): \delta(\mathrm{ppm})=7.19(\mathrm{ddd}, J=8.0,7.0,1.0 \mathrm{~Hz}$, $1 \mathrm{H}, \mathrm{ArH}), 7.30(\mathrm{ddd}, J=8.2,7.1,1.2 \mathrm{~Hz}, 1 \mathrm{H}, \mathrm{ArH}), 7.43(\mathrm{dd}, J=8.5,0.6 \mathrm{~Hz}, 1 \mathrm{H}, \mathrm{ArH})$, 7.53-7.62 (m, 2H, ArH), $7.90(\mathrm{dt}, J=8.0,1.0 \mathrm{~Hz}, 1 \mathrm{H}, \mathrm{ArH}), 8.22(\mathrm{~s}, 1 \mathrm{H}), 8.33(\mathrm{~s}, 1 \mathrm{H}, \mathrm{ArH})$, $8.39(\mathrm{dd}, J=1.7,0.5 \mathrm{~Hz}, 1 \mathrm{H}, \mathrm{ArH}), 12.53(\mathrm{~s}, 2 \mathrm{H}, \mathrm{NH}) ;{ }^{13} \mathrm{C}-\mathrm{NMR}\left(151 \mathrm{MHz}, \mathrm{DMSO}-d_{6}\right): \delta$ $(\mathrm{ppm})=112.7,115.0,121.4,122.6,123.2,131.1,131.1,131.3,131.6(\mathrm{CH}), 85.5,105.7,106.2$, 124.9, 127.6, 135.9, 136.9, 176.4, 177.3, 194.7, 194.8 (C); $\mathrm{C}_{20} \mathrm{H}_{11} \mathrm{IN}_{2} \mathrm{O}_{2}$ [438.22]; Anal. calcd. for $\mathrm{C}_{20} \mathrm{H}_{11} \mathrm{IN}_{2} \mathrm{O}_{2}$ : C 54.82, H 2.35, N 6.39; found C 54.93, H 2.49, N 6.25; MS (EI): $m / z$ 
$(\%)=438[\mathrm{M}]^{+\cdot}(33), 382\left[\mathrm{M}^{+}-56\right](100)$; isocratic HPLC: $97.6 \%$ at $254 \mathrm{~nm}$ and $97.7 \%$ at $280 \mathrm{~nm}, \mathrm{t}_{\mathrm{ms}}=6.47 \mathrm{~min}, \mathrm{t}_{\mathrm{m}}=1.11 \mathrm{~min}\left(\mathrm{ACN} / \mathrm{H}_{2} \mathrm{O} 50: 50\right) ; \lambda_{\max }(\mathrm{nm}): 273,330$ and 345; gradient HPLC: $97.9 \%$ at $254 \mathrm{~nm}, \mathrm{t}_{\mathrm{ms}}=12.2 \mathrm{~min}, \mathrm{t}_{\mathrm{m}}=1.25 \mathrm{~min}$.

3-(5-Bromo-1H-indol-3-yl)-4-(2-phenyl-1H-indol-3-yl)cyclobut-3-ene-1,2-dione (2s)

Synthesis according to General Procedure C (reaction time: $24 \mathrm{~h}$ ) from 3-chloro-4-(2phenyl-1H-indol-3-yl)cyclobut-3-ene-1,2-dione (5d, $309 \mathrm{mg}, 1.00 \mathrm{mmol}$ ) and 5-bromo- $1 H$ indole $(297 \mathrm{mg}, 1.52 \mathrm{mmol})$. Crystallization from ethyl acetate yielded an orange powder (130 mg, 28\%). IR (KBr): $3253 \mathrm{~cm}^{-1}(\mathrm{NH}), 1753 \mathrm{~cm}^{-1}, 1712 \mathrm{~cm}^{-1}(\mathrm{C}=\mathrm{O}), 1615 \mathrm{~cm}^{-1}$, $1548 \mathrm{~cm}^{-1}, 1524 \mathrm{~cm}^{-1}$ (C=C, arom.); ${ }^{1} \mathrm{H}-\mathrm{NMR}\left(400 \mathrm{MHz}, \mathrm{DMSO}-d_{6}\right): \delta(\mathrm{ppm})=7.07-7.39$ (m, 7H, ArH), 7.42-7.51 (m, 1H, ArH), 7.51-7.62 (m, 3H, ArH), 7.76 (s, 1H, ArH), 7.93 (d, $J=13.7 \mathrm{~Hz}, 1 \mathrm{H}, \mathrm{ArH}), 12.34(\mathrm{~s}, 1 \mathrm{H}, \mathrm{NH}), 12.51(\mathrm{~s}, 1 \mathrm{H}, \mathrm{NH}) ;{ }^{13} \mathrm{C}-\mathrm{NMR}\left(101 \mathrm{MHz}, \mathrm{DMSO}-d_{6}\right)$ : $\delta(\mathrm{ppm})=112.1,114.3,120.9,121.5,123.0,124.6,125.3,128.2,128.2,128.6,132.9(\mathrm{CH})$, 102.8, 106.5, 113.9, 126.7, 128.3, 131.4, 135.2, 136.8, 140.0, 179.1, 179.19, 194.3, 196.5 (C); $\mathrm{C}_{26} \mathrm{H}_{15} \mathrm{BrN}_{2} \mathrm{O}_{2}$ [467.32]; Anal. calcd. for $\mathrm{C}_{26} \mathrm{H}_{15} \mathrm{BrN}_{2} \mathrm{O}_{2}$ : C 66.82, $\mathrm{H} 3.24, \mathrm{~N}$ 5.99; found C 67.10, H 3.48, N 5.70; MS (EI): $m / z(\%)=466[\mathrm{M}]^{+}(20), 438\left[\mathrm{M}^{+}-28\right](10), 410\left[\mathrm{M}^{+}-56\right]$ (100); isocratic HPLC: $97.7 \%$ at $254 \mathrm{~nm}, 97.9 \%$ at $280 \mathrm{~nm}, \mathrm{t}_{\mathrm{ms}}=3.77 \mathrm{~min}, \mathrm{t}_{\mathrm{m}}=1.15 \mathrm{~min}$ (ACN/ $\left.\mathrm{H}_{2} \mathrm{O} 60: 40\right) ; \lambda_{\max }(\mathrm{nm}): 230$, 292; gradient HPLC: $95.7 \%$ at $254 \mathrm{~nm}, \mathrm{t}_{\mathrm{ms}}=12.5 \mathrm{~min}$, $\mathrm{t}_{\mathrm{m}}=1.25 \mathrm{~min}$.

3-(5-Bromo-1H-indol-3-yl)-4-(1-methyl-1H-indol-3-yl)cyclobut-3-ene-1,2-dione (2t)

Synthesis according to General Procedure C (reaction time: $22 \mathrm{~h}$ ) from 3-chloro-4-(1methyl-1H-indol-3-yl)cyclobut-3-ene-1,2-dione (5b, $189 \mathrm{mg}, 0.77 \mathrm{mmol}$ ) and 5-bromo- $1 \mathrm{H}$ indole (221 mg, $1.13 \mathrm{mmol})$. Crystallization from dichloromethane/ethyl acetate/ethanol yielded a yellow powder (190 mg, 61\%). IR (KBr): $3420 \mathrm{~cm}^{-1}(\mathrm{NH}), 1749 \mathrm{~cm}^{-1}, 1712 \mathrm{~cm}^{-1}$ (C=O), $1615 \mathrm{~cm}^{-1}, 1548 \mathrm{~cm}^{-1}, 1521 \mathrm{~cm}^{-1}$ (C=C, arom.); ${ }^{1} \mathrm{H}-\mathrm{NMR}\left(400 \mathrm{MHz}, \mathrm{DMSO}-d_{6}\right): \delta$ $(\mathrm{ppm})=3.99\left(\mathrm{~s}, 3 \mathrm{H}, \mathrm{CH}_{3}\right), 7.25(\mathrm{ddd}, J=8.1,7.1,1.0 \mathrm{~Hz}, 1 \mathrm{H}, \mathrm{ArH}), 7.32-7.45(\mathrm{~m}, 2 \mathrm{H}, \mathrm{ArH})$, $7.55(\mathrm{dd}, J=8.7,0.5 \mathrm{~Hz}, 1 \mathrm{H}, \mathrm{ArH}), 7.67(\mathrm{dt}, J=8.3,0.9 \mathrm{~Hz}, 1 \mathrm{H}, \mathrm{ArH}), 7.89-7.99(\mathrm{~m}, 1 \mathrm{H}$, $\mathrm{ArH}), 8.26-8.32$ (m, 2H, ArH), $8.44(\mathrm{~s}, 1 \mathrm{H}), 12.58(\mathrm{~s}, 1 \mathrm{H}, \mathrm{NH}) ;{ }^{13} \mathrm{C}-\mathrm{NMR}(101 \mathrm{MHz}, \mathrm{DMSO}-$ $\left.d_{6}\right): \delta(\mathrm{ppm})=33.4\left(\mathrm{CH}_{3}\right), 111.1,114.5,121.7,122.8,123.2,124.9,125.6,132.0,134.7(\mathrm{CH})$, $105.1,106.0,113.8,125.3,127.1,135.5,137.5,176.1,176.6,194.5,194.6(C) ; \mathrm{C}_{21} \mathrm{H}_{13} \mathrm{BrN}_{2} \mathrm{O}_{2}$

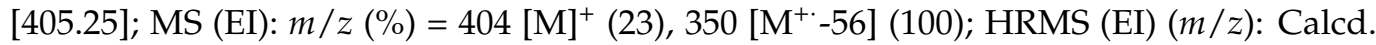
for $[\mathrm{M}]^{+}=404.01549$, found $[\mathrm{M}]^{+}=404.01552$; isocratic HPLC: $99.4 \%$ at $254 \mathrm{~nm}, 99.7 \%$ at $280 \mathrm{~nm}, \mathrm{t}_{\mathrm{ms}}=4.38 \mathrm{~min}, \mathrm{t}_{\mathrm{m}}=1.15 \min \left(\mathrm{ACN} / \mathrm{H}_{2} \mathrm{O} 60: 40\right) ; \lambda_{\max }(\mathrm{nm}): 275,328$, and 344; gradient HPLC: $99.0 \%$ at $254 \mathrm{~nm}, \mathrm{t}_{\mathrm{ms}}=12.8 \mathrm{~min}, \mathrm{t}_{\mathrm{m}}=1.25 \mathrm{~min}$.

3-(1-Methyl-1H-indol-3-yl)-4-(2-phenyl-1H-indol-3-yl)cyclobut-3-ene-1,2-dione (2u)

Synthesis according to General Procedure D from 3-chloro-4-(2-phenyl- $1 H$-indol-3yl)cyclobut-3-ene-1,2-dione (5d, $310 \mathrm{mg}, 1.01 \mathrm{mmol})$ and 1-methyl-1H-indole $(190 \mathrm{~mL}$, $1.52 \mathrm{mmol})$. Crystallization from petroleum ether/acetone yielded a yellow powder (105 mg, 26\%). IR (KBr): $3438 \mathrm{~cm}^{-1}(\mathrm{NH}), 1767 \mathrm{~cm}^{-1}, 1732 \mathrm{~cm}^{-1}(\mathrm{C}=\mathrm{O}), 1616 \mathrm{~cm}^{-1}$, $1565 \mathrm{~cm}^{-1}, 1533 \mathrm{~cm}^{-1}$ (C=C, arom.); ${ }^{1} \mathrm{H}-\mathrm{NMR}\left(600 \mathrm{MHz}, \mathrm{DMSO}-d_{6}\right): \delta(\mathrm{ppm})=3.70(\mathrm{~s}, 3 \mathrm{H}$, $\left.\mathrm{CH}_{3}\right), 7.06-7.13(\mathrm{~m}, 2 \mathrm{H}, \mathrm{ArH}), 7.18-7.30(\mathrm{~m}, 6 \mathrm{H}, \mathrm{ArH}), 7.47$ (dt, $\left.J=8.2,0.9 \mathrm{~Hz}, 1 \mathrm{H}, \mathrm{ArH}\right)$, 7.53-7.61 (m, 4H, ArH), $12.49(\mathrm{~s}, 1 \mathrm{H}), 7.69(\mathrm{~s}, 1 \mathrm{H}, \mathrm{ArH}) ;{ }^{13} \mathrm{C}-\mathrm{NMR}\left(151 \mathrm{MHz}, \mathrm{DMSO}-d_{6}\right): \delta$ $(\mathrm{ppm})=33.1\left(\mathrm{CH}_{3}\right), 110.7,112.0,120.7,121.4,121.7,122.3,122.9,122.9,128.2,128.2,128.6$, 135.7 (CH), 102.9, 105.7, 125.6, 126.8, 131.7, 136.7, 136.9, 139.1, 178.5, 178.9, 194.2, 196.5 (C); $\mathrm{C}_{27} \mathrm{H}_{18} \mathrm{~N}_{2} \mathrm{O}_{2}$ [402.45]; C 80.58, H 6.96, N 4.51; found C 80.22, H 7.06, N 4.66; MS (EI): $m / z(\%)=402[\mathrm{M}]^{+}(14), 374\left[\mathrm{M}^{+}-28\right](4), 346\left[\mathrm{M}^{+}-56\right](100)$; isocratic HPLC: $98.2 \%$ at $254 \mathrm{~nm}, 98.6 \%$ at $280 \mathrm{~nm}, \mathrm{t}_{\mathrm{ms}}=4.05 \mathrm{~min}, \mathrm{t}_{\mathrm{m}}=1.15 \mathrm{~min}\left(\mathrm{ACN} / \mathrm{H}_{2} \mathrm{O} 60: 40\right) ; \lambda_{\max }(\mathrm{nm}): 297$, 334; gradient HPLC: $98.1 \%$ at $254 \mathrm{~nm}, \mathrm{t}_{\mathrm{ms}}=12.6 \mathrm{~min}, \mathrm{t}_{\mathrm{m}}=1.25 \mathrm{~min}$.

3-(5-Methoxy-1H-indol-3-yl)-4-(2-methyl-1H-indol-3-yl)cyclobut-3-ene-1,2-dione (2v)

Synthesis according to General Procedure C (reaction time: $48 \mathrm{~h}$ ) from 3-chloro-4-(2methyl-1H-indol-3-yl)cyclobut-3-ene-1,2-dione (5e, $257 \mathrm{mg}, 1.05 \mathrm{mmol}$ ) and 5-methoxy- 
$1 \mathrm{H}$-indole $(149 \mathrm{mg}, 1.01 \mathrm{mmol})$. Crystallization from ethanol/toluene yielded a yellow powder (70 mg, 20\%). IR (KBr): $3191 \mathrm{~cm}^{-1}(\mathrm{NH}), 1756 \mathrm{~cm}^{-1}, 1710 \mathrm{~cm}^{-1}(\mathrm{C}=\mathrm{O}), 1622 \mathrm{~cm}^{-1}$, $1554 \mathrm{~cm}^{-1}, 1524 \mathrm{~cm}^{-1}$ (C=C, arom.); ${ }^{1} \mathrm{H}-\mathrm{NMR}\left(600 \mathrm{MHz}, \mathrm{DMSO}-d_{6}\right): \delta(\mathrm{ppm})=2.57(\mathrm{~s}, 3 \mathrm{H}$, $\left.\mathrm{CH}_{3}\right), 3.32\left(\mathrm{~s}, 3 \mathrm{H}, \mathrm{OCH}_{3}\right), 6.81(\mathrm{dd}, J=8.8,2.5 \mathrm{~Hz}, 1 \mathrm{H}, \mathrm{ArH}), 6.94(\mathrm{ddd}, J=8.0,7.1,1.0 \mathrm{~Hz}$, 1H, ArH), 7.10-7.19 (m, 3H, ArH), $7.38-7.46$ (m, 2H, ArH), 8.00 (s, 1H, ArH), 12.13 (s, 1H, $\mathrm{NH}), 12.29(\mathrm{~s}, 1 \mathrm{H}, \mathrm{NH}) ;{ }^{13} \mathrm{C}-\mathrm{NMR}\left(151 \mathrm{MHz}, \mathrm{DMSO}-d_{6}\right): \delta(\mathrm{ppm})=13.9,54.4\left(\mathrm{CH}_{3}\right), 104.2$, $111.4,113.0,113.2,120.3,120.9,121.8,132.2(\mathrm{CH}), 104.0,106.6,125.7,156.0,131.4,136.2,140.9$, 154.6, 177.8, 179.0, 194.4, $196.0(\mathrm{C}) ; \mathrm{C}_{22} \mathrm{H}_{16} \mathrm{~N}_{2} \mathrm{O}_{3}$ [356.38]; MS (EI): $m / z(\%)=356$ [M] ${ }^{+}$(30), $300\left[\mathrm{M}^{+}-56\right](100) ;$ HRMS (EI) $(\mathrm{m} / z)$ : Calcd. for $[\mathrm{M}]^{+}=356.11554$, found $[\mathrm{M}]^{+}=356.11599$; isocratic HPLC: $98.3 \%$ at $254 \mathrm{~nm}, 99.5 \%$ at $280 \mathrm{~nm}, \mathrm{t}_{\mathrm{ms}}=3.52 \mathrm{~min}, \mathrm{t}_{\mathrm{m}}=1.11 \mathrm{~min}\left(\mathrm{ACN} / \mathrm{H}_{2} \mathrm{O}\right.$ 50:50), $\lambda_{\max }: 276 \mathrm{~nm}$; gradient HPLC: $95.4 \%$ at $254 \mathrm{~nm}, \mathrm{t}_{\mathrm{ms}}=11.0 \mathrm{~min}, \mathrm{t}_{\mathrm{m}}=1.25 \mathrm{~min}$.

3-(2-Methyl-1H-indol-3-yl)-4-(2-phenyl-1H-indol-3-yl)cyclobut-3-ene-1,2-dione (2w)

Synthesis according to General Procedure C (reaction time: $28 \mathrm{~h}$ ) from 3-chloro-4(2-methyl-1H-indol-3-yl)cyclobut-3-ene-1,2-dione (5e, $244 \mathrm{mg}, 0.99 \mathrm{mmol}$ ) and 2-phenyl$1 \mathrm{H}$-indole $(403 \mathrm{mg}, 3.02 \mathrm{mmol})$. Crystallization from acetone yielded a yellow powder (50 mg, 13\%). IR (KBr): $3467 \mathrm{~cm}^{-1}(\mathrm{NH}), 1764 \mathrm{~cm}^{-1}, 1732 \mathrm{~cm}^{-1}(\mathrm{C}=\mathrm{O}), 1616 \mathrm{~cm}^{-1}$, $1552 \mathrm{~cm}^{-1}, 1522 \mathrm{~cm}^{-1}$ (C=C, arom.); ${ }^{1} \mathrm{H}-\mathrm{NMR}\left(400 \mathrm{MHz}, \mathrm{DMSO}-d_{6}\right): \delta(\mathrm{ppm})=2.42(\mathrm{~s}, 3 \mathrm{H}$, $\left.\mathrm{CH}_{3}\right), 6.80(\mathrm{ddd}, J=8.0,7.1,1.0 \mathrm{~Hz}, 1 \mathrm{H}, \mathrm{ArH}), 6.92(\mathrm{~d}, J=8.0 \mathrm{~Hz}, 1 \mathrm{H}, \mathrm{ArH}), 6.96-7.28(\mathrm{~m}$, 9H, ArH), $7.51(\mathrm{dt}, J=8.1,0.9 \mathrm{~Hz}, 1 \mathrm{H}, \mathrm{ArH}), 7.63-7.70(\mathrm{~m}, 1 \mathrm{H}, \mathrm{ArH}), 11.85$ (s, 1H, NH), $12.34(\mathrm{~s}, 1 \mathrm{H}, \mathrm{NH}) ;{ }^{13} \mathrm{C}-\mathrm{NMR}\left(101 \mathrm{MHz}, \mathrm{DMSO}-d_{6}\right): \delta(\mathrm{ppm})=13.7\left(\mathrm{CH}_{3}\right), 111.0,112.0,120.2$, 120.3, 120.9, 121.2, 121.7, 122.9, 127.1, 128.0, 128.1 (CH), 103.7, 105.6, 125.7, 127.2, 131.0, $136.1,136.5,141.2,141.9,180.4,181.2,195.2,196.4(\mathrm{C}) ; \mathrm{C}_{27} \mathrm{H}_{18} \mathrm{~N}_{2} \mathrm{O}_{2}$ [402.45] MS (EI): $m / z$ $(\%)=402[\mathrm{M}]^{+\cdot}(22), 374\left[\mathrm{M}^{+}-28\right](100), 346\left[\mathrm{M}^{+}-56\right](100) ; \mathrm{HRMS}(\mathrm{EI})(\mathrm{m} / \mathrm{z})$ : Calcd. for $[\mathrm{M}]^{+}=402.13628$, found $[\mathrm{M}]^{+}=402.13693$; isocratic HPLC: $98.8 \%$ at $254 \mathrm{~nm}, 98.8 \%$ at $280 \mathrm{~nm}, \mathrm{t}_{\mathrm{ms}}=6.23 \mathrm{~min}, \mathrm{t}_{\mathrm{m}}=1.11 \mathrm{~min}\left(\mathrm{ACN} / \mathrm{H}_{2} \mathrm{O} 50: 50\right) ; \lambda_{\max }(\mathrm{nm}): 285,233 ;$ gradient HPLC: $98.5 \%$ at $254 \mathrm{~nm}, \mathrm{t}_{\mathrm{ms}}=11.9 \mathrm{~min}, \mathrm{t}_{\mathrm{m}}=1.25 \mathrm{~min}$.

3-(5-Bromo-1H-indol-3-yl)-4-(2-methyl-1H-indol-3-yl)cyclobut-3-ene-1,2-dione (2x)

Synthesis according to General Procedure C (reaction time: $26 \mathrm{~h}$ ) from 3-chloro-4(2-methyl-1H-indol-3-yl)cyclobut-3-ene-1,2-dione (5e, $245 \mathrm{mg}, 1.00 \mathrm{mmol}$ ) and 5-bromo$1 \mathrm{H}$-indole $(364 \mathrm{mg}, 1.86 \mathrm{mmol})$. Crystallization from acetone yielded a yellow powder (70 mg, 17\%). IR (KBr): $3387 \mathrm{~cm}^{-1}(\mathrm{NH}), 1754 \mathrm{~cm}^{-1}, 1714 \mathrm{~cm}^{-1}(\mathrm{C}=\mathrm{O}), 1615 \mathrm{~cm}^{-1}$, $1550 \mathrm{~cm}^{-1}, 1524 \mathrm{~cm}^{-1}$ (C=C, arom.); ${ }^{1} \mathrm{H}-\mathrm{NMR}\left(600 \mathrm{MHz}, \mathrm{DMSO}-d_{6}\right): \delta(\mathrm{ppm})=2.59(\mathrm{~s}, 3 \mathrm{H}$, $\left.\mathrm{CH}_{3}\right), 7.00(\mathrm{ddd}, J=8.0,7.1,1.0 \mathrm{~Hz}, 1 \mathrm{H}, \mathrm{ArH}), 7.09$ (dt, J = 7.9, 0.9 Hz, 1H, ArH), 7.18 (ddd, $J=8.1,7.1,1.2 \mathrm{~Hz}, 1 \mathrm{H}, \mathrm{ArH}), 7.37(\mathrm{dd}, J=8.6,2.0 \mathrm{~Hz}, 1 \mathrm{H}, \mathrm{ArH}), 7.44-7.54(\mathrm{~m}, 2 \mathrm{H}, \mathrm{ArH}), 7.83$ (s, 1H, ArH), $8.14(\mathrm{~d}, J=1.9 \mathrm{~Hz}, 1 \mathrm{H}, \mathrm{ArH}), 12.24(\mathrm{~s}, 1 \mathrm{H}, \mathrm{NH}), 12.50(\mathrm{~s}, 1 \mathrm{H}, \mathrm{NH}) ;{ }^{13} \mathrm{C}-\mathrm{NMR}$ $\left(151 \mathrm{MHz}, \mathrm{DMSO}-d_{6}\right): \delta(\mathrm{ppm})=14.0\left(\mathrm{CH}_{3}\right), 111.6,114.5,120.4,121.1,121.9,124.6,125.5$, $133.0(\mathrm{CH}), 103.7,106.2,113.8,124.9,127.2,135.2,136.4,141.6,178.0,178.7,194.6,195.6(\mathrm{C})$; $\mathrm{C}_{21} \mathrm{H}_{13} \mathrm{BrN}_{2} \mathrm{O}_{2}$ [405.25]; Anal. calcd. for $\mathrm{C}_{21} \mathrm{H}_{13} \mathrm{BrN}_{2} \mathrm{O}_{2}$ : C 62.24, $\mathrm{H}$ 3.23, N 6.91; found C 62.37, H 3.02, N 6.66; MS (EI): $m / z(\%)=404[\mathrm{M}]^{+}(28), 348\left[\mathrm{M}^{+}-56\right](100)$; isocratic HPLC: $99.3 \%$ at $254 \mathrm{~nm}, 98.6 \%$ at $280 \mathrm{~nm}, \mathrm{t}_{\mathrm{ms}}=6.00 \mathrm{~min}, \mathrm{t}_{\mathrm{m}}=1.11 \mathrm{~min}\left(\mathrm{ACN} / \mathrm{H}_{2} \mathrm{O} 50: 50\right) ; \lambda_{\max }$ (nm): 276, 328, 334; gradient HPLC: $95.3 \%$ at $254 \mathrm{~nm}, \mathrm{t}_{\mathrm{ms}}=11.7 \mathrm{~min}, \mathrm{t}_{\mathrm{m}}=1.25 \mathrm{~min}$.

3-(1-Methyl-1H-indol-3-yl)-4-(2-methyl-1H-indol-3-yl)cyclobut-3-ene-1,2-dione (2y)

Synthesis according to General Procedure C (reaction time: $22 \mathrm{~h}$ ) from 3-chloro-4-(2methyl-1H-indol-3-yl)cyclobut-3-ene-1,2-dione (5e, $221 \mathrm{mg}, 0.90 \mathrm{mmol}$ ) and 1-methyl-1Hindole $(0.268 \mathrm{~mL}, 2.15 \mathrm{mmol})$ yielded a yellow powder $(16 \mathrm{mg}, 5 \%)$. IR (KBr): $3446 \mathrm{~cm}^{-1}$ (NH), $3295 \mathrm{~cm}^{-1}$ (CH, arom.), $1764 \mathrm{~cm}^{-1}, 1735 \mathrm{~cm}^{-1}$ (C=O), $1611 \mathrm{~cm}^{-1}, 1563 \mathrm{~cm}^{-1}, 1538 \mathrm{~cm}^{-1}$ $\left(\mathrm{C}=\mathrm{C}\right.$, arom.); ${ }^{1} \mathrm{H}-\mathrm{NMR}\left(600 \mathrm{MHz}, \mathrm{DMSO}-d_{6}\right): \delta(\mathrm{ppm})=2.51\left(\mathrm{~s}, 3 \mathrm{H}, \mathrm{CH}_{3}\right), 3.91(\mathrm{~s}, 3 \mathrm{H}$, $\mathrm{N}^{-\mathrm{CH}_{3}}$ ), $6.97(\mathrm{ddd}, J=8.1,7.1,1.0 \mathrm{~Hz}, 1 \mathrm{H}, \mathrm{ArH}), 7.09$ (ddd, $\left.J=8.0,7.1,1.0 \mathrm{~Hz}, 1 \mathrm{H}, \mathrm{ArH}\right)$, $7.16(\mathrm{ddd}, J=8.1,7.1,1.1 \mathrm{~Hz}, 1 \mathrm{H}, \mathrm{ArH}), 7.21$ (dt, $J=7.9,0.9 \mathrm{~Hz}, 1 \mathrm{H}, \mathrm{ArH}), 7.29$ (ddd, $J=8.2$, 7.1, $1.1 \mathrm{~Hz}, 1 \mathrm{H}, \mathrm{ArH}), 7.45(\mathrm{dt}, J=8.1,0.9 \mathrm{~Hz}, 1 \mathrm{H}, \mathrm{ArH}), 7.60(\mathrm{dt}, J=8.3,0.9 \mathrm{~Hz}, 1 \mathrm{H}, \mathrm{ArH})$, $7.72(\mathrm{~d}, J=8.0 \mathrm{~Hz}, 1 \mathrm{H}, \mathrm{ArH}), 8.07$ (s, 1H, ArH), 12.17 (s, 1H, NH); ${ }^{3} \mathrm{C}-\mathrm{NMR}(151 \mathrm{MHz}$, 
DMSO- $\left.d_{6}\right): \delta(\mathrm{ppm})=14.0\left(\mathrm{CH}_{3}\right), 33.3\left(\mathrm{~N}-\mathrm{CH}_{3}\right), 111.0,111.5,120.3,121.0,121.6,121.9,123.0$, $135.4(\mathrm{CH}), 104.0,105.5,122.2,125.6,125.7,136.3,137.2,141.0,177.9,178.2,194.57,195.7$ (C); $\mathrm{C}_{22} \mathrm{H}_{16} \mathrm{~N}_{2} \mathrm{O}_{2}$ [340.38]; MS (EI): $m / z(\%)=340[\mathrm{M}]^{+}$(34), $284\left[\mathrm{M}^{+}-56\right]$ (100); HRMS (EI) $(\mathrm{m} / z)$ : Calcd. for $[\mathrm{M}]^{+}=340.12063$, found $[\mathrm{M}]^{+}=340.10261$; isocratic HPLC: $99.6 \%$ at $254 \mathrm{~nm}$, $99.7 \%$ at $280 \mathrm{~nm}, \mathrm{t}_{\mathrm{ms}}=6.56 \mathrm{~min}, \mathrm{t}_{\mathrm{m}}(\mathrm{DMSO})=1.11 \mathrm{~min}\left(\mathrm{ACN} / \mathrm{H}_{2} \mathrm{O} 50: 50\right) ; \lambda_{\max }(\mathrm{nm}): 274$; gradient HPLC: $97.3 \%$ at $254 \mathrm{~nm}, \mathrm{t}_{\mathrm{ms}}=11.9 \mathrm{~min}, \mathrm{t}_{\mathrm{m}}=1.25 \mathrm{~min}$.

3-(5-Bromo-1-methyl-1H-indol-3-yl)-4-(2-methyl-1H-indol-3-yl)cyclobut-3-ene-1,2dione $(2 z)$

Synthesis according to General Procedure D from 3-chloro-4-(2-methyl- $1 H$-indol-3yl)cyclobut-3-ene-1,2-dione (5e, $246 \mathrm{mg}, 1.02 \mathrm{mmol}$ ) and 5-bromo-1-methyl-1H-indole $(316 \mathrm{mg}, 1.50 \mathrm{mmol})$. Crystallization from ethanol/toluene yielded an orange powder (138 mg, 32\%). IR (KBr): $3422 \mathrm{~cm}^{-1}(\mathrm{NH}), 1767 \mathrm{~cm}^{-1}, 1716 \mathrm{~cm}^{-1}(\mathrm{C}=\mathrm{O}), 1607 \mathrm{~cm}^{-1}$, $1557 \mathrm{~cm}^{-1}, 1529 \mathrm{~cm}^{-1}$ (C=C, arom.); ${ }^{1} \mathrm{H}-\mathrm{NMR}\left(400 \mathrm{MHz}, \mathrm{DMSO}-d_{6}\right): \delta(\mathrm{ppm})=2.56(\mathrm{~s}, 3 \mathrm{H}$, $\left.\mathrm{CH}_{3}\right), 3.88\left(\mathrm{~s}, 3 \mathrm{H}, \mathrm{N}-\mathrm{CH}_{3}\right), 6.99$ (ddd, $\left.J=8.0,7.0,1.1 \mathrm{~Hz}, 1 \mathrm{H}, \mathrm{ArH}\right), 7.11-7.24(\mathrm{~m}, 2 \mathrm{H}, \mathrm{ArH})$, 7.37-7.50 (m, 2H, ArH), 7.59 (d, J = 8.7 Hz, 1H, ArH), 7.98 (s, 1H, ArH), 8.01 (d, J = 1.9 Hz, $1 \mathrm{H}, \mathrm{ArH}), 12.23(\mathrm{~s}, 1 \mathrm{H}, \mathrm{NH}) ;{ }^{13} \mathrm{C}-\mathrm{NMR}\left(101 \mathrm{MHz}, \mathrm{DMSO}-d_{6}\right): \delta(\mathrm{ppm})=14.2\left(\mathrm{CH}_{3}\right), 33.5$ $\left(\mathrm{N}-\mathrm{CH}_{3}\right), 111.6,113.2,120.4,121.1,122.1,124.8,125.4,136.3(\mathrm{CH}), 103.9,105.2,114.3,125.5$, $127.5,136.1,136.5,141.4,177.4,178.6,194.6,195.6(\mathrm{C}) ; \mathrm{C}_{22} \mathrm{H}_{15} \mathrm{BrN}_{2} \mathrm{O}_{2}$ [419.28]; C 63.02, $\mathrm{H}$ 3.61, N 6.68; found C 63.15, H 3.58, N 6.34; MS (EI): $m / z(\%)=418[\mathrm{M}]^{+}(25), 362\left[\mathrm{M}^{+}-56\right]$ (100); isocratic HPLC: $96.2 \%$ at $254 \mathrm{~nm}, 98.1 \%$ at $280 \mathrm{~nm}, \mathrm{t}_{\mathrm{ms}}=4.48 \mathrm{~min}, \mathrm{t}_{\mathrm{m}}=1.15 \mathrm{~min}$ (ACN/ $\left.\mathrm{H}_{2} \mathrm{O} 60: 40\right) ; \lambda_{\max }(\mathrm{nm}): 277,334$; gradient HPLC: $95.6 \%$ at $254 \mathrm{~nm}, \mathrm{t}_{\mathrm{ms}}=12.9 \mathrm{~min}$, $\mathrm{t}_{\mathrm{m}}=1.25 \mathrm{~min}$.

3-(5-Methoxy-1H-indol-3-yl)-4-(2-phenyl-1H-indol-3-yl)cyclobut-3-ene-1,2-dione (2aa)

Synthesis according to General Procedure C (reaction time: $65 \mathrm{~h}$ ) from 3-chloro-4-(5methoxy-1H-indol-3-yl)cyclobut-3-ene-1,2-dione (5c, $225 \mathrm{mg}, 0.86 \mathrm{mmol}$ ) and 2-phenyl$1 \mathrm{H}$-indole $(272 \mathrm{mg}, 1.42 \mathrm{mmol})$. Crystallization from ethanol/toluene yielded a yellow powder (62 mg, 17\%). IR (KBr): $3257 \mathrm{~cm}^{-1}(\mathrm{NH}), 1751 \mathrm{~cm}^{-1}, 1708 \mathrm{~cm}^{-1}$ (C=O), $1624 \mathrm{~cm}^{-1}$, $1547 \mathrm{~cm}^{-1}, 1523 \mathrm{~cm}^{-1}$ (C=C, arom.); ${ }^{1} \mathrm{H}-\mathrm{NMR}\left(600 \mathrm{MHz}, \mathrm{DMSO}-d_{6}\right): \delta(\mathrm{ppm})=3.32(\mathrm{~s}, 3 \mathrm{H}$, $\left.\mathrm{O}-\mathrm{CH}_{3}\right), 6.75(\mathrm{dd}, J=8.8,2.5 \mathrm{~Hz}, 1 \mathrm{H}), 7.03(\mathrm{ddd}, J=8.0,6.9,1.0 \mathrm{~Hz}, 1 \mathrm{H}, \mathrm{ArH}), 7.21-7.36$ (m, 6H, ArH), 7.38-7.43 (m, 1H, ArH), 7.53-7.62 (m, 4H, ArH), 12.22 (s, 1H, NH), 12.42 $(\mathrm{s}, 1 \mathrm{H}, \mathrm{NH}) ;{ }^{13} \mathrm{C}-\mathrm{NMR}\left(151 \mathrm{MHz}, \mathrm{DMSO}-d_{6}\right): \delta(\mathrm{ppm})=54.4\left(\mathrm{CH}_{3}\right), 111.9,112.8,113.1$, 120.7, 121.1, 122.9, 127.4, 128.0, 128.4, 128.5, 131.3 (CH), 102.8, 104.1, 106.9, 125.8, 131.4, $132.3,136.6,139.3,154.7,178.3,180.7,193.9,197.2(\mathrm{C}) ; \mathrm{C}_{27} \mathrm{H}_{18} \mathrm{~N}_{2} \mathrm{O}_{3}$ [418.45]; MS (EI): $m / z$ $(\%)=418[\mathrm{M}]^{+\cdot}(17), 390\left[\mathrm{M}^{+}-56\right](6), 362\left[\mathrm{M}^{+}-56\right](100) ; H R M S(E I)(m / z)$ : Calcd. for $[\mathrm{M}]^{+}=418.13119$, found $[\mathrm{M}]^{+}=418.13126$; isocratic HPLC: $97.1 \%$ at $254 \mathrm{~nm}, 97.2 \%$ at $280 \mathrm{~nm}, \mathrm{t}_{\mathrm{ms}}=5.21 \mathrm{~min}, \mathrm{t}_{\mathrm{m}}=1.11 \mathrm{~min}\left(\mathrm{ACN} / \mathrm{H}_{2} \mathrm{O} 50: 50\right) ; \lambda_{\max }(\mathrm{nm}): 294,344$, 377; gradient HPLC: $95.1 \%$ at $254 \mathrm{~nm}, \mathrm{t}_{\mathrm{ms}}=11.6 \mathrm{~min}, \mathrm{t}_{\mathrm{m}}=1.25 \mathrm{~min}$.

3-(5-Fluoro-1H-indol-3-yl)-4-(5-methoxy-1H-indol-3-yl)cyclobut-3-ene-1,2-dione (2ab)

Synthesis according to General Procedure C (reaction time: $20 \mathrm{~h}$ ) from 3-chloro-4(5-methoxy-1H-indol-3-yl)cyclobut-3-ene-1,2-dione (5c, $260 \mathrm{mg}, 0.99 \mathrm{mmol}$ ) and 5-fluoro$1 H$-indole (201 mg, $1.49 \mathrm{mmol})$. Crystallization from ethanol/DMF yielded a tan powder (184 mg, 51\%). IR (KBr): $3443 \mathrm{~cm}^{-1}(\mathrm{NH}), 1747 \mathrm{~cm}^{-1}, 1712 \mathrm{~cm}^{-1}(\mathrm{C}=\mathrm{O}), 1629 \mathrm{~cm}^{-1}$, $1538 \mathrm{~cm}^{-1}$ (C=C, arom.); ${ }^{1} \mathrm{H}-\mathrm{NMR}\left(600 \mathrm{MHz}, \mathrm{DMSO}-d_{6}\right): \delta(\mathrm{ppm})=3.58\left(\mathrm{~s}, 3 \mathrm{H}, \mathrm{OCH}_{3}\right)$, $6.91(\mathrm{dd}, J=8.8,2.5 \mathrm{~Hz}, 1 \mathrm{H}, \mathrm{ArH}), 7.14(\mathrm{td}, J=9.1,2.6 \mathrm{~Hz}, 1 \mathrm{H}, \mathrm{ArH}), 7.31-7.37(\mathrm{~m}, 1 \mathrm{H}$, ArH), $7.48(\mathrm{dd}, J=8.8,0.5 \mathrm{~Hz}, 1 \mathrm{H}, \mathrm{ArH}), 7.59$ (ddd, $J=8.8,4.7,0.5 \mathrm{~Hz}, 1 \mathrm{H}, \mathrm{ArH}), 7.75$ (dd, $J=10.1,2.6 \mathrm{~Hz}, 1 \mathrm{H}, \mathrm{ArH}), 8.24(\mathrm{~d}, J=3.1 \mathrm{~Hz}, 1 \mathrm{H}, \mathrm{ArH}), 8.31(\mathrm{~d}, J=3.2 \mathrm{~Hz}, 1 \mathrm{H}, \mathrm{ArH}), 12.39$ $(\mathrm{d}, J=3.3 \mathrm{~Hz}, 1 \mathrm{H}, \mathrm{NH}), 12.50(\mathrm{~d}, J=3.1 \mathrm{~Hz}, 1 \mathrm{H}, \mathrm{NH}) ;{ }^{13} \mathrm{C}-\mathrm{NMR}\left(151 \mathrm{MHz}, \mathrm{DMSO}-d_{6}\right): \delta$ $(\mathrm{ppm})=55.0\left(\mathrm{O}-\mathrm{CH}_{3}\right), 104.8,107.6\left(\mathrm{~d},{ }^{2} J_{\mathrm{C}, \mathrm{F}}=24.9 \mathrm{~Hz}\right), 111.3\left(\mathrm{~d},{ }^{2} J_{\mathrm{C}, \mathrm{F}}=26.0 \mathrm{~Hz}\right), 113.0,113.5$, $113.8\left(\mathrm{~d},{ }^{3} J_{\mathrm{C}, \mathrm{F}}=10.0 \mathrm{~Hz}\right), 113.9,132.6(\mathrm{CH}), 106.2,106.7\left(\mathrm{~d},{ }^{4} J_{\mathrm{C}, \mathrm{F}}=4.2 \mathrm{~Hz}\right), 113.8,125.6$, $126.0\left(\mathrm{~d},{ }^{3} J_{\mathrm{C}, \mathrm{F}}=10.9 \mathrm{~Hz}\right), 133.4,154.7,157.8\left(\mathrm{~d},{ }^{1} J_{\mathrm{C}, \mathrm{F}}=234.4 \mathrm{~Hz}\right), 175.9,177.0,194.5,194.9$ (C); $\mathrm{C}_{21} \mathrm{H}_{13} \mathrm{FN}_{2} \mathrm{O}_{2}$ [360.34]; MS (EI): $m / z(\%)=360[\mathrm{M}]^{+}$(35), 304 [M $\left.{ }^{+\cdot}-56\right]$ (100); HRMS (EI) $(\mathrm{m} / z)$ : Calcd. for $[\mathrm{M}]^{+}=360.09047$, found $[\mathrm{M}]^{+}=360.09119$; isocratic HPLC: $97.2 \%$ at 
$254 \mathrm{~nm}$ and $98.2 \%$ at $280 \mathrm{~nm}, \mathrm{t}_{\mathrm{ms}}=3.68 \mathrm{~min}, \mathrm{t}_{\mathrm{m}}=1.11 \mathrm{~min}\left(\mathrm{ACN} / \mathrm{H}_{2} \mathrm{O} 50: 50\right) ; \lambda_{\max }(\mathrm{nm})$ : 276; gradient HPLC: $98.4 \%$ at $254 \mathrm{~nm}, \mathrm{t}_{\mathrm{ms}}=11.1 \mathrm{~min}, \mathrm{t}_{\mathrm{m}}=1.25 \mathrm{~min}$.

3-(5-Chloro-1H-indol-3-yl)-4-(5-methoxy-1H-indol-3-yl)cyclobut-3-ene-1,2-dione (2ac)

Synthesis according to General Procedure C (reaction time: $24 \mathrm{~h}$ ) from 3-chloro-4-(5methoxy-1H-indol-3-yl)cyclobut-3-ene-1,2-dione (5c, $262 \mathrm{mg}, 1.00 \mathrm{mmol}$ ) and 5-chloro- $1 \mathrm{H}$ indole $(220 \mathrm{mg}, 1.45 \mathrm{mmol})$. The dark green precipitate was crystallized from ethanol/toluene to yield a yellow powder (195 mg, 52\%). IR (KBr): $3428 \mathrm{~cm}^{-1}(\mathrm{NH}), 1750 \mathrm{~cm}^{-1}, 1715 \mathrm{~cm}^{-1}$ $(\mathrm{C}=\mathrm{O}), 1624 \mathrm{~cm}^{-1}, 1540 \mathrm{~cm}^{-1}, 1517 \mathrm{~cm}^{-1}\left(\mathrm{C}=\mathrm{C}\right.$, arom.); ${ }^{1} \mathrm{H}-\mathrm{NMR}\left(400 \mathrm{MHz}\right.$, DMSO- $\left.d_{6}\right): \delta$ $(\mathrm{ppm})=3.59\left(\mathrm{~s}, 3 \mathrm{H}, \mathrm{O}-\mathrm{CH}_{3}\right), 6.93(\mathrm{dd}, J=8.8,2.5 \mathrm{~Hz}, 1 \mathrm{H}, \mathrm{ArH}), 7.26-7.35(\mathrm{~m}, 2 \mathrm{H}, \mathrm{ArH})$, $7.50(\mathrm{~d}, J=8.8 \mathrm{~Hz}, 1 \mathrm{H}, \mathrm{ArH}), 7.61(\mathrm{dd}, J=8.6,0.5 \mathrm{~Hz}, 1 \mathrm{H}, \mathrm{ArH}), 8.07(\mathrm{~d}, J=2.1 \mathrm{~Hz}, 1 \mathrm{H}$, ArH), $8.24(\mathrm{~d}, J=3.1 \mathrm{~Hz}, 1 \mathrm{H}, \mathrm{ArH}), 8.33(\mathrm{~d}, J=3.2 \mathrm{~Hz}, 1 \mathrm{H}, \mathrm{ArH}), 12.41(\mathrm{~d}, J=3.1 \mathrm{~Hz}$, $1 \mathrm{H}, \mathrm{NH}), 12.55(\mathrm{~d}, J=3.1 \mathrm{~Hz}, 1 \mathrm{H}, \mathrm{NH}) ;{ }^{13} \mathrm{C}-\mathrm{NMR}\left(101 \mathrm{MHz}, \mathrm{DMSO}-d_{6}\right): \delta(\mathrm{ppm})=55.0$ $\left(\mathrm{O}^{-} \mathrm{CH}_{3}\right), 104.9,113.0,113.5,114.1,121.8,123.0,131.6,132.2(\mathrm{CH}), 106.2,106.2,125.5,125.7$, 126.5, 131.7, 135.2, 154.8, 175.7, 177.2, 194.4, 195.0 (C); $\mathrm{C}_{21} \mathrm{H}_{13} \mathrm{ClN}_{2} \mathrm{O}_{3}$ [376.80]; Anal. calcd. for $\mathrm{C}_{21} \mathrm{H}_{13} \mathrm{ClN}_{2} \mathrm{O}_{3}$ : C 66.94, H 3.48, N 7.43; found C 66.65, H 3.38, N 7.13; MS (EI): $m / z$ $(\%)=376[\mathrm{M}]^{+}(28), 320\left[\mathrm{M}^{+-}-56\right](100)$; isocratic HPLC: $98.3 \%$ at $254 \mathrm{~nm}$ and $98.9 \%$ at $280 \mathrm{~nm}, \mathrm{t}_{\mathrm{ms}}=4.87 \mathrm{~min}, \mathrm{t}_{\mathrm{m}}=1.11 \mathrm{~min}\left(\mathrm{ACN} / \mathrm{H}_{2} \mathrm{O} 50: 50\right) ; \lambda_{\max }(\mathrm{nm}): 277$; gradient HPLC: $95.6 \%$ at $254 \mathrm{~nm}, \mathrm{t}_{\mathrm{ms}}=11.5 \mathrm{~min}, \mathrm{t}_{\mathrm{m}}=1.25 \mathrm{~min}$.

3-(5-Bromo-1H-indol-3-yl)-4-(5-methoxy-1H-indol-3-yl)cyclobut-3-ene-1,2-dione (2ad)

Synthesis according to General Procedure F from 3-chloro-4-(5-methoxy- $1 H$-indol3-yl)cyclobut-3-ene-1,2-dione (5c, $262 \mathrm{mg}, 1.00 \mathrm{mmol})$ and 5-bromo- $1 \mathrm{H}$-indole $(585 \mathrm{mg}$, $2.98 \mathrm{mmol})$. Crystallization from petroleum ether/ethyl acetate yielded a yellow powder (84 mg, 20\%). IR (KBr): $3418 \mathrm{~cm}^{-1}(\mathrm{NH}), 1746 \mathrm{~cm}^{-1}, 1700 \mathrm{~cm}^{-1}(\mathrm{C}=\mathrm{O}), 1530 \mathrm{~cm}^{-1}(\mathrm{C}=\mathrm{C}$, arom.); ${ }^{1} \mathrm{H}-\mathrm{NMR}\left(600 \mathrm{MHz}, \mathrm{DMSO}-d_{6}\right): \delta(\mathrm{ppm})=3.58\left(\mathrm{~s}, 3 \mathrm{H}, \mathrm{CH}_{3}\right), 6.92(\mathrm{ddd}, J=8.8$, 2.5, $0.4 \mathrm{~Hz}, 1 \mathrm{H}, \mathrm{ArH}), 7.28-7.34(\mathrm{~m}, 1 \mathrm{H}, \mathrm{ArH}), 7.40(\mathrm{dd}, J=8.6,2.0 \mathrm{~Hz}, 1 \mathrm{H}, \mathrm{ArH}), 7.48(\mathrm{dd}$, $J=8.8,0.5 \mathrm{~Hz}, 1 \mathrm{H}, \mathrm{ArH}), 7.55(\mathrm{dd}, J=8.6,0.5 \mathrm{~Hz}, 1 \mathrm{H}, \mathrm{ArH}), 8.19-8.23(\mathrm{~m}, 2 \mathrm{H}, \mathrm{ArH}), 8.32(\mathrm{~d}$, $J=0.4 \mathrm{~Hz}, 1 \mathrm{H}, \mathrm{ArH}), 12.45(\mathrm{~s}, 2 \mathrm{H}, \mathrm{NH}) ;{ }^{13} \mathrm{C}-\mathrm{NMR}\left(151 \mathrm{MHz}, \mathrm{DMSO}-d_{6}\right): \delta(\mathrm{ppm})=54.9$ $\left(\mathrm{CH}_{3}\right), 104.7,112.9,113.4,114.5,124.8,125.5,131.54,132.0(\mathrm{CH}), 105.9,106.1,113.6,125.4$, 127.3, 131.6, 135.4, 154.7, 175.5, 177.1, 194.3, 194.9 (C); $\mathrm{C}_{21} \mathrm{H}_{13} \mathrm{BrN}_{2} \mathrm{O}_{2}$ [421.25]; Anal. calcd. for $\mathrm{C}_{21} \mathrm{H}_{13} \mathrm{BrN}_{2} \mathrm{O}_{2}$ : C 59.88, H 3.11, N 6.65; found C 59.83, H 3.04, N 6.40; MS (EI): $\mathrm{m} / z$ $(\%)=422[\mathrm{M}]^{+}(25), 366\left[\mathrm{M}^{+}-56\right](100) ;$ isocratic HPLC: $99.4 \%$ at $254 \mathrm{~nm}, 99.7 \%$ at $280 \mathrm{~nm}$, $\mathrm{t}_{\mathrm{ms}}=5.24 \mathrm{~min}, \mathrm{t}_{\mathrm{m}}=1.11 \mathrm{~min}\left(\mathrm{ACN} / \mathrm{H}_{2} \mathrm{O} 50: 50\right) ; \lambda_{\max }(\mathrm{nm}): 278$; gradient HPLC: $99.4 \%$ at $254 \mathrm{~nm}, \mathrm{t}_{\mathrm{ms}}=11.8 \mathrm{~min}, \mathrm{t}_{\mathrm{m}}=1.25 \mathrm{~min}$.

3-(5-Iodo-1H-indol-3-yl)-4-(5-methoxy-1H-indol-3-yl)cyclobut-3-en-1,2-dione (2ae)

Synthesis according to General Procedure C (reaction time: $24 \mathrm{~h}$ ) from 3-chloro-4(5-methoxy-1H-indol-3-yl)cyclobut-3-ene-1,2-dione (5c, $262 \mathrm{mg}, 1.00 \mathrm{mmol}$ ) and 5-iodo$1 H$-indole ( $362 \mathrm{mg}, 1.45 \mathrm{mmol}$ ). The green precipitate crystallized from ethanol/toluene to yield a tan powder (200 mg, 43\%). IR (KBr): $3400 \mathrm{~cm}^{-1}(\mathrm{NH}), 1750 \mathrm{~cm}^{-1}, 1703 \mathrm{~cm}^{-1}$ $(\mathrm{C}=\mathrm{O}), 1626 \mathrm{~cm}^{-1}, 1539 \mathrm{~cm}^{-1}, 1512 \mathrm{~cm}^{-1}(\mathrm{C}=\mathrm{C}$, arom. $) ;{ }^{1} \mathrm{H}-\mathrm{NMR}\left(400 \mathrm{MHz}, \mathrm{DMSO}-d_{6}\right)$ : $\delta(\mathrm{ppm})=3.57\left(\mathrm{~s}, 3 \mathrm{H}, \mathrm{O}-\mathrm{CH}_{3}\right), 6.93(\mathrm{dd}, J=8.8,2.5 \mathrm{~Hz}, 1 \mathrm{H}, \mathrm{ArH}), 7.30(\mathrm{~d}, J=2.5 \mathrm{~Hz}, 1 \mathrm{H}$, $\mathrm{ArH}), 7.44(\mathrm{dd}, J=8.6,0.6 \mathrm{~Hz}, 1 \mathrm{H}, \mathrm{ArH}), 7.47-7.60(\mathrm{~m}, 2 \mathrm{H}, \mathrm{ArH}), 8.17(\mathrm{~d}, J=3.0 \mathrm{~Hz}, 1 \mathrm{H})$, $8.31(\mathrm{~d}, J=3.2 \mathrm{~Hz}, 1 \mathrm{H}, \mathrm{ArH}), 8.37(\mathrm{~d}, J=1.7 \mathrm{~Hz}, 1 \mathrm{H}, \mathrm{ArH}), 12.40(\mathrm{~d}, J=3.2 \mathrm{~Hz}, 1 \mathrm{H}, \mathrm{NH})$, $12.52(\mathrm{~d}, J=3.0 \mathrm{~Hz}, 1 \mathrm{H}, \mathrm{NH}) ;{ }^{13} \mathrm{C}-\mathrm{NMR}\left(101 \mathrm{MHz}, \mathrm{DMSO}-d_{6}\right): \delta(\mathrm{ppm})=54.9\left(\mathrm{O}_{-} \mathrm{CH}_{3}\right)$, 104.9, 113.0, 113.4, 114.9, 131.0, 131.1, 131.6 (2C) (CH), 85.3, 105.7, 106.2, 125.5, 127.7, 131.7, 135.8, 154.7, 175.7, 177.2, 194.4, $195.0(\mathrm{C}) ; \mathrm{C}_{21} \mathrm{H}_{13} \mathrm{IN}_{2} \mathrm{O}_{3}$ [468.25]; MS (EI): $m / z(\%)=468$ $[\mathrm{M}]^{+}(33), 412\left[\mathrm{M}^{+}-56\right]$ (100); HRMS (EI) $(\mathrm{m} / z)$ : Calcd. for $[\mathrm{M}]^{+}=467.99654$, found $[\mathrm{M}]^{+\cdot}=467.99523$; isocratic HPLC: $95.6 \%$ at $254 \mathrm{~nm}$ and $96.8 \%$ at $280 \mathrm{~nm}, \mathrm{t}_{\mathrm{ms}}=6.01 \mathrm{~min}$, $\mathrm{t}_{\mathrm{m}}=1.11 \mathrm{~min}\left(\mathrm{ACN} / \mathrm{H}_{2} \mathrm{O} 50: 50\right) ; \lambda_{\max }(\mathrm{nm}): 256,309 ;$ gradient HPLC: $95.6 \%$ at $254 \mathrm{~nm}$, $\mathrm{t}_{\mathrm{ms}}=12.0 \mathrm{~min}, \mathrm{t}_{\mathrm{m}}=1.25 \mathrm{~min}$. 
3-(5-Methoxy-1H-indol-3-yl)-4-(1-methyl-1H-indol-3-yl)cyclobut-3-ene-1,2-dione (2af)

Synthesis according to General Procedure C (reaction time: $65 \mathrm{~h}$ ) from 3-chloro-4-(5methoxy-1H-indol-3-yl)cyclobut-3-ene-1,2-dione ( $5 c, 245 \mathrm{mg}, 0.90 \mathrm{mmol}$ ) and 1-methyl-1 $\mathrm{H}$ indole (0.190 mL, $1.52 \mathrm{mmol}$ ) yielded a yellow powder (56 mg, 18\%). IR (KBr): $3416 \mathrm{~cm}^{-1}$ (NH), $1751 \mathrm{~cm}^{-1}, 1708 \mathrm{~cm}^{-1}$ (C=O), $1624 \mathrm{~cm}^{-1}, 1530 \mathrm{~cm}^{-1}, 1514 \mathrm{~cm}^{-1}$ (C=C, arom.); ${ }^{1} \mathrm{H}-$ NMR $\left(600 \mathrm{MHz}, \mathrm{DMSO}-d_{6}\right): \delta(\mathrm{ppm})=3.55\left(\mathrm{~s}, 3 \mathrm{H}, \mathrm{N}-\mathrm{CH}_{3}\right), 3.98\left(\mathrm{~s}, 3 \mathrm{H}, \mathrm{O}-\mathrm{CH}_{3}\right), 6.90(\mathrm{dd}$, $J=8.8,2.5 \mathrm{~Hz}, 1 \mathrm{H}, \mathrm{ArH}), 7.20$ (ddd, $J=8.0,7.0,1.0 \mathrm{~Hz}, 1 \mathrm{H}, \mathrm{ArH}), 7.34$ (ddd, $J=8.2,7.1$, $1.1 \mathrm{~Hz}, 1 \mathrm{H}, \mathrm{ArH}), 7.41-7.44(\mathrm{~m}, 1 \mathrm{H}, \mathrm{ArH}), 7.47(\mathrm{dd}, J=8.8,0.5 \mathrm{~Hz}, 1 \mathrm{H}, \mathrm{ArH}), 7.65(\mathrm{dt}$, $J=8.3,0.9 \mathrm{~Hz}, 1 \mathrm{H}, \mathrm{ArH}), 7.92(\mathrm{dt}, J=8.0,1.0 \mathrm{~Hz}, 1 \mathrm{H}), 8.25(\mathrm{~s}, 1 \mathrm{H}, \mathrm{ArH}), 8.32(\mathrm{~s}, 1 \mathrm{H}, \mathrm{ArH})$, $12.35(\mathrm{~s}, 1 \mathrm{H}, \mathrm{NH}) ;{ }^{13} \mathrm{C}-\mathrm{NMR}\left(151 \mathrm{MHz}, \mathrm{DMSO}-d_{6}\right): \delta(\mathrm{ppm})=33.3\left(\mathrm{~N}^{-\mathrm{CH}_{3}}\right), 54.8\left(\mathrm{O}_{-} \mathrm{CH}_{3}\right)$, 104.7, 110.9, 112.9, 113.2, 121.4, 122.7, 123.0, 131.3, $134.3(\mathrm{CH}), 105.2,106.3,125.4,125.8$, 131.5, 137.3, 154.6, 175.6, 176.8, 194.3, 194.8 (C); $\mathrm{C}_{22} \mathrm{H}_{16} \mathrm{~N}_{2} \mathrm{O}_{3}$ [356.38] C 74.15, H 4.53, N 7.86; found C 74.01, H 4.44, N 7.61; MS (EI): $m / z(\%)=356[\mathrm{M}]^{+}(30), 300\left[\mathrm{M}^{+}-56\right](100)$; isocratic HPLC: $99.6 \%$ at $254 \mathrm{~nm}, 99.7 \%$ at $280 \mathrm{~nm}, \mathrm{t}_{\mathrm{ms}}=5.12 \mathrm{~min}, \mathrm{t}_{\mathrm{m}}=1.11 \mathrm{~min}\left(\mathrm{ACN} / \mathrm{H}_{2} \mathrm{O}\right.$ 50:50); $\lambda_{\max }(\mathrm{nm}): 275,351$; gradient HPLC: $97.3 \%$ at $254 \mathrm{~nm}, \mathrm{t}_{\mathrm{ms}}=11.8 \mathrm{~min}, \mathrm{t}_{\mathrm{m}}=1.25 \mathrm{~min}$.

3-(5-Bromo-1-methyl-1H-indol-3-yl)-4-(5-methoxy-1H-indol-3-yl)cyclobut-3-ene-1,2dione (2ag)

Synthesis according to General Procedure C (reaction time: $20 \mathrm{~h}$ ) from 3-chloro-4-(5methoxy-1H-indol-3-yl)cyclobut-3-ene-1,2-dione (5c, $265 \mathrm{mg}, 1.01 \mathrm{mmol}$ ) and 5-bromo-1methyl-1H-indole ( $319 \mathrm{mg}, 1.52 \mathrm{mmol})$. The yellow precipitate crystallized from ethanol/ toluene to yield a yellow powder (215 mg, 49\%). IR (KBr): $3400 \mathrm{~cm}^{-1}(\mathrm{NH}), 1751 \mathrm{~cm}^{-1}$, $1714 \mathrm{~cm}^{-1}$ (C=O), $1623 \mathrm{~cm}^{-1}, 1609 \mathrm{~cm}^{-1}, 1547 \mathrm{~cm}^{-1}, 1519 \mathrm{~cm}^{-1}$ (C=C, arom.); ${ }^{1} \mathrm{H}-\mathrm{NMR}$ $\left(600 \mathrm{MHz}, \mathrm{DMSO}-d_{6}\right): \delta(\mathrm{ppm})=3.60\left(\mathrm{~s}, 3 \mathrm{H}, \mathrm{CH}_{3}\right), 3.97\left(\mathrm{~s}, 3 \mathrm{H}, \mathrm{O}_{-} \mathrm{CH}_{3}\right), 6.92(\mathrm{dd}, J=8.8$, $2.5 \mathrm{~Hz}, 1 \mathrm{H}, \mathrm{ArH}), 7.43(\mathrm{~d}, J=2.4 \mathrm{~Hz}, 1 \mathrm{H}, \mathrm{ArH}), 7.45-7.50(\mathrm{~m}, 2 \mathrm{H}, \mathrm{ArH}), 7.63(\mathrm{dd}, J=8.7$, $0.5 \mathrm{~Hz}, 1 \mathrm{H}, \mathrm{ArH}), 8.21(\mathrm{dd}, J=2.0,0.6 \mathrm{~Hz}, 1 \mathrm{H}, \mathrm{ArH}), 8.31-8.37(\mathrm{~m}, 2 \mathrm{H}, \mathrm{ArH}), 12.41(\mathrm{~s}, 1 \mathrm{H}$, $\mathrm{NH}) ;{ }^{13} \mathrm{C}-\mathrm{NMR}\left(151 \mathrm{MHz}, \mathrm{DMSO}-d_{6}\right): \delta(\mathrm{ppm})=34.1\left(\mathrm{CH}_{3}\right), 55.5\left(\mathrm{O}-\mathrm{CH}_{3}\right), 105.3,113.6$, 113.9, 125.6, 126.0, 132.0, $135.7(\mathrm{CH}), 105.5,106.8,114.7,126.3,127.9,132.2,136.6,155.4$, 175.4, 177.6, 194.7, $195.3(\mathrm{C}) ; \mathrm{C}_{22} \mathrm{H}_{15} \mathrm{BrN}_{2} \mathrm{O}_{3}$ [435.28] MS (EI): $m / z(\%)=434[\mathrm{M}]^{+}(27)$, $406\left[\mathrm{M}^{+}-28\right](1), 378\left[\mathrm{M}^{+}-56\right](100) ;$ HRMS (EI) $(\mathrm{m} / z)$ : Calcd. for $[\mathrm{M}]^{+}=434.02606$, found $[\mathrm{M}]^{+}=434.02622$; isocratic HPLC: $97.9 \%$ at $254 \mathrm{~nm}, 98.0 \%$ at $280 \mathrm{~nm}, \mathrm{t}_{\mathrm{ms}}=3.83 \mathrm{~min}$, $\mathrm{t}_{\mathrm{m}}=1.15 \mathrm{~min}\left(\mathrm{ACN} / \mathrm{H}_{2} \mathrm{O} 60: 40\right) ; \lambda_{\max }(\mathrm{nm}): 279,349 ;$ gradient HPLC: $98.7 \%$ at $254 \mathrm{~nm}$, $\mathrm{t}_{\mathrm{ms}}=12.5 \mathrm{~min}, \mathrm{t}_{\mathrm{m}}=1.25 \mathrm{~min}$.

3-[2-(5-Methoxy-1H-indol-3-yl)-3,4-dioxocyclobut-1-en-1-yl]-1H-indole-5carbonitrile (2ah)

Synthesis according to General Procedure C (reaction time: $24 \mathrm{~h}$ ) from 3-chloro4-(5-methoxy-1H-indol-3-yl)cyclobut-3-ene-1,2-dione (5c, $258 \mathrm{mg}, 0.99 \mathrm{mmol}$ ) and $1 H$ indole-5-carbonitrile $(220 \mathrm{mg}, 1.55 \mathrm{mmol})$. The yellow precipitate was crystallized from ethanol/toluene to yield a yellow powder $(202 \mathrm{mg}, 56 \%)$. IR $(\mathrm{KBr}): 3370 \mathrm{~cm}^{-1}(\mathrm{NH})$, $2220 \mathrm{~cm}^{-1}(\mathrm{C} \equiv \mathrm{N}), 1752 \mathrm{~cm}^{-1}, 1719 \mathrm{~cm}^{-1}(\mathrm{C}=\mathrm{O}), 1620 \mathrm{~cm}^{-1}, 1553 \mathrm{~cm}^{-1}, 1520 \mathrm{~cm}^{-1}(\mathrm{C}=\mathrm{C}$, arom.); ${ }^{1} \mathrm{H}-\mathrm{NMR}\left(400 \mathrm{MHz}, \mathrm{DMSO}-d_{6}\right): \delta(\mathrm{ppm})=3.58\left(\mathrm{~s}, 3 \mathrm{H}, \mathrm{CH}_{3}\right), 6.94(\mathrm{dd}, J=8.8,2.5 \mathrm{~Hz}$, $1 \mathrm{H}, \mathrm{ArH}), 7.28(\mathrm{~d}, J=2.5 \mathrm{~Hz}, 1 \mathrm{H}, \mathrm{ArH}), 7.45-7.55(\mathrm{~m}, 1 \mathrm{H}, \mathrm{ArH}), 7.65(\mathrm{dd}, J=8.5,1.6 \mathrm{~Hz}, 1 \mathrm{H}$, ArH), $7.77(\mathrm{dd}, J=8.4,0.8 \mathrm{~Hz}, 1 \mathrm{H}, \mathrm{ArH}), 8.37(\mathrm{dd}, J=20.9,3.1 \mathrm{~Hz}, 2 \mathrm{H}, \mathrm{ArH}), 8.47(\mathrm{dd}, J=1.5$, $0.7 \mathrm{~Hz}, 1 \mathrm{H}, \mathrm{ArH}), 12.47(\mathrm{~d}, J=3.2 \mathrm{~Hz}, 1 \mathrm{H}, \mathrm{NH}), 12.82(\mathrm{~d}, J=2.9 \mathrm{~Hz}, 1 \mathrm{H}, \mathrm{NH}) ;{ }^{13} \mathrm{C}-\mathrm{NMR}$ $\left(101 \mathrm{MHz}\right.$, DMSO- $\left.d_{6}\right): \delta(\mathrm{ppm})=55.0\left(\mathrm{O}-\mathrm{CH}_{3}\right), 104.9,113.0,113.6,114.0,125.6,127.1,132.0$, $132.8(\mathrm{CH}), 103.2,106.2,106.9,120.1,125.3,125.5,131.8,138.5,154.9,174.9,177.9,194.2,195.2$ (C); $\mathrm{C}_{21} \mathrm{H}_{13} \mathrm{~N}_{3} \mathrm{O}_{3}$ [367.36]; MS (EI): $m / z(\%)=367$ [M] ${ }^{+}$(25), $311\left[\mathrm{M}^{+}-56\right]$ (100); HRMS (EI) $(m / z)$ : Calcd. for $[\mathrm{M}]^{+\cdot}=367.09514$, found $[\mathrm{M}]^{+}=367.09491$; isocratic HPLC: $97.5 \%$ at $254 \mathrm{~nm}$ and $97.5 \%$ at $280 \mathrm{~nm}, \mathrm{t}_{\mathrm{ms}}=5.79 \mathrm{~min}, \mathrm{t}_{\mathrm{m}}=1.11 \mathrm{~min}\left(\mathrm{ACN} / \mathrm{H}_{2} \mathrm{O} 40: 60\right) ; \lambda_{\max }(\mathrm{nm})$ : 266, 308; gradient HPLC: $96.0 \%$ at $254 \mathrm{~nm}, \mathrm{t}_{\mathrm{ms}}=10.4 \mathrm{~min}, \mathrm{t}_{\mathrm{m}}=1.25 \mathrm{~min}$. 
3-(7-Chloro-1H-indol-3-yl)-4-(5-methoxy-1H-indol-3-yl)cyclobut-3-ene-1,2-dione (2ai)

Synthesis according to General Procedure C (reaction time: $48 \mathrm{~h}$ ) from 3-chloro-4-(5methoxy-1H-indol-3-yl)cyclobut-3-ene-1,2-dione (5c, $267 \mathrm{mg}, 1.02 \mathrm{mmol}$ ) and 7-chloro- $1 \mathrm{H}$ indole $(228 \mathrm{mg}, 1.50 \mathrm{mmol})$. The yellow precipitate recrystallized from ethanol/toluene to yield a yellow powder (199 mg, 52\%). IR (KBr): $3420 \mathrm{~cm}^{-1}, 3383 \mathrm{~cm}^{-1}(\mathrm{NH}), 1754 \mathrm{~cm}^{-1}$, $1718 \mathrm{~cm}^{-1}$ (C=O), $1620 \mathrm{~cm}^{-1}, 1586 \mathrm{~cm}^{-1}, 1540 \mathrm{~cm}^{-1}, 1513 \mathrm{~cm}^{-1}$ (C=C, arom.); ${ }^{1} \mathrm{H}-\mathrm{NMR}$ $\left(600 \mathrm{MHz}, \mathrm{DMSO}-d_{6}\right): \delta(\mathrm{ppm})=3.54\left(\mathrm{~s}, 3 \mathrm{H}, \mathrm{CH}_{3}\right), 6.91(\mathrm{dd}, J=8.8,2.5 \mathrm{~Hz}, 1 \mathrm{H}, \mathrm{ArH}), 7.17$ $(\mathrm{t}, J=7.9 \mathrm{~Hz}, 1 \mathrm{H}, \mathrm{ArH}), 7.23(\mathrm{~d}, J=2.4 \mathrm{~Hz}, 1 \mathrm{H}, \mathrm{ArH}), 7.37(\mathrm{dd}, J=7.6,0.9 \mathrm{~Hz}, 1 \mathrm{H}, \mathrm{ArH})$, $7.48(\mathrm{~d}, J=8.9 \mathrm{~Hz}, 1 \mathrm{H}, \mathrm{ArH}), 7.90(\mathrm{dt}, J=7.9,0.8 \mathrm{~Hz}, 1 \mathrm{H}, \mathrm{ArH}), 8.11(\mathrm{~d}, J=3.0 \mathrm{~Hz}, 1 \mathrm{H}$, ArH), $8.30(\mathrm{~d}, J=3.2 \mathrm{~Hz}, 1 \mathrm{H}, \mathrm{ArH}), 12.42(\mathrm{~d}, J=3.2 \mathrm{~Hz}, 1 \mathrm{H}, \mathrm{NH}), 12.79(\mathrm{~d}, J=3.0 \mathrm{~Hz}, 1 \mathrm{H}$, $\mathrm{NH}) ;{ }^{13} \mathrm{C}-\mathrm{NMR}\left(151 \mathrm{MHz}, \mathrm{DMSO}-d_{6}\right): \delta(\mathrm{ppm})=54.9\left(\mathrm{CH}_{3}\right), 104.8,113.0,113.6,121.5,122.2$, 122.6, 131.3, 132.0 (CH) 106.2, 107.4, 116.8, 125.5, 127.2, 131.8, 133.6, 154.8, 175.6, 177.9, 194.1, 195.4 (C); $\mathrm{C}_{21} \mathrm{H}_{13} \mathrm{ClN}_{2} \mathrm{O}_{3}$ [376.80]; C 66.94, H 3.48, N 7.43; found C 67.05, H 3.36, N 7.37; MS (EI): $m / z(\%)=376[\mathrm{M}]^{+}(32), 320\left[\mathrm{M}^{+}-56\right](100)$; isocratic HPLC: $97.5 \%$ at $254 \mathrm{~nm}$, $98.0 \%$ at $280 \mathrm{~nm}, \mathrm{t}_{\mathrm{ms}}=5.69 \mathrm{~min}, \mathrm{t}_{\mathrm{m}}=1.15 \mathrm{~min}\left(\mathrm{ACN} / \mathrm{H}_{2} \mathrm{O} 50: 50\right) ; \lambda_{\max }(\mathrm{nm}): 274 ;$ gradient HPLC: $97.8 \%$ at $254 \mathrm{~nm}, \mathrm{t}_{\mathrm{ms}}=11.8 \mathrm{~min}, \mathrm{t}_{\mathrm{m}}=1.25 \mathrm{~min}$.

3-(7-Bromo-1H-indol-3-yl)-4-(5-methoxy-1H-indol-3-yl)cyclobut-3-ene-1,2-dione (2aj)

Synthesis according to General Procedure D from 3-chloro-4-(5-methoxy-1H-indol3-yl)cyclobut-3-ene-1,2-dione (5c, $270 \mathrm{mg}, 1.03 \mathrm{mmol})$ and 7-bromo- $1 \mathrm{H}$-indole ( $294 \mathrm{mg}$, $1.50 \mathrm{mmol})$. Crystallization from ethanol/toluene yielded a yellow powder $(162 \mathrm{mg}, 37 \%)$ IR (KBr): $3325 \mathrm{~cm}^{-1}(\mathrm{NH}), 1749 \mathrm{~cm}^{-1}, 1708 \mathrm{~cm}^{-1}(\mathrm{C}=\mathrm{O}), 1619 \mathrm{~cm}^{-1}, 1536 \mathrm{~cm}^{-1}, 1514 \mathrm{~cm}^{-1}$ $\left(\mathrm{C}=\mathrm{C}\right.$, arom.); ${ }^{1} \mathrm{H}-\mathrm{NMR}\left(600 \mathrm{MHz}, \mathrm{DMSO}-d_{6}\right): \delta(\mathrm{ppm})=3.54\left(\mathrm{~s}, 3 \mathrm{H}, \mathrm{CH}_{3}\right), 6.91(\mathrm{dd}, J=8.8$, $2.5 \mathrm{~Hz}, 1 \mathrm{H}, \mathrm{ArH}), 7.12(\mathrm{t}, J=7.9 \mathrm{~Hz}, 1 \mathrm{H}, \mathrm{ArH}), 7.22(\mathrm{~d}, J=2.4 \mathrm{~Hz}, 1 \mathrm{H}, \mathrm{ArH}), 7.46-7.54$ $(\mathrm{m}, 2 \mathrm{H}, \mathrm{ArH}), 7.93(\mathrm{dt}, J=8.0,0.8 \mathrm{~Hz}, 1 \mathrm{H}, \mathrm{ArH}), 8.08(\mathrm{~d}, J=3.2 \mathrm{~Hz}, 1 \mathrm{H}, \mathrm{ArH}), 8.30(\mathrm{~d}$, $J=3.2 \mathrm{~Hz}, 1 \mathrm{H}, \mathrm{ArH}), 12.43(\mathrm{~d}, J=3.2 \mathrm{~Hz}, 1 \mathrm{H}, \mathrm{NH}), 12.63(\mathrm{~d}, J=3.1 \mathrm{~Hz}, 1 \mathrm{H}, \mathrm{NH}) ;{ }^{13} \mathrm{C}-\mathrm{NMR}$ $\left(151 \mathrm{MHz}, \mathrm{DMSO}-d_{6}\right): \delta(\mathrm{ppm})=54.9\left(\mathrm{CH}_{3}\right), 104.8,113.0,113.6,121.9,122.5,125.7,131.2$, $132.0(\mathrm{CH}), 104.9,106.2,107.5,125.4,126.9,131.8,135.1,154.8,175.7,177.9,194.1,195.4(\mathrm{C})$; $\mathrm{C}_{21} \mathrm{H}_{13} \mathrm{BrN}_{2} \mathrm{O}_{3}$ [421.25]; C 59.88, H 3.11, N 6.65; found C 59.92, H 3.01, N 6.65; MS (EI): $\mathrm{m} / \mathrm{z}$ $(\%)=420[\mathrm{M}]^{+\cdot}(26), 364\left[\mathrm{M}^{+}-56\right](100)$; isocratic HPLC: $97.7 \%$ at $254 \mathrm{~nm}, 98.5 \%$ at $280 \mathrm{~nm}$, $\mathrm{t}_{\mathrm{ms}}=5.69 \mathrm{~min}, \mathrm{t}_{\mathrm{m}}=1.15 \mathrm{~min}\left(\mathrm{ACN} / \mathrm{H}_{2} \mathrm{O} 50: 50\right) ; \lambda_{\max }(\mathrm{nm}): 275$; gradient HPLC: $98.2 \%$ at $254 \mathrm{~nm}, \mathrm{t}_{\mathrm{ms}}=12.0 \mathrm{~min}, \mathrm{t}_{\mathrm{m}}=1.25 \mathrm{~min}$.

3-(7-Iodo-1H-indol-3-yl)-4-(5-methoxy-1H-indol-3-yl)cyclobut-3-ene-1,2-dione (2ak)

Synthesis according to General Procedure D from 3-chloro-4-(5-methoxy-1H-indol3-yl)cyclobut-3-ene-1,2-dione (5c, $263 \mathrm{mg}, 1.01 \mathrm{mmol}$ ) and 7-iodo- $1 \mathrm{H}$-indole ( $244 \mathrm{mg}$, $1.00 \mathrm{mmol})$. Crystallization from acetone yielded a yellow powder $(111 \mathrm{mg}, 24 \%)$. IR (KBr): $3413 \mathrm{~cm}^{-1}(\mathrm{NH}), 1754 \mathrm{~cm}^{-1}, 1721 \mathrm{~cm}^{-1}(\mathrm{C}=\mathrm{O}), 1608 \mathrm{~cm}^{-1}, 1544 \mathrm{~cm}^{-1}, 1512 \mathrm{~cm}^{-1}(\mathrm{C}=\mathrm{C}$, arom.); ${ }^{1} \mathrm{H}-\mathrm{NMR}\left(600 \mathrm{MHz}, \mathrm{DMSO}-d_{6}\right): \delta(\mathrm{ppm})=3.53\left(\mathrm{~s}, 3 \mathrm{H}, \mathrm{CH}_{3}\right), 6.90(\mathrm{dd}, J=8.8,2.5 \mathrm{~Hz}$, $1 \mathrm{H}, \mathrm{ArH}), 6.93-6.99(\mathrm{~m}, 1 \mathrm{H}, \mathrm{ArH}), 7.21(\mathrm{~d}, J=2.4 \mathrm{~Hz}, 1 \mathrm{H}, \mathrm{ArH}), 7.48(\mathrm{~d}, J=8.8 \mathrm{~Hz}, 1 \mathrm{H}, \mathrm{ArH})$, $7.68(\mathrm{dd}, J=7.4,1.0 \mathrm{~Hz}, 1 \mathrm{H}, \mathrm{ArH}), 7.92(\mathrm{dt}, J=8.0,0.9 \mathrm{~Hz}, 1 \mathrm{H}, \mathrm{ArH}), 8.04(\mathrm{~d}, J=3.2 \mathrm{~Hz}, 1 \mathrm{H}$, ArH), $8.28(\mathrm{~d}, J=3.2 \mathrm{~Hz}, 1 \mathrm{H}, \mathrm{ArH}), 12.33(\mathrm{~d}, J=3.1 \mathrm{~Hz}, 1 \mathrm{H}, \mathrm{ArH}), 12.42(\mathrm{~d}, J=3.1 \mathrm{~Hz}, 1 \mathrm{H}$, $\mathrm{NH}) ;{ }^{13} \mathrm{C}-\mathrm{NMR}\left(151 \mathrm{MHz}, \mathrm{DMSO}-d_{6}\right): \delta(\mathrm{ppm})=54.9\left(\mathrm{CH}_{3}\right), 104.8,113.0,113.6,122.5,122.9$, 131.0, 131.8, $132.1(\mathrm{CH}), 77.8,106.2,107.6,125.4,125.8,131.9,138.6,154.8,175.9,177.8,194.2$, 195.4 (C); $\mathrm{C}_{21} \mathrm{H}_{13} \mathrm{IN}_{2} \mathrm{O}_{3}$ [468.25]; C 53.87, $\mathrm{H}$ 2.80, N 5.98; found C 54.00, H 2.58, N 5.78; MS (EI): $m / z(\%)=468[\mathrm{M}]^{+\cdot}(33), 364\left[\mathrm{M}^{+}-56\right](100)$; isocratic HPLC: $99.4 \%$ at $254 \mathrm{~nm}, 99.8 \%$ at $280 \mathrm{~nm}, \mathrm{t}_{\mathrm{ms}}=7.13 \mathrm{~min}, \mathrm{t}_{\mathrm{m}}=1.15 \mathrm{~min}\left(\mathrm{ACN} / \mathrm{H}_{2} \mathrm{O} 50: 50\right) ; \lambda_{\max }(\mathrm{nm})$ : 275; gradient HPLC: $96.8 \%$ at $254 \mathrm{~nm}, \mathrm{t}_{\mathrm{ms}}=12.2 \mathrm{~min}, \mathrm{t}_{\mathrm{m}}=1.25 \mathrm{~min}$.

3-(7-Ethyl-1H-indol-3-yl)-4-(5-methoxy-1H-indol-3-yl)cyclobut-3-ene-1,2-dione (2al)

Synthesis according to General Procedure D from 3-chloro-4-(5-methoxy- $1 \mathrm{H}$-indol3-yl)cyclobut-3-ene-1,2-dione (5c, $267 \mathrm{mg}, 1.02 \mathrm{mmol})$ and 7-ethyl- $1 \mathrm{H}$-indole $(0.205 \mathrm{~mL}$, $1.50 \mathrm{mmol})$. Crystallization from acetone yielded a yellow powder $(62 \mathrm{mg}, 16 \%)$. IR (KBr): $3400 \mathrm{~cm}^{-1}, 3379 \mathrm{~cm}^{-1}(\mathrm{NH}), 1753 \mathrm{~cm}^{-1}, 1714 \mathrm{~cm}^{-1}(\mathrm{C}=\mathrm{O}), 1612 \mathrm{~cm}^{-1}, 1587 \mathrm{~cm}^{-1}, 1536 \mathrm{~cm}^{-1}$, 
$1514 \mathrm{~cm}^{-1}$ (C=C, arom.); ${ }^{1} \mathrm{H}-\mathrm{NMR}\left(400 \mathrm{MHz}, \mathrm{DMSO}-d_{6}\right): \delta(\mathrm{ppm})=1.29(\mathrm{t}, J=7.5 \mathrm{~Hz}, 3 \mathrm{H}$, $\left.\mathrm{CH}_{2}-\mathrm{CH}_{3}\right), 2.94\left(\mathrm{q}, J=7.5 \mathrm{~Hz}, 2 \mathrm{H}, \mathrm{CH}_{2}-\mathrm{CH}_{3}\right), 3.51\left(\mathrm{~s}, 3 \mathrm{H}, \mathrm{CH}_{3}\right), 6.89(\mathrm{dd}, J=8.8,2.5 \mathrm{~Hz}, 1 \mathrm{H}$, $\mathrm{ArH}), 7.03-7.14(\mathrm{~m}, 2 \mathrm{H}, \mathrm{ArH}), 7.29(\mathrm{~d}, J=2.5 \mathrm{~Hz}, 1 \mathrm{H}, \mathrm{ArH}), 7.47(\mathrm{~d}, J=8.8 \mathrm{~Hz}, 1 \mathrm{H}, \mathrm{ArH})$, $7.70(\mathrm{dd}, J=7.2,1.8 \mathrm{~Hz}, 1 \mathrm{H}, \mathrm{ArH}), 8.12(\mathrm{~d}, J=3.2 \mathrm{~Hz}, 1 \mathrm{H}, \mathrm{ArH}), 8.23(\mathrm{~d}, J=3.1 \mathrm{~Hz}, 1 \mathrm{H}, \mathrm{ArH})$, $12.34(\mathrm{~d}, J=3.2 \mathrm{~Hz}, 1 \mathrm{H}, \mathrm{NH}), 12.44(\mathrm{~d}, J=3.1 \mathrm{~Hz}, 1 \mathrm{H}, \mathrm{NH}) ;{ }^{13} \mathrm{C}-\mathrm{NMR}\left(101 \mathrm{MHz}, \mathrm{DMSO}-d_{6}\right)$ : $\delta(\mathrm{ppm})=14.6\left(\mathrm{CH}_{2}-\mathrm{CH}_{3}\right), 54.8\left(\mathrm{OCH}_{3}\right), 23.6\left(\mathrm{CH}_{2}-\mathrm{CH}_{3}\right), 104.8,112.9,113.4,120.1,121.4$, $121.8,130.5,131.5(\mathrm{CH}), 106.3,106.8,125.2,125.6,128.2,131.7,135.4,154.6,176.4,177.2$, 194.5, 195.1 (C); $\mathrm{C}_{23} \mathrm{H}_{18} \mathrm{~N}_{2} \mathrm{O}_{3}$ [370.41]; $\mathrm{MS}(\mathrm{EI}): \mathrm{m} / z(\%)=370[\mathrm{M}]^{+}(30), 314\left[\mathrm{M}^{+}-56\right]$ (100); HRMS (EI) $(\mathrm{m} / z)$ : Calcd. for $[\mathrm{M}]^{+}=370.13119$, found $[\mathrm{M}]^{+}=370.13142$; isocratic HPLC: $95.5 \%$ at $254 \mathrm{~nm}, 96.7 \%$ at $280 \mathrm{~nm}, \mathrm{t}_{\mathrm{ms}}=5.71 \mathrm{~min}, \mathrm{t}_{\mathrm{m}}=1.15 \mathrm{~min}\left(\mathrm{ACN} / \mathrm{H}_{2} \mathrm{O} 50: 50\right)$; $\lambda_{\max }(\mathrm{nm}): 350,273$; gradient HPLC: $96.2 \%$ at $254 \mathrm{~nm}, \mathrm{t}_{\mathrm{ms}}=11.9 \mathrm{~min}, \mathrm{t}_{\mathrm{m}}=1.25 \mathrm{~min}$.

3-(6-Bromo-1H-indol-3-yl)-4-(5-methoxy-1H-indol-3-yl)cyclobut-3-ene-1,2-dione (2am)

Synthesis according to General Procedure D from 3-chloro-4-(5-methoxy- $1 H$-indol3-yl)cyclobut-3-ene-1,2-dione (5c, $267 \mathrm{mg}, 1.02 \mathrm{mmol})$ and 6-bromo- $1 \mathrm{H}$-indole (293 mg, $1.49 \mathrm{mmol})$. Crystallization from ethanol/toluene yielded a yellow powder $(42 \mathrm{mg}, 10 \%)$. IR (KBr): $3307 \mathrm{~cm}^{-1}(\mathrm{NH}), 1751 \mathrm{~cm}^{-1}, 1710 \mathrm{~cm}^{-1}(\mathrm{C}=\mathrm{O}), 1611 \mathrm{~cm}^{-1}, 1529 \mathrm{~cm}^{-1}, 1510 \mathrm{~cm}^{-1}$ $\left(\mathrm{C}=\mathrm{C}\right.$, arom.); ${ }^{1} \mathrm{H}-\mathrm{NMR}\left(600 \mathrm{MHz}, \mathrm{DMSO}-d_{6}\right): \delta(\mathrm{ppm})=3.56\left(\mathrm{~s}, 3 \mathrm{H}, \mathrm{O}-\mathrm{CH}_{3}\right), 6.91(\mathrm{dd}$, $J=8.8,2.5 \mathrm{~Hz}, 1 \mathrm{H}, \mathrm{ArH}), 7.27-7.34(\mathrm{~m}, 2 \mathrm{H}, \mathrm{ArH}), 7.48(\mathrm{~d}, J=8.8 \mathrm{~Hz}, 1 \mathrm{H}, \mathrm{ArH}), 7.77(\mathrm{~d}$, $J=1.7 \mathrm{~Hz}, 1 \mathrm{H}, \mathrm{ArH}), 7.89$ (d, $J=8.5 \mathrm{~Hz}, 1 \mathrm{H}, \mathrm{ArH}), 8.20$ (s, 1H, ArH), 8.28 (s, 1H, ArH), 12.43 $(\mathrm{s}, 2 \mathrm{H}, \mathrm{NH}) ;{ }^{13} \mathrm{C}-\mathrm{NMR}\left(151 \mathrm{MHz}, \mathrm{DMSO}-d_{6}\right): \delta(\mathrm{ppm})=54.9\left(\mathrm{CH}_{3}\right), 104.8,113.0,113.52$, $115.2,124.0,124.4,131.8(2 \mathrm{C})(\mathrm{CH}), 106.2,106.5,115.7,124.2,125.6,131.7,137.7,154.8,175.7$, 177.5, 194.3, 195.2 (C); $\mathrm{C}_{21} \mathrm{H}_{13} \mathrm{BrN}_{2} \mathrm{O}_{3}$ [421.25]; Anal. calcd. for $\mathrm{C}_{21} \mathrm{H}_{13} \mathrm{BrN}_{2} \mathrm{O}_{3}: \mathrm{C} 59.88, \mathrm{H}$ 3.11, N 6.65; found C 59.59, H 3.04, N 6.59; MS (EI): $m / z(\%)=420[\mathrm{M}]^{+}(27), 364\left[\mathrm{M}^{+}-56\right]$ (100); isocratic HPLC: $97.5 \%$ at $254 \mathrm{~nm}, 98.2 \%$ at $280 \mathrm{~nm}, \mathrm{t}_{\mathrm{ms}}=4.25 \mathrm{~min}, \mathrm{t}_{\mathrm{m}}=1.15 \mathrm{~min}$ $\left(\mathrm{ACN} / \mathrm{H}_{2} \mathrm{O} 50: 50\right) ; \lambda_{\max }(\mathrm{nm}): 278$; gradient HPLC: $95.0 \%$ at $254 \mathrm{~nm}, \mathrm{t}_{\mathrm{ms}}=12.0 \mathrm{~min}$, $\mathrm{t}_{\mathrm{m}}=1.25 \mathrm{~min}$.

3-(4-Bromo-1H-indol-3-yl)-4-(5-methoxy-1H-indol-3-yl)cyclobut-3-en-1,2-dione (2an)

Synthesis according to General Procedure D from 3-chloro-4-(5-methoxy- $1 \mathrm{H}$-indol3-yl)cyclobut-3-ene-1,2-dione (5c, $267 \mathrm{mg}, 1.02 \mathrm{mmol})$ and 4-bromo- $1 \mathrm{H}$-indole $(0.188 \mathrm{~mL}$, $1.50 \mathrm{mmol})$. Crystallization from ethyl acetate yielded a yellow powder $(20 \mathrm{mg}, 5 \%)$. IR (KBr): $3238 \mathrm{~cm}^{-1}(\mathrm{NH}), 1769 \mathrm{~cm}^{-1}, 1713 \mathrm{~cm}^{-1}(\mathrm{C}=\mathrm{O}), 1623 \mathrm{~cm}^{-1}, 1528 \mathrm{~cm}^{-1}, 1517 \mathrm{~cm}^{-1}$ $(\mathrm{C}=\mathrm{C}$, arom. $) ;{ }^{1} \mathrm{H}-\mathrm{NMR}\left(600 \mathrm{MHz}, \mathrm{DMSO}-d_{6}\right): \delta(\mathrm{ppm})=2.96\left(\mathrm{~s}, 3 \mathrm{H}, \mathrm{CH}_{3}\right), 6.76(\mathrm{dd}, J=8.8$, $2.5 \mathrm{~Hz}, 1 \mathrm{H}, \mathrm{ArH}), 7.10-7.18$ (m, 1H, ArH), 7.26-7.34 (m, 2H, ArH), 7.37-7.45 (m, 1H, ArH), $7.58(\mathrm{dd}, J=8.2,0.8 \mathrm{~Hz}, 1 \mathrm{H}, \mathrm{ArH}), 7.91$ (s, 1H, ArH), 8.40 (s, 1H, ArH), 12.37 (s, 2H, NH); ${ }^{13} \mathrm{C}-\mathrm{NMR}\left(151 \mathrm{MHz}, \mathrm{DMSO}-d_{6}\right): \delta(\mathrm{ppm})=53.8\left(\mathrm{CH}_{3}\right), 111.9,113.2,113.4,113.6,123.9$, 124.6, 128.4, $132.7(\mathrm{CH}), 103.0,105.3,107.3,125.1,125.9,131.7,137.8,154.9,178.6,183.6$, $194.7,198.0(\mathrm{C}) ; \mathrm{C}_{21} \mathrm{H}_{13} \mathrm{BrN}_{2} \mathrm{O}_{3}$ [421.25] MS (EI): $\mathrm{m} / z(\%)=420[\mathrm{M}]^{+}(26), 364\left[\mathrm{M}^{+}-56\right]$ (100); HRMS (EI) $(\mathrm{m} / \mathrm{z})$ : Calcd. for $[\mathrm{M}]^{+\cdot}=420.01041$, found $[\mathrm{M}]^{+}=420.01102$; isocratic HPLC: $97.2 \%$ at $254 \mathrm{~nm}, 97.8 \%$ at $280 \mathrm{~nm}, \mathrm{t}_{\mathrm{ms}}=3.19 \mathrm{~min}, \mathrm{t}_{\mathrm{m}}=1.15 \mathrm{~min}\left(\mathrm{ACN} / \mathrm{H}_{2} \mathrm{O} 45: 55\right)$; $\lambda_{\max }(\mathrm{nm}): 276$, 364; gradient HPLC: $96.2 \%$ at $254 \mathrm{~nm}, \mathrm{t}_{\mathrm{ms}}=10.9 \mathrm{~min}, \mathrm{t}_{\mathrm{m}}=1.25 \mathrm{~min}$.

3-(5-Bromo-1H-indol-3-yl)-4-(5-methoxy-1-methyl-1H-indol-3-yl)cyclobut-3-en-1,2dione (2ao)

Synthesis according to General Procedure D from 3-(5-bromo-1H-indol-3-yl)-4-chlorocyclobut-3-ene-1,2-dione (5f, $314 \mathrm{mg}, 1.01 \mathrm{mmol}$ ) and 5-methoxy-1-methyl-1H-indole (193 mg, $1.20 \mathrm{mmol})$. Crystallization from chloroform/DMF yielded a yellow powder (80 mg, 18\%). IR (KBr): $3422 \mathrm{~cm}^{-1}(\mathrm{NH}), 1751 \mathrm{~cm}^{-1}, 1712 \mathrm{~cm}^{-1}(\mathrm{C}=\mathrm{O}), 1625 \mathrm{~cm}^{-1}$, $1544 \mathrm{~cm}^{-1}, 1518 \mathrm{~cm}^{-1}$ (C=C, arom.); ${ }^{1} \mathrm{H}-\mathrm{NMR}\left(600 \mathrm{MHz}, \mathrm{DMSO}-d_{6}\right): \delta(\mathrm{ppm})=3.58(\mathrm{~s}, 3 \mathrm{H}$, $\left.\mathrm{CH}_{3}\right), 3.97\left(\mathrm{~d}, \mathrm{~J}=0.4 \mathrm{~Hz}, 3 \mathrm{H}, \mathrm{CH}_{3}\right), 6.95-7.01(\mathrm{~m}, 1 \mathrm{H}, \mathrm{ArH}), 7.34(\mathrm{~d}, J=2.4 \mathrm{~Hz}, 1 \mathrm{H}, \mathrm{ArH})$, 7.37-7.43 (m, 1H, ArH), 7.56 (ddd, $J=11.3,8.8,0.5$ Hz, 2H, ArH), 8.21-8.28 (m, 2H, ArH), $8.41(\mathrm{t}, J=0.5 \mathrm{~Hz}, 1 \mathrm{H}, \mathrm{ArH}), 12.61(\mathrm{~d}, J=2.9 \mathrm{~Hz}, 1 \mathrm{H}, \mathrm{NH}) ;{ }^{13} \mathrm{C}-\mathrm{NMR}\left(151 \mathrm{MHz}, \mathrm{DMSO}-d_{6}\right)$ : $\delta(\mathrm{ppm})=33.6,55.0\left(\mathrm{CH}_{3}\right), 105.2,112.1,112.9,114.5,124.9,125.6,132.1,135.0(\mathrm{CH}), 105.0$ 106.1, 113.7, 126.0, 127.2, 132.6, 135.4, 155.1, 175.4, 176.5, 194.2, $194.9(\mathrm{C}) ; \mathrm{C}_{22} \mathrm{H}_{15} \mathrm{BrN}_{2} \mathrm{O}_{3}$ 
[435.28]; Anal. calcd. for $\mathrm{C}_{22} \mathrm{H}_{15} \mathrm{BrN}_{2} \mathrm{O}_{3}$ : C 60.71, $\mathrm{H} 3.47, \mathrm{~N}$ 6.44; found C 60.52, $\mathrm{H} 3.19$, $\mathrm{N}$ 6.32; MS (EI): $m / z(\%)=434[\mathrm{M}]^{+}(30), 378\left[\mathrm{M}^{+}-56\right](100)$; isocratic HPLC: $98.3 \%$ at $254 \mathrm{~nm}, 99.0 \%$ at $280 \mathrm{~nm}, \mathrm{t}_{\mathrm{ms}}=4.09 \mathrm{~min}, \mathrm{t}_{\mathrm{m}}=1.15 \mathrm{~min}\left(\mathrm{ACN} / \mathrm{H}_{2} \mathrm{O} 60: 40\right) ; \lambda_{\max }(\mathrm{nm}): 229$, 278, 350; gradient HPLC: $97.0 \%$ at $254 \mathrm{~nm}, \mathrm{t}_{\mathrm{ms}}=12.7 \mathrm{~min}, \mathrm{t}_{\mathrm{m}}=1.25 \mathrm{~min}$.

3-(5-Bromo-1H-indol-3-yl)-4-(5-hydroxy-1H-indol-3-yl)cyclobut-3-ene-1,2-dione (2ap)

To a suspension of 3-(5-bromo- $1 H$-indol- 3-yl)-4-(5-methoxy- $1 H$-indol-3-yl)cyclobut3-ene-1,2-dione (2ad, $100 \mathrm{mg}, 0.237 \mathrm{mmol})$ in anhydrous dichloromethane $(10 \mathrm{~mL})$ was added a solution of boron tribromide (1 M in dichloromethane, $4.00 \mathrm{~mL}, 4 \mathrm{mmol})$. The reaction was stirred at $\mathrm{rt}$ for $15 \mathrm{~h}$. Under ice cooling, water $(50 \mathrm{~mL})$ was carefully added and the mixture was stirred for a further hour. The suspension was extracted with ethyl acetate $(2 \times 100 \mathrm{~mL})$. The combined organic layers were washed with water $(2 \times 50 \mathrm{~mL})$ and saturated $\mathrm{NaCl}$ solution $(1 \times 50 \mathrm{~mL})$ and dried with anhydrous $\mathrm{Na}_{2} \mathrm{SO}_{4}$. After subsequent evaporation to dryness, the resulting residue was crystallized from petroleum ether/acetone to yield a yellow powder (55 mg, 57\%). IR (KBr): $3422 \mathrm{~cm}^{-1}(\mathrm{NH}), 1751 \mathrm{~cm}^{-1}$, $1712 \mathrm{~cm}^{-1}$ (C=O), $1625 \mathrm{~cm}^{-1}, 1544 \mathrm{~cm}^{-1}, 1518 \mathrm{~cm}^{-1}$ (C=C, arom.); ${ }^{1} \mathrm{H}-\mathrm{NMR}$ (600 MHz, DMSO- $\left.d_{6}\right): \delta(\mathrm{ppm})=6.78(\mathrm{dd}, J=8.7,2.4 \mathrm{~Hz}, 1 \mathrm{H}, \mathrm{ArH}), 7.23(\mathrm{~d}, J=2.4 \mathrm{~Hz}, 1 \mathrm{H}, \mathrm{ArH}), 7.39$ $(\mathrm{d}, J=8.8 \mathrm{~Hz}, 1 \mathrm{H}, \mathrm{ArH}), 7.41(\mathrm{dd}, J=8.6,2.0 \mathrm{~Hz}, 1 \mathrm{H}, \mathrm{ArH}), 7.55(\mathrm{~d}, J=8.6 \mathrm{~Hz}, 1 \mathrm{H}, \mathrm{ArH}), 8.14$ $(\mathrm{d}, J=3.1 \mathrm{~Hz}, 1 \mathrm{H}, \mathrm{ArH}), 8.24(\mathrm{~d}, J=3.2 \mathrm{~Hz}, 1 \mathrm{H}, \mathrm{ArH}), 8.30(\mathrm{~d}, J=1.9 \mathrm{~Hz}, 1 \mathrm{H}, \mathrm{ArH}), 9.14$ (s, 1H, ArH), 12.30 (d, J = 3.1 Hz, 1H, NH), 12.55 (d, J = 3.1 Hz, 1H, NH); ${ }^{13} \mathrm{C}-\mathrm{NMR}(151 \mathrm{MHz}$, DMSO- $\left.d_{6}\right): \delta(\mathrm{ppm})=107.3,113.1,113.3,114.6,124.9,125.6,131.4,132.0(\mathrm{CH}), 105.7,106.1$, 113.7, 125.9, 127.2, 131.0, 135.5, 152.7, 175.4, 177.4, 194.4, 194.9 (C); $\mathrm{C}_{20} \mathrm{H}_{11} \mathrm{BrN}_{2} \mathrm{O}_{3}$ [407.2]; Anal. calcd. for $\mathrm{C}_{20} \mathrm{H}_{11} \mathrm{BrN}_{2} \mathrm{O}_{3}$ : C 58.99, $\mathrm{H}$ 2.72, N 6.88; found C 58.61, H 2.74, N 6.35; MS (EI): $m / z(\%)=406[\mathrm{M}]^{+}(29), 350\left[\mathrm{M}^{+}-56\right](100)$; isocratic HPLC: $96.4 \%$ at $254 \mathrm{~nm}, 98.5 \%$ at $280 \mathrm{~nm}, \mathrm{t}_{\mathrm{ms}}=5.35 \mathrm{~min}, \mathrm{t}_{\mathrm{m}}=1.15 \mathrm{~min}\left(\mathrm{ACN} / \mathrm{H}_{2} \mathrm{O} 40: 60\right) ; \lambda_{\max }(\mathrm{nm}): 255,309 ;$ gradient HPLC: $95.0 \%$ at $254 \mathrm{~nm}, \mathrm{t}_{\mathrm{ms}}=10.4 \mathrm{~min}, \mathrm{t}_{\mathrm{m}}=1.25 \mathrm{~min}$.

\section{3,4-Bis(5-iodo-1H-indol-3-yl)cyclobut-3-ene-1,2-dione (2aq)}

Synthesis according to General Procedure E from squaric acid dichloride $(4,150 \mathrm{mg}$, $0.99 \mathrm{mmol})$ anf 5-iodo- $1 \mathrm{H}$-indole $(729 \mathrm{mg}, 3.00 \mathrm{mmol})$. Crystallization from ethyl acetate/ethanol yielded an orange powder $(70 \mathrm{mg}, 12 \%)$. IR $(\mathrm{KBr}): 3375 \mathrm{~cm}^{-1}(\mathrm{NH})$, $1755 \mathrm{~cm}^{-1}, 1695 \mathrm{~cm}^{-1}$ (C=O), $1529 \mathrm{~cm}^{-1}, 1505 \mathrm{~cm}^{-1}$ (C=C, arom.); ${ }^{1} \mathrm{H}-\mathrm{NMR}(600 \mathrm{MHz}$, DMSO- $\left.d_{6}\right): \delta(\mathrm{ppm})=7.42-7.47(\mathrm{~m}, 2 \mathrm{H}, \mathrm{ArH}), 7.57(\mathrm{dd}, J=8.5,1.7 \mathrm{~Hz}, 2 \mathrm{H}, \mathrm{ArH}), 8.30(\mathrm{~s}$, 2H, ArH), 8.34 (d, J = 1.8 Hz, 2H, ArH), 12.62 (s, 2H, NH); ${ }^{13} \mathrm{C}-\mathrm{NMR}(151 \mathrm{MHz}, \mathrm{DMSO}-$ $\left.d_{6}\right): \delta(\mathrm{ppm})=115.5,131.6,131.6,132.2(\mathrm{CH}), 86.1,106.0,128.0,136.4,177.1,195.1(\mathrm{C})$; $\mathrm{C}_{20} \mathrm{H}_{10} \mathrm{I}_{2} \mathrm{~N}_{2} \mathrm{O}_{2}$ [564.12]; Anal. calcd. for $\mathrm{C}_{20} \mathrm{H}_{10} \mathrm{I}_{2} \mathrm{~N}_{2} \mathrm{O}_{2}$ : C 42.58, $\mathrm{H} 1.79, \mathrm{~N}$ 4.97; found C 45.52, H 1.52, N 4.76; MS (EI): $m / z(\%)=564[\mathrm{M}]^{+\cdot}(33), 508\left[\mathrm{M}^{+}-56\right](100)$; isocratic HPLC: $97.1 \%$ at $254 \mathrm{~nm}$ and $98.0 \%$ at $280 \mathrm{~nm}, \mathrm{t}_{\mathrm{ms}}=5.03 \mathrm{~min}, \mathrm{t}_{\mathrm{m}}=1.11 \mathrm{~min}\left(\mathrm{ACN} / \mathrm{H}_{2} \mathrm{O} 60: 40\right)$; $\lambda_{\max }(\mathrm{nm}): 280,329,344$; gradient HPLC: $96.5 \%$ at $254 \mathrm{~nm}, \mathrm{t}_{\mathrm{ms}}=13.4 \mathrm{~min}, \mathrm{t}_{\mathrm{m}}=1.25 \mathrm{~min}$.

3-[5-(Benzyloxy)-1H-indol-3-yl]-4-(5-methoxy-1H-indol-3-yl)cyclobut-3-ene-1,2dione (2ar)

Synthesis according to General Procedure F from 3-chloro-4-(5-methoxy- $1 H$-indol-3yl)cyclobut-3-ene-1,2-dione (5c, $274 \mathrm{mg}, 1.05 \mathrm{mmol})$ and 5-(Benzyloxy)-1H-indole (670 mg, $3.00 \mathrm{mmol})$. Crystallization from petroleum ether/ethylacetate yielded an orange powder $(35 \mathrm{mg}, 7 \%)$. IR (KBr): $3307 \mathrm{~cm}^{-1}(\mathrm{NH}), 1747 \mathrm{~cm}^{-1}, 1711 \mathrm{~cm}^{-1}(\mathrm{C}=\mathrm{O}), 1624 \mathrm{~cm}^{-1}$, $1536 \mathrm{~cm}^{-1}, 1508 \mathrm{~cm}^{-1}$ (C=C, arom.); ${ }^{1} \mathrm{H}-\mathrm{NMR}\left(600 \mathrm{MHz}, \mathrm{DMSO}-d_{6}\right): \delta(\mathrm{ppm})=3.47(\mathrm{~s}, 3 \mathrm{H}$,

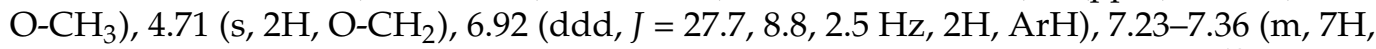
ArH), 7.47 (dd, J = 11.3, $8.8 \mathrm{~Hz}, 2 \mathrm{H}, \mathrm{ArH}), 8.22$ (s, 2H, ArH), 12.33 (s, 2H, NH); ${ }^{13} \mathrm{C}-\mathrm{NMR}$ $\left(101 \mathrm{MHz}, \mathrm{DMSO}-d_{6}\right): \delta(\mathrm{ppm})=54.8\left(\mathrm{CH}_{3}\right), 69.4\left(\mathrm{CH}_{2}\right), 104.7,106.2(2 \mathrm{C}), 113.1,113.4(2 \mathrm{C})$, 113.5, 127.5 (2C), 127.7, 128.4 (2C), 131.4, 131.7 (CH), 106.4 (2C) 125.7, 125.8, 131.8, 137.1, 153.6, 154.6, 176.3, 176.4, 194.7, 194.8 (C); $\mathrm{C}_{28} \mathrm{H}_{20} \mathrm{~N}_{2} \mathrm{O}_{4}$ [448.48]; MS (EI): $m / z(\%)=448$ $[\mathrm{M}]^{+}(74), 392\left[\mathrm{M}^{+}-56\right](100) ; \operatorname{HRMS}(\mathrm{EI})(\mathrm{m} / \mathrm{z})$ : Calcd. for $[\mathrm{M}]^{+} \cdot=448.14176$, found $[\mathrm{M}]^{+}=448.14204$; isocratic HPLC: $98.4 \%$ at $254 \mathrm{~nm}$ and $99.1 \%$ at $280 \mathrm{~nm}, \mathrm{t}_{\mathrm{ms}}=7.02 \mathrm{~min}$, 
$\mathrm{t}_{\mathrm{m}}=1.11 \mathrm{~min}\left(\mathrm{ACN} / \mathrm{H}_{2} \mathrm{O} 50: 50\right) ; \lambda_{\max }(\mathrm{nm}): 352,277$; gradient HPLC: $98.5 \%$ at $254 \mathrm{~nm}$, $\mathrm{t}_{\mathrm{ms}}=12.2 \mathrm{~min}, \mathrm{t}_{\mathrm{m}}=1.25 \mathrm{~min}$.

\subsection{Molecular Docking}

For docking studies, the plasmodial protein kinase crystal structures 1V0P, 4MVF, 2PML, 3LLT, and 3NIE were downloaded from the Protein Data Bank [32] and three homology models of $P f G S K-3$ were selected, which had been created using the crystal structures of human GSK-3 (pdb-id: 1J1B, 2OW3 and 1R0E, respectively) [33]. After protonation optimization and energy minimization (defaults) conducted with MOE (Molecular Operating Environment, 2013.08 ed., Chemical Computing Group Inc. Montreal, QB, Canada), the .pdb files of the protein structures were used for the subsequent docking experiments. In the same way, the ligands were prepared with MOE and saved as mol2 files. The docking experiments were carried out with GOLD Suite 2.2.5 [31] without the definition of constraints. The spatial extent of the ATP binding pocket was defined as a $10 \AA$ zone with respect to either the originally enclosed ligand or, in the homology models, with respect to the gatekeeper residue. After the relevant water molecules in the binding pocket for the automatic toggle were established, the remaining water molecules were removed. For the respective ligands, ten genetic algorithm runs were generated, the options "save lone pairs" and "allow early termination" being disabled. The docking accuracy was set to $200 \%$. The evaluated docking solutions by the integrated ChemScore.kinase templates were stored with ChemScore values in descending order as .mol2 or .sdf files. The thus rated poses were mapped and analyzed using the visualization program Chimera [51]. By additional visual inspection, the poses were interpreted regarding meaningful orientation, considering important polar interactions, occupation of the hydrophobic back pocket, and optional formation of halogen bonds. Chimera is developed by the Resource for Biocomputing, Visualization, and Informatics at the UCSF (supported by NIFMS P41-GM103311).

\subsection{Luciferase-Based Viability Screening for Antiplasmodial Activity}

Screening for the antiplasmodial activity of test compounds was performed by luciferasebased viability assays as reported previously [30]. In brief, asexual erythrocytic stages of transgenic NF54-luc P. falciparum were cultured as described elsewhere [28,52]. Parasite cultures with parasitaemia of $0.5-1 \%$ were incubated in the presence of $3 \mu \mathrm{M}$ test compounds for $48 \mathrm{~h}$. After the subsequent addition of Bright-Glo substrate solution (Promega, Madison, $\mathrm{WI})$, the resulting luminescence was measured. Untreated cultures $(0.01 \% \mathrm{DMSO})$ were used as negative controls. Experiments were performed in triplicate and were repeated as a whole at least twice. Blasticidin (Sigma-Aldrich, St. Louis, MO, USA) was included as a positive control [53]. Test compounds exhibiting satisfactorily inhibition activity in $3 \mu \mathrm{M}$ concentration (in most cases $>20 \%$ inhibition of viability) were rated as actives of which $\mathrm{IC}_{50}$ values were determined from dose-response curves.

\subsection{Cytotoxicity Assay on Human THP-1 Cell Line}

The cytotoxicity of selected antiplasmodial bisindolylcyclobutenediones was determined against THP-1 cells following a protocol described previously [54-56]. In brief, THP-1 cells were incubated with test compounds in serial compound dilutions in the presence of $0.01 \%$ DMSO at $37^{\circ} \mathrm{C}$. After $48 \mathrm{~h}$, Alamar Blue was added, and after $4 \mathrm{~h}$ the fluorescence was read $\left(\lambda_{\mathrm{ex}}=544 \mathrm{~nm}, \lambda_{\mathrm{em}}=590 \mathrm{~nm}\right)$ using a microplate reader. THP- 1 cells in wells containing medium plus $0.01 \%$ DMSO served as negative controls. Experiments were performed in triplicate and were repeated as a whole at least twice.

\subsection{Production of Recombinant PfGSK-3}

PfGSK-3 was produced as published before [42]. In brief, PfGSK-3 was cloned into pOPIN J expression vector [57] which was transformed into E. coli BL21 (DE3)-RIL. Expression of recombinant 6xHis-GST-PfGSK-3 was induced by incubation with isopropyl $\beta$-D-1-thiogalactopyranoside (IPTG). The recombinant protein was purified by affinity 
chromatography using glutathione resin and elution by digestion with human rhinovirus $3 \mathrm{C}$ protease.

\subsection{PfGSK-3 Inhibition Assay}

The PfGSK-3 inhibition assay was carried out using the commercial KinaseGlo Plus assay (KinaseGlo Plus, Promega) as described before [42]. In brief, the kinase and a corresponding substrate (GS-1 substrate, Promega) in the presence of ATP were used to perform substrate phosphorylation. Subsequently, luminescence is generated utilizing luciferase which is a component of the KinaseGlo Reagent. The intensity of the luminescence signal corresponds to the amount of remaining ATP in the reaction mixture. For the investigation, potential kinase inhibitors were dissolved in DMSO and were added directly to the kinase reaction. The final DMSO concentration in the kinase reaction was at most $1 \%$. As the negative control, $1 \%$ DMSO without test compound was measured. A control reaction without kinase was measured simultaneously. The difference between kinase reaction and control reaction corresponds to the kinase activity. While the published selective $P f G S K-3$ inhibitor $5 \mathrm{v}$ [28] exhibited the expected inhibitory activity in this assay, the potent antiplasmodial bisindolylcyclobutenediones $\mathbf{2 k}$, $2 \mathbf{a d}$, and $\mathbf{2 a e}$ failed to show kinase inhibitory activity up to a concentration of $10 \mu \mathrm{M}$.

\section{Conclusions}

In view of the high incidence and the spreading resistance to approved drugs, new active agents against the malaria pathogens are urgently needed. Such new drugs should hit previously unaddressed targets and thus be based on novel mechanisms of action. Although plasmodial protein kinases have been frequently proposed as biological targets for malaria therapy, no drugs have yet been developed on this basis. Against this background, novel $\mathrm{N}$-unsubstituted bisindolylcyclobutenediones were synthesized as analogs to the kinase-inhibiting bisindolylmaleimides using a sequential Friedel-Crafts acylation starting from squaric acid dichloride. Docking experiments on various plasmodial kinases revealed plausible orientations in the ATP-binding pocket of the enzymes. When the new compounds were screened in vitro on erythrocytic $P$. falciparum forms, several derivatives showed good inhibition values with favorable selectivity profiles. The 7-chloro-5'-methoxysubstituted compound 2ai proved to be the most interesting representative, showing submicromolar antiparasitic activity and a three-digit selectivity index against a human cell line. Whether inhibition of plasmodial protein kinases is responsible for the antiparasitic activity of the new compounds remains unclear for the time being. The protein kinase PfGSK-3, initially assumed to be the target structure, was not inhibited by particularly active representatives of the new substance class. As selective submicromolar antiplasmodial agents, the $\mathrm{N}$-unsubstituted bisindolylcyclobutenediones are promising starting structures in searching for therapeutic antimalarials, although for a rational development the biological target addressed by these compounds remains to be identified.

\section{Patents}

The syntheses and antiplasmodial activities of compounds reported in this article have been claimed by some of the authors in a patent application [58].

Supplementary Materials: The following are available online. Table S1: Structures of all test compounds, Table S2: ${ }^{1} \mathrm{H}$ NMR-spectra of test compounds displayed in Table 2, Figure S1: Docking pose of $\mathbf{2} \mathbf{b}$ (orange) and $\mathbf{2 a d}$ (blue) in the ATP binding pocket of a PfGSK-3 homology model.

Author Contributions: Conceptualization, C.K., J.G., T.W.G. and R.D.; methodology and formal analysis, D.H.L., J.G., A.N. and A.A.; writing-original draft preparation, D.H.L. and C.K.; writingreview and editing, A.N., A.A., T.W.G., J.G. and R.D.; visualization, D.H.L.; supervision, J.G., C.K., T.W.G., R.D.; project administration, C.K.; funding acquisition, C.K. and R.D. All authors have read and agreed to the published version of the manuscript. 
Funding: The project was funded by the German Federal Ministry of Education and Research (BMBF BioDisc 7; 13GW0024) awarded to R.D. and C.K., A.A. is supported by a Jürgen Manchot-Stiftung fellowship. We acknowledge support by the German Research Foundation and the Open Access Publication Funds of Technische Universität Braunschweig.

Data Availability Statement: The data presented in this study are available in Section 4: "Materials and Methods" and in the Supplementary Materials published with this article.

Acknowledgments: We are grateful to Sophia Reindl, Christian Löw and Samuel Pazicky for advice on the purification of recombinant PfGSK-3.

Conflicts of Interest: The syntheses and antiplasmodial activities of compounds reported in this article have been claimed by C.K., D.H.L., J.G., R.D and A.N. in a patent application as stated in Section 6 . The authors declare no otherwise conflict of interest. The funders had no role in the design of the study; in the collection, analyses, or interpretation of data; in the writing of the manuscript, or in the decision to publish the results.

Sample Availability: Samples of the compounds are not available from the authors.

\section{References}

1. World Health Organization. World Malaria Report 2020: 20 Years of Global Progress and Challenges; World Health Organization: Geneva, Switzerland, 2020; ISBN 978-92-4-001579-1.

2. Gallup, J.L.; Sachs, J.D. The economic burden of malaria. Am. J. Trop. Med. Hyg. 2001, 64, 85-96. [CrossRef]

3. Sato, S. Plasmodium-A brief introduction to the parasites causing human malaria and their basic biology. J. Physiol. Anthr. 2021, 40, 1. [CrossRef] [PubMed]

4. Wells, T.; van Huijsduijnen, R.H.; Van Voorhis, W.C. Malaria medicines: A glass half full? Nat. Rev. Drug Discov. 2015, 14, 424-442. [CrossRef]

5. Daily, J.P. Malaria 2017: Update on the clinical literature and management. Curr. Infect. Dis. Rep. 2017, 19, 28. [CrossRef]

6. Okombo, J.; Chibale, K. Recent updates in the discovery and development of novel antimalarial drug candidates. MedChemComm 2018, 9, 437-453. [CrossRef]

7. Porter-Kelley, J.M.; Cofie, J.; Jean, S.; Brooks, M.E.; Lassiter, M.; Mayer, D.G. Acquired resistance of malarial parasites against artemisinin-based drugs: Social and economic impacts. Infect. Drug Resist. 2010, 3, 87-94. [CrossRef] [PubMed]

8. Ippolito, M.M.; Moser, K.A.; Kabuya, J.-B.B.; Cunningham, C.; Juliano, J.J. Antimalarial drug resistance and implications for the WHO global technical strategy. Curr. Epidemiol. Rep. 2021, 8, 46-62. [CrossRef] [PubMed]

9. Noedl, H.; Se, Y.; Schaecher, K.; Smith, B.L.; Socheat, D.; Fukuda, M.M. Evidence of artemisinin-resistant malaria in western Cambodia. N. Engl. J. Med. 2008, 359, 2619-2620. [CrossRef]

10. Shibeshi, M.A.; Kifle, Z.D.; Atnafie, S.A. Antimalarial drug resistance and novel targets for antimalarial drug discovery. Infect. Drug Resist. 2020, 13, 4047-4060. [CrossRef]

11. Adderley, J.; Williamson, T.; Doerig, C. Parasite and host erythrocyte kinomics of plasmodium infection. Trends Parasitol. 2021, 37, 508-524. [CrossRef]

12. Arendse, L.B.; Wyllie, S.; Chibale, K.; Gilbert, I.H. Plasmodium kinases as potential drug targets for malaria: Challenges and opportunities. ACS Infect. Dis. 2021, 7, 518-534. [CrossRef]

13. Doerig, C.; Billker, O.; Haystead, T.; Sharma, P.; Tobin, A.B.; Waters, N.C. Protein kinases of malaria parasites: An update. Trends Parasitol. 2008, 24, 570-577. [CrossRef] [PubMed]

14. Solyakov, L.; Halbert, J.; Alam, M.M.; Semblat, J.-P.; Dorin-Semblat, D.; Reininger, L.; Bottrill, A.; Mistry, S.; Abdi, A.; Fennell, C.; et al. Global kinomic and phospho-proteomic analyses of the human malaria parasite Plasmodium falciparum. Nat. Commun. 2011, 2, 565. [CrossRef]

15. Paquet, T.; Le Manach, C.; Cabrera, D.G.; Younis, Y.; Henrich, P.P.; Abraham, T.S.; Lee, M.; Basak, R.; Ghidelli-Disse, S.; LafuenteMonasterio, M.J.; et al. Antimalarial efficacy of MMV390048, an inhibitor of Plasmodium phosphatidylinositol 4-kinase. Sci. Transl. Med. 2017, 9, eaad9735. [CrossRef]

16. McCarthy, J.; Donini, C.; Chalon, S.; Woodford, J.; Marquart, L.; Collins, K.; Rozenberg, F.; Fidock, D.; Cherkaoui-Rbati, M.H.; Gobeau, N.; et al. A Phase 1, Placebo-controlled, randomized, single ascending dose study and a volunteer infection study to characterize the safety, pharmacokinetics, and antimalarial activity of the Plasmodium phosphatidylinositol 4-kinase inhibitor MMV390048. Clin. Infect. Dis. 2020, 71, e657-e664. [CrossRef] [PubMed]

17. Kunick, C.; Egert-Schmidt, A.-M. Die kurze Geschichte der Proteinkinase-Inhibitoren. Jung, kompetitiv, erfolgreich. Pharm. Unserer Zeit 2008, 37, 360-368. [CrossRef]

18. Pajak, B.; Orzechowska, S.; Gajkowska, B.; Orzechowski, A. Bisindolylmaleimides in anti-cancer therapy-More than PKC inhibitors. Adv. Med. Sci. 2008, 53, 21-31. [CrossRef] [PubMed]

19. Toullec, D.; Pianetti, P.; Coste, H.; Bellevergue, P.; Grand-Perret, T.; Ajakane, M.; Baudet, V.; Boissin, P.; Boursier, E.; Loriolle, F. The bisindolylmaleimide GF $109203 X$ is a potent and selective inhibitor of protein kinase C. J. Biol. Chem. 1991, 266, 15771-15781. [CrossRef] 
20. Chen, Y.-B.; LaCasce, A.S. Enzastaurin. Expert Opin. Investig. Drugs 2008, 17, 939-944. [CrossRef]

21. Bansal, D.; Badhan, Y.; Gudala, K.; Schifano, F. Ruboxistaurin for the treatment of diabetic peripheral neuropathy: A systematic review of randomized clinical trials. Diabetes Metab. J. 2013, 37, 375-384. [CrossRef]

22. Chasák, J.; Šlachtová, V.; Urban, M.; Brulíková, L. Squaric acid analogues in medicinal chemistry. Eur. J. Med. Chem. 2021, 209, 112872. [CrossRef]

23. Kumar, S.P.; Glória, P.M.C.; Gonçalves, L.; Gut, J.; Rosenthal, P.J.; Moreira, R.; Santos, M. Squaric acid: A valuable scaffold for developing antimalarials? MedChemComm 2012, 3, 489-493. [CrossRef]

24. Lovering, F.; Kirincich, S.; Wang, W.; Combs, K.; Resnick, L.; Sabalski, J.E.; Butera, J.; Liu, J.; Parris, K.; Telliez, J. Identification and SAR of squarate inhibitors of mitogen activated protein kinase-activated protein kinase 2 (MK-2). Bioorg. Med. Chem. 2009, 17, 3342-3351. [CrossRef]

25. Villalonga, P.; de Mattos, S.F.; Ramis, G.; Obrador, A.; Sampedro, A.; Rotger, C.; Costa, A. Cyclosquaramides as kinase inhibitors with anticancer activity. ChemMedChem 2012, 7, 1472-1480. [CrossRef]

26. Matsuoka, M.; Soejima, H.; Kitao, T. Syntheses of 3,4-bisaryl-3-cyclobutene-1,2-diones and related heterocycles. Dye. Pigment. 1991, 16, 309-315. [CrossRef]

27. Droucheau, E.; Primot, A.; Thomas, V.; Mattei, D.; Knockaert, M.; Richardson, C.; Sallicandro, P.; Alano, P.; Jafarshad, A.; Baratte, B.; et al. Plasmodium falciparum glycogen synthase kinase-3: Molecular model, expression, intracellular localisation and selective inhibitors. Biochim. Biophys. Acta Proteins Proteom. 2004, 1697, 181-196. [CrossRef]

28. Fugel, W.; Oberholzer, A.E.; Gschloessl, B.; Dzikowski, R.; Pressburger, N.; Preu, L.; Pearl, L.; Baratte, B.; Ratin, M.; Okun, I.; et al. 3,6-Diamino-4-(2-halophenyl)-2-benzoylthieno[2,3-b]pyridine-5-carbonitriles are selective inhibitors of Plasmodium falciparum glycogen synthase kinase-3. J. Med. Chem. 2013, 56, 264-275. [CrossRef]

29. Masch, A.; Kunick, C. Selective inhibitors of Plasmodium falciparum glycogen synthase-3 (PfGSK-3): New antimalarial agents? Biochim. Biophys. Acta Proteins Proteom. 2015, 1854, 1644-1649. [CrossRef]

30. Masch, A.; Nasereddin, A.; Alder, A.; Bird, M.J.; Schweda, S.I.; Preu, L.; Doerig, C.; Dzikowski, R.; Gilberger, T.-W.; Kunick, C. Structure-activity relationships in a series of antiplasmodial thieno2,3-bpyridines. Malar. J. 2019, 18, 89. [CrossRef] [PubMed]

31. Jones, G.; Willett, P.; Glen, R.C.; Leach, A.R.; Taylor, R. Development and validation of a genetic algorithm for flexible docking. J. Mol. Biol. 1997, 267, 727-748. [CrossRef] [PubMed]

32. Berman, H.M.; Westbrook, J.; Feng, Z.; Gilliland, G.; Bhat, T.N.; Weissig, H.; Shindyalov, I.N.; Bourne, P.E. The protein data bank. Nucleic Acids Res. 2000, 28, 235-242. [CrossRef] [PubMed]

33. Kruggel, S.; Lemcke, T. Generation and evaluation of a homology model of PfGSK-3. Arch. Pharm. 2009, 342, 327-332. [CrossRef]

34. Aoki, M.; Yokota, T.; Sugiura, I.; Sasaki, C.; Hasegawa, T.; Okumura, C.; Ishiguro, K.; Kohno, T.; Sugio, S.; Matsuzaki, T. Structural insight into nucleotide recognition in tau-protein kinase I/glycogen synthase kinase 3? Acta Crystallogr. Sect. D Biol. Crystallogr. 2004, 60, 439-446. [CrossRef] [PubMed]

35. Holton, S.; Merckx, A.; Burgess, D.; Doerig, C.; Noble, M.; Endicott, J. Structures of P. falciparum PfPK5 test the CDK regulation paradigm and suggest mechanisms of small molecule inhibition. Structure 2003, 11, 1329-1337. [CrossRef]

36. Lande, D.H. Neuartige Bisindolylcyclobutendione als Potentielle Antimalaria-Wirkstoffe. Ph.D. Thesis, Technische Universität Braunschweig, Braunschweig, Germany, 2016.

37. Brenner, M.; Rexhausen, H.; Steffan, B.; Steglich, W. Synthesis of arcyriarubin b and related bisindolylmaleimides. Tetrahedron 1988, 44, 2887-2892. [CrossRef]

38. Lunelli, B. New, optimized preparation of 1,2-dichlorocyclobuten-3,4-dione ( $4 \mathrm{O} 2 \mathrm{Cl} 2)$ from squaric acid and oxalyl chloride. Tetrahedron Lett. 2007, 48, 3595-3597. [CrossRef]

39. Green, B.R.; Neuse, E.W. Synthesis of 1,2-diphenylcyclobutene-3,4-dione. Synthesis 1974, 1974, 46-47. [CrossRef]

40. Schmidt, A.H.; Thiel, S.H.; Gaschler, O. Oxocarbons and related compounds. Part 24. Chlorosquarylation of indoles. J. Chem. Soc. Perkin Trans. 1996, 1, 495-496. [CrossRef]

41. Faul, M.M.; Sullivan, K.A.; Winneroski, L.L. A general approach to the synthesis of bisindolylmaleimides: Synthesis of staurosporine aglycone. Synthesis 1995, 1995, 1511-1516. [CrossRef]

42. Schweda, S.I.; Alder, A.; Gilberger, T.; Kunick, C. 4-Arylthieno[2,3-b]pyridine-2-carboxamides are a new class of antiplasmodial agents. Molecules 2020, 25, 3187. [CrossRef] [PubMed]

43. Al-Ali, H. The evolution of drug discovery: From phenotypes to targets, and back. MedChemComm 2016, 7, 788-798. [CrossRef]

44. Gilbert, I.H. Drug discovery for neglected diseases: Molecular target-based and phenotypic approaches. J. Med. Chem. 2013, 56, 7719-7726. [CrossRef]

45. Hovlid, M.L.; Winzeler, E.A. Phenotypic screens in antimalarial drug discovery. Trends Parasitol. 2016, 32, 697-707. [CrossRef] [PubMed]

46. Quancard, J.; Bach, A.; Cox, B.; Craft, R.; Finsinger, D.; Guéret, S.M.; Hartung, I.V.; Laufer, S.; Messinger, J.; Sbardella, G.; et al. The European Federation for Medicinal Chemistry and Chemical Biology (EFMC) best practice initiative: Phenotypic drug discovery. ChemMedChem 2021, 16, 1737-1740. [CrossRef] [PubMed]

47. Swinney, D.C. Phenotypic vs. target-based drug discovery for first-in-class medicines. Clin. Pharmacol. Ther. 2013, 93, 299-301. [CrossRef]

48. Swinney, D.C. The contribution of mechanistic understanding to phenotypic screening for first-in-class medicines. J. Biomol. Screen. 2013, 18, 1186-1192. [CrossRef] 
49. Sykes, M.L.; Avery, V.M. Approaches to protozoan drug discovery: Phenotypic screening. J. Med. Chem. 2013, 56, 7727-7740. [CrossRef]

50. Li, J.; Sun, X.; Li, J.; Yu, F.; Zhang, Y.; Huang, X.; Jiang, F. The antimalarial activity of indole alkaloids and hybrids. Arch. Pharm. 2020, 353, 2000131. [CrossRef] [PubMed]

51. Pettersen, E.F.; Goddard, T.D.; Huang, C.C.; Couch, G.S.; Greenblatt, D.M.; Meng, E.C.; Ferrin, T.E. UCSF Chimera-A visualization system for exploratory research and analysis. J. Comput. Chem. 2004, 25, 1605-1612. [CrossRef]

52. Dzikowski, R.; Frank, M.; Deitsch, K. Mutually exclusive expression of virulence genes by malaria parasites is regulated independently of antigen production. PLoS Pathog. 2006, 2, e22. [CrossRef]

53. van Schalkwyk, D.; Moon, R.W.; Blasco, B.; Sutherland, C.J. Comparison of the susceptibility of Plasmodium knowlesi and Plasmodium falciparum to antimalarial agents. J. Antimicrob. Chemother. 2017, 72, 3051-3058. [CrossRef] [PubMed]

54. Reichwald, C.; Shimony, O.; Dunkel, U.; Sacerdoti-Sierra, N.; Jaffe, C.L.; Kunick, C. 2-(3-Aryl-3-oxopropen-1-yl)-9-tert-butylpaullones: A new antileishmanial chemotype. J. Med. Chem. 2008, 51, 659-665. [CrossRef] [PubMed]

55. Ryczak, J.; Papini, M.; Lader, A.; Nasereddin, A.; Kopelyanskiy, D.; Preu, L.; Jaffe, C.L.; Kunick, C. 2-Arylpaullones are selective antitrypanosomal agents. Eur. J. Med. Chem. 2013, 64, 396-400. [CrossRef] [PubMed]

56. Weidner, T.; Lucantoni, L.; Nasereddin, A.; Preu, L.; Jones, P.G.; Dzikowski, R.; Avery, V.M.; Kunick, C. Antiplasmodial dihetarylthioethers target the coenzyme a synthesis pathway in Plasmodium falciparum erythrocytic stages. Malar. J. 2017, 16, 192. [CrossRef]

57. Berrow, N.; Alderton, D.; Sainsbury, S.; Nettleship, J.; Assenberg, R.; Rahman, N.; Stuart, D.; Owens, R. A versatile ligationindependent cloning method suitable for high-throughput expression screening applications. Nucleic Acids Res. 2007, 35, e45. [CrossRef] [PubMed]

58. Kunick, C.; Lande, H.; Gruenefeld, J.; Dzikowski, R.; Nasereddin, A. New Indole Compounds Having Antiprotozoal Activity and Its Use as well as Methods for Producing the Same. International Patent Application PCT/EP2015/065812, 10 July 2015. 